\title{
Populationsdynamik und Produktion des Zooplanktons im Greifensee und im Vierwaldstättersee
}

\author{
Von ERIK MitTelholzer
}

Eidg. Anstalt für Wasserversorgung, Abwasserreinigung und Gewässerschutz an der Eidg. Technischen Hochschule Zürich

Direktion: Prof. 1)r. O. Jaag

Manuskript erhalten am 29. Dezember 1969 


\title{
Populationsdynamik und Produktion des Zooplanktons im Greifensee und im Vierwaldstättersee
}

\author{
Von ERIK MítTelholzer \\ Eidg. Anstalt für Wasserversorgung, Abwasserreinigung und Gewässerschutz \\ an der Eidg. Technischen Hochschule Zürich \\ Jirektion: Prof. Dr. O. Jaag \\ Manuskript orhalten am 29. Dezember 1969
}

INHALTSVERZEICHNIS

1. Einleitung . . . . . . . . . . . . . . . . . . . . . 91

2. Seen . . . . . . . . . . . . . . . . . . . . . . . . . 92

2.1 Greifensee . . . . . . . . . . . . . . . . . . . . . . . . . 92

2.2 Gersauerbecken des Vierwaldstättersees . . . . . . . . . . . . . . . . . . . 97

3. Zooplankton . . . . . . . . . . . . . . . . . . . . . . . . . . . 97

3.1 Artenlistc . . . . . . . . . . . . . . . . . . . . . . . . . . . . . . . 97

3.2 Ontogenese . . . . . . . . . . . . . . . . . . . . . . . . . . . . . . 999

3.3 Untersuchungsmethodik . . . . . . . . . . . . . . . . . . . . . . . . . . . . . . . . . . 99

3.4 Darstellung und Analyse der Zäblresultate . . . . . . . . . . . . . . . . . . . . . 102

3.5 Schlammuntcrsuchungen . . . . . . . . . . . . . . . . . . . . . . . . . 104

3.6 Expcrimentelle Untersuchungen . . . . . . . . . . . . . . . . . . . . . . 105

3.7 Jahreszyklen. . . . . . . . . . . . . . . . . . . . . . . . . . . . . . 108

3.71 Eudiaptomus gracilis . . . . . . . . . . . . . . . . . . . . . . . . . . . 108

3.72 Cyclopsabyssorm . . . . . . . . . . . . . . . . . . . . . . . . . . . . . . 112

3.73 Cyclops vicinus . . . . . . . . . . . . . . . . . . . . . . . . . . . . . . . . . . . . 114

3.74 Mesocyclopsleuckarti . . . . . . . . . . . . . . . . . . . . . . . . . 117

3.75 Daphnia sp. . . . . . . . . . . . . . . . . . . . . . . . . . . . . . . . 122

3.76 Bosmina sp. . . . . . . . . . . . . . . . . . . . . . . . . . . . . . . 123

3.77 Diaphanosomabrachyurum . . . . . . . . . . . . . . . . . . . . . . . . . . . . 125

3.78 Leptodora kindtii und Bythotrephes longimanus . . . . . . . . . . . . . . . . . . . . . . 125

3.8 Aufenthaltstiefe des Zooplanktons . . . . . . . . . . . . . . . . . . . . . 126

4. Produktion . . . . . . . . . . . . . . . . . . . . . . . . . . . . . . 127

4.1 Erfolgsraten . . . . . . . . . . . . . . . . . . . . . . . . . 128

4.2 Biomassebestimmung. . . . . . . . . . . . . . . . . . . . . . . . . . . 133

4.3 Biomasscberechnung . . . . . . . . . . . . . . . . . . . . . 138

5. Diskussion . . . . . . . . . . . . . . . . . . . . . 140

6. Zusammenfassung . . . . . . . . . . . . . . . . . . . . . . . . . 142

Summary . . . . . . . . . . . . . . . . . . . . . . 143

[itcraturverzeichnis . . . . . . . . . . . . . . . 147 


\section{Einleitung}

Die genaue Kenntnis der Produktion von biologischem Material in den eutrophen Seen des Schweizerischen Mittellandes, aber auch in den oligo- bis mesotrophen Alpenrandseen wird mit der weiter zunehmenden Verschmutzung immer dringender. Die meisten Arbeiten aus neuerer Zeit beschränken sich auf das Phytoplankton. Aus der grossen Zahl von Publikationen aus diesem Gebiet seien erwähnt: THomas [49], Gaechter [20] und Zimmermann [58]. Das Zooplankton hingegen ist für Schweizerseen noch nie gründlich bearbeitet worden. Dabei stellt es ein wichtiges Glied in der Nahrungskette Primärproduktion-Sekundärproduktion-Fische dar.

NAUWERCK [34] führte an einem kleineren schwedischen See umfassende Untersuchungen durch, wobei Detritus, Phytoplankton, Zooplankton und Bakterien mit einbezogen wurden. Andere Arbeiten über die Produktion des Zooplanktons blieben meist auf eine einzelne Art beschränkt $[9,12,13]$.

Zielsetzung. Als erstes galt es, die Lebenszyklen des Crustaceenplanktons in zwei verschiedenen Seen kennenzulernen. Auf diesen Grundlagen war es mit Hilfe chemischer Analysen möglich, die Biomasse zu berechnen, welche die einzelnen Arten im Laufe eines Jahres liefern. Selbstverständlich wäre es wünschenswert, den Übergang von der vorhergehenden Stufe der Nahrungskette (Phytoplankton) zum Zooplankton, respektive vom Zooplankton zur darauffolgenden Stufe (Fische) genau zu bearbeiten. Versuche in dieser Richtung führten aber rasch zu sehr komplexen Problemen (Selektivität bei der Nahrungsaufnahme, unterschiedlicher Nährwert der einzelnen Futteralgen, usw.), die nicht mehr im Rahmen einer einzelnen Arbeit zu bewältigen sind, weshalb ich mich auf die Probleme des Zooplanktons beschränken musste.

Wahl der Seen. Um die beiden wichtigsten Seetypen der Schweiz zu erfassen, kam ein flacher, stark eutropher Mittellandsee sowie ein oligo- bis mesotropher Alpenrandsee in Frage. Als Beispiel für den ersten Typ wählte ich den in der Nähe von Zürich gelegenen Greifensee, als Vertreter des zweiten Typs bot sich der Vierwaldstättersee an. An seinem Ufer liegt nämlich das Hydrobiologische Laboratorium der ETH in Kastanienbaum, das für Probenahmen und Untersuchungen sehr gut ausgerüstet ist. Der stark unterschiedliche Charakter der beiden Seen ermöglichte zudem interessante Vergleiche.

Dank. Diese Arbeit war nur möglich mit grosszügiger Unterstützung von verschiedenen Seiten. Zuerst möchte ich Herrn Prof. Dr. O. Jaag, Direktor der Eidgenössischen Anstalt für Wasserversorgung, Abwasserreinigung und Gewässerschutz (EAWAG), danken für die Möglichkeit, meine Arbeit an seinem gut eingerichteten Institut ausführen zu können. Besonders dankbar bin ich ihm dafür, dass ich die Forschungsschiffe auf dem Vierwaldstättersee und das Hydrobiologische Laboratorium in Kastanienbaum benutzen durfte.

Herrn Dr. H. Ambühl, Leiter der limnologischen Abteilung der EAWAG und des Hydrobiologischen Laboratoriums Kastanienbaum, danke ich für die vielen wertvollen Hinweise während der Ausführung der Arbeit, vor allem für die Überlassung der Temperatur- und Sauerstoffwerte des Vierwaldstättersees wie auch für die kritische Durchsicht des Manuskripts. Frau Dr. M. Boosli-Pavoni bin ich dankbar für die 
Unterstützung bei der Bearbeitung des Phytoplanktons. Bei Herrn Dr. R. Gächter möchte ich mich bedanken für die Hilfe bei den Probenahmen auf dem Vierwaldstättersee und für seine wissenschaftlichen Anregungen. Herrn E. Szabo danke ich für die tatkräftige Mitarbeit bei den chemischen Analysen des Zooplanktons.

Die vielen Probenahmen auf dem Greifensee waren nur dank der grossen Hilfe von Herrn Eugster, Fischereiaufseher der kantonalen Fischzuchtanstalt in Greifensee, möglich; für seine ständige Bereitschaft danke ich ihm sehr.

Zu ganz besonderem Dank verpflichtet bin ich Herrn Dr. U. Einsle von der Anstalt für Bodenseeforschung der Stadt Konstanz, der mir in ausgedehnten Diskussionen zahlreiche Fragen aus dem Problemkreis des Zooplanktons beantworten half.

\section{Seen}

\subsection{Greifensee}

\subsection{Charakterisierung}

Der Greifensee ist ein mittelgrosser, stark eutropher See im schweizerischen Mittelland in der Nähe von Zürich (Abb.1). Eine erste grössere Untersuchung über diesen See veröffentlichte GUYER [21] 1910; 1915/16 erstellten FEHLMANN [19] und Silberschmidt [41] Gutachten über die Fischereiverhältnisse. Seit 1941 sind von Thomas [50] eine ganze Reihe von Arbeiten erschienen, die sich ganz oder teilweise mit dem Greifensee befassen. (Literaturzusammenstellung in THomas [50]).

Im Sommer (Mai bis Oktober) zeigt der Greifensee eine scharfe Trennung in Epilimnion ( 0 bis ca. $5 \mathrm{~m}, \mathrm{O}_{2}$ - Übersättigung), Metalimnion (ca. 5 bis ca. $7 \mathrm{~m}$ ) und Hypolimnion (ca. $7 \mathrm{~m}$-Grund bei $32 \mathrm{~m}$, sauerstofflos, in der Tiefe $\mathrm{H}_{2} \mathrm{~S}$-haltig). In beiden Wintern der Untersuchungsperiode erreichte die Herbst- und Frühahrszirkulation den Boden. Einzelheiten sind im Abschnitt 2.142, «Resultate: Temperatur-, Sauerstoff- und Schichtungsverhältnisse», dargestellt.

\subsection{Orographie (nach Thomas [50])}

Der kleine Mittellandsee liegt auf $435 \mathrm{~m}$ über Meereshöhe. Die Oberfläche beträgt $8,375 \mathrm{~km}^{2}$, die mittlere Tiefe $19 \mathrm{~m}$, die maximale Tiefe $34 \mathrm{~m}$. Wasserführung der Zuflüisse: Aabach : $1,26 \mathrm{~m}^{3} / \mathrm{s}=40$ Millionen $\mathrm{m}^{3} / \mathrm{Jahr}$, Mönchaltorfer Aa: $0,863 \mathrm{~m}^{3} / \mathrm{s}=$ 27,216 Millionen $\mathrm{m}^{3} / \mathrm{J}$ ahr und kleinere Zuflüsse total ungefähr 21,8 Millionen $\mathrm{m}^{3} / \mathrm{Jahr}$. Bei einem Seevolumen von 155 Millionen $\mathrm{m}^{3}$ ergibt sich eine theoretische Erneuerungszeit von 1,75 Jahren.

\subsection{Probestelle}

Die Probestelle liegt ungefähr in der Mitte des Sees über einer Tiefe von $32 \mathrm{~m}$.

\subsection{Physikalische und chemische Verhältnisse}

Von den vielen chemischen und physikalischen Faktoren, die das Leben im See beeinflussen, wählte ich diejenigen zwei aus, die auf das Zooplankton den grössten Einfluss ausüben:

- Temperatur: von ihr hängt in hohem Masse die Entwicklungsgeschwindigkeit der Tiere $a b$.

- Sauerstoff: im Sommer schränkt der Sauerstoffschwund in der Tiefe des Sees den Lebensraum der Zooplankter auf die obersten $5 \mathrm{~m}$ ein. 


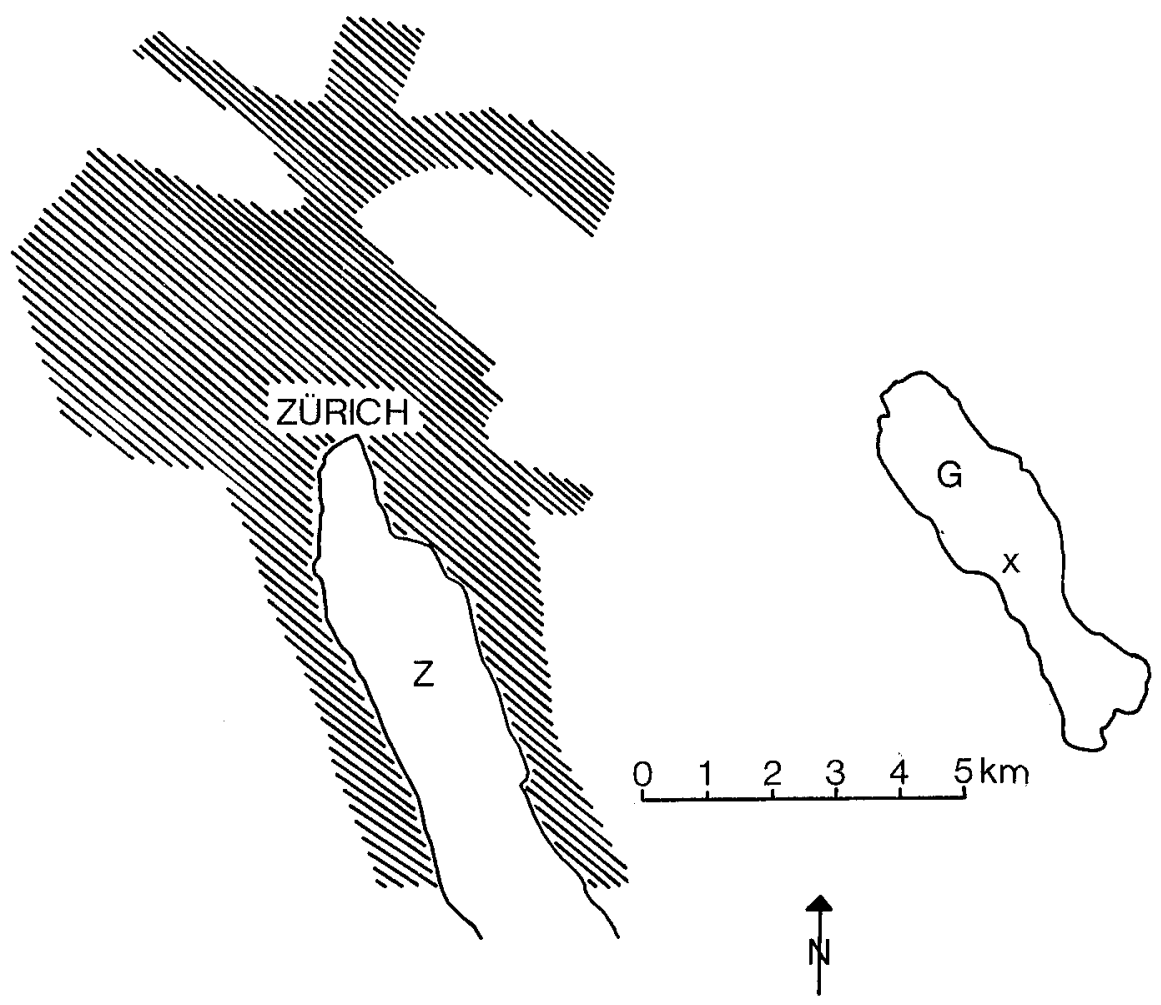

Abb. 1. Lage ales Greifensees; $G=$ Greifensee, $x=$ Probestelle, $Z=Z$ ürichsee.

\subsection{Methoden}

Probenahme: Die Wasserproben wurden mit einem Friedinger Wasserschöpfer aus den Schichtungsverhältnissen angepassten Tiefen entnommen. Temperatur: Die Temperatur wurde elektrometrisch mit dem Oxytester nach AмвӥнL [2] bestimmt. Sauerstoff: Bestimmung nach WinkLER [56], modifiziert nach AlsTERBERG [1] (Vorschrift der EAWAG). Schwefelwasserstoff: Die quantitative Bestimmung erfolgte kolorimetrisch mit Dimethyl-p-phenylendiaminchlorid und Eisen-III-ammoniumsulfat nach den Vorschriften der EAWAG.

2.142 Resultate: Temperatur-, Sauerstoff- und Schichtungsverhältnisse (Abb. 2 und 3)

Im August und September 1967 liegt eine starke Sprungschicht bei 5-7 $\mathrm{m}$. Die Temperatur des Epilimnions beträgt rund $20^{\circ} \mathrm{C}$, die Sauerstoffsättigung schwankt zwischen 110 und $170 \%$.

Im Oktober und November kühlen sich die oberflächlichen Schichten kräftig ab. Das führt zu einer immer tiefergreifenden Durchmischung. Die Vermengung mit sauerstofflosem Wasser der Tiefe verursacht eine Abnahme des Sauerstoffgehaltes und der Sauerstoffsättigung auf 50\% (am 9. November 1967). 


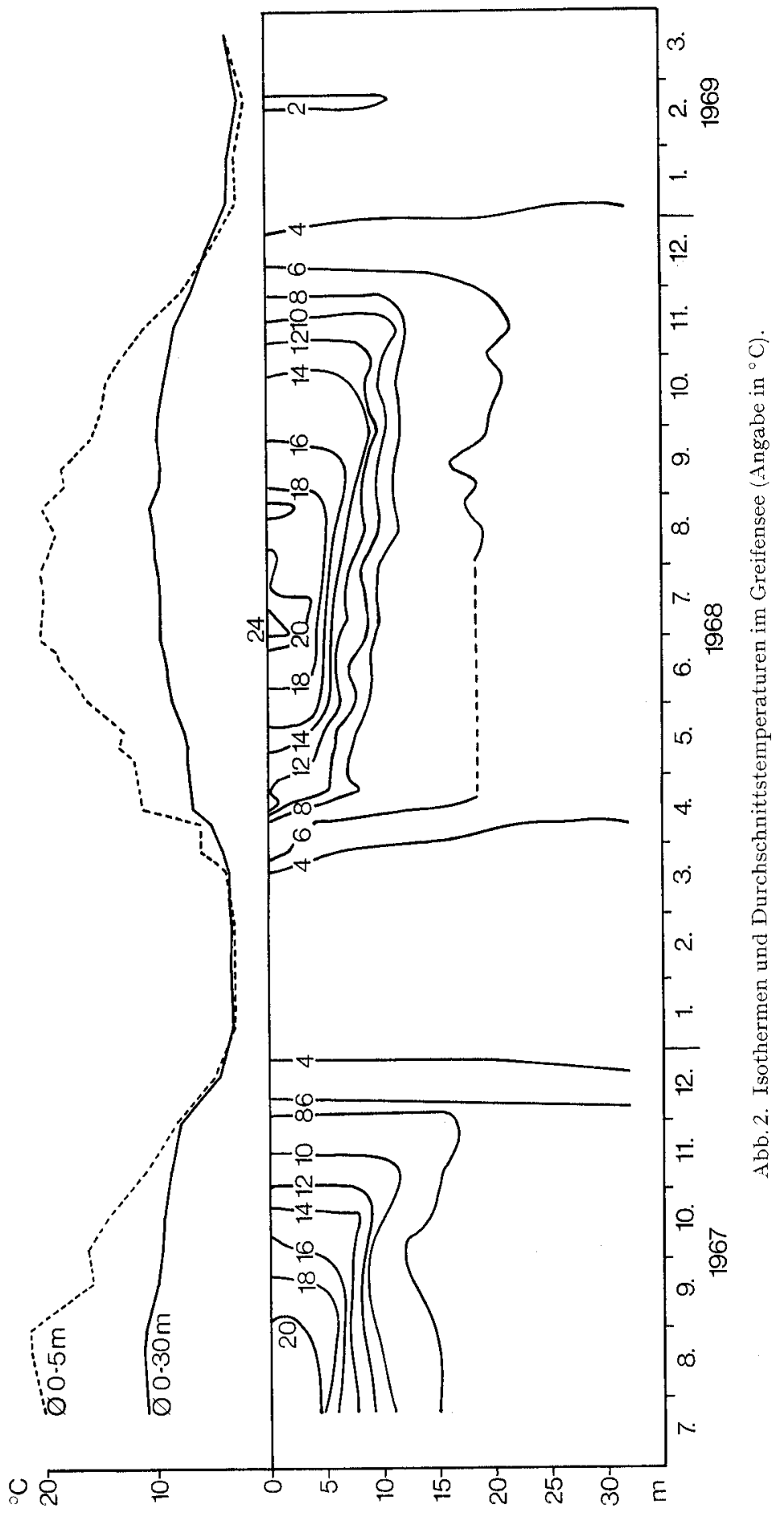




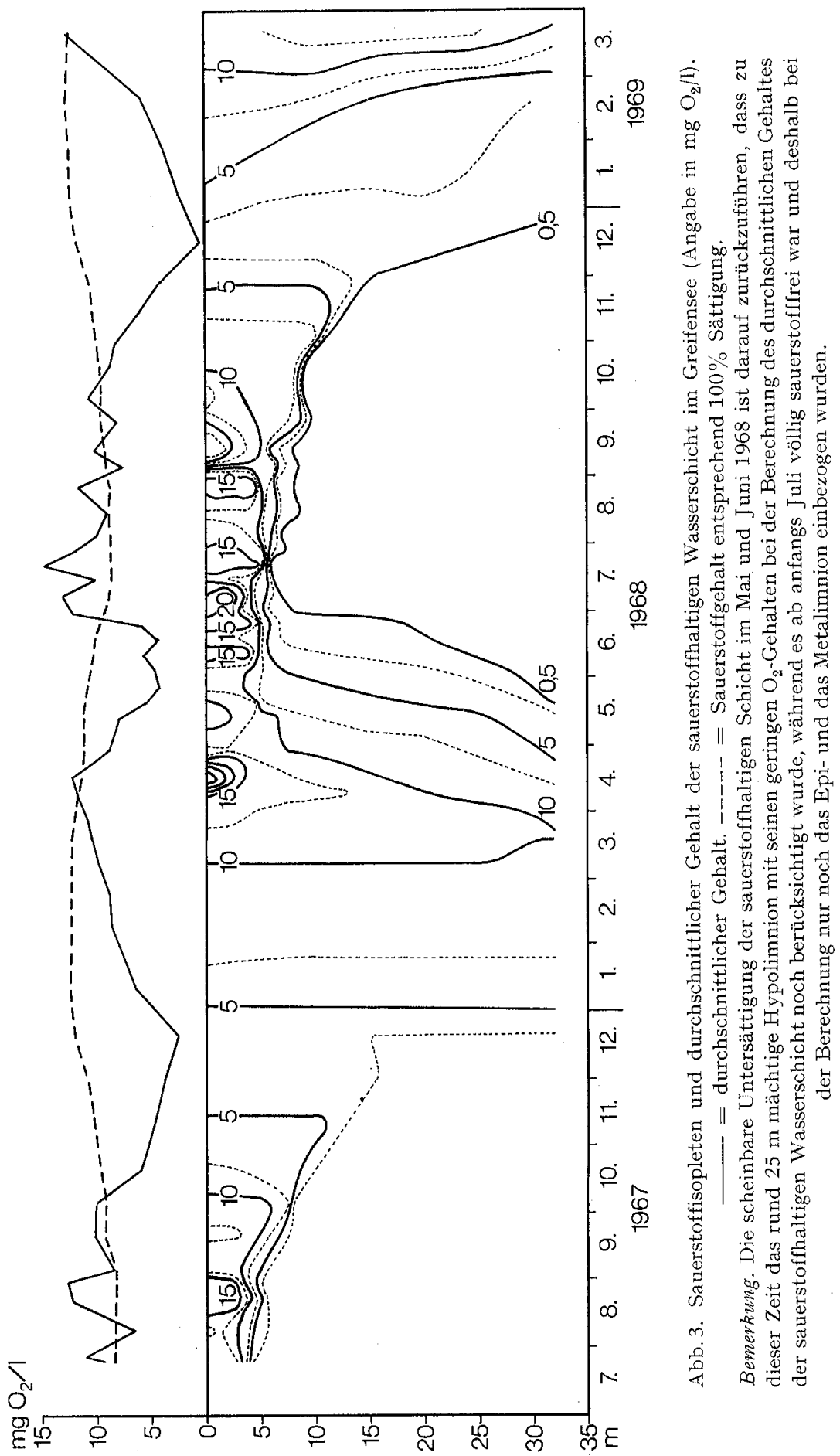


Am 20.12.67 tritt Vollzirkulation ein, die Temperatur beträgt dabei $4,3^{\circ} \mathrm{C}$, der Sauerstoffgehalt 2,5 mg/l, entsprechend $20 \%$ Sättigung.

Die Vollzirkulation dauert fast durchgehend bis anfangs März, eine schwache inverse Schichtung besteht nur am 9.2.68. Ihre Stabilität ist nicht genügend gross, um die Bildung einer Eisdecke zu ermöglichen. Die Sauerstoffsättigung beträgt am Ende dieser Zirkulationsperiode $85 \%$.

Ende März erwärmen sich die obersten 2,5 m erstmals deutlich, was zu einer Sauerstoffsättigung von $120 \%$ führt. Mitte April beträgt die Oberflächentemperatur $15^{\circ} \mathrm{C}$. Eine starke Phytoplanktonentwicklung verursacht die gewaltige Sauerstoffübersättigung von $386 \%$ an der Oberfläche. Ab Ende April bildet sich eine stabile Sprungschicht, die zwischen 4 und $7 \mathrm{~m}$ liegt. Im Hypolimnion schwindet der Sauerstoff rasch.

Die bis Mitte September anhaltende Sommerstagnation zeigt folgendes Bild: Das $6-8 \mathrm{~m}$ mächtige Epilimnion weist Temperaturen von $18-20^{\circ} \mathrm{C}$ und wechselnde
Sauerstoffsättigungen von $110-210 \%$ auf. Unterhalb der scharf ausgeprägten Sprungschicht ist das Hypolimnion sauerstoffrei, gegen Ende dieser Periode finden wir in den bodennahen Wasserschichten sogar bis zu 1,0 $\mathrm{mg} \mathrm{H}_{2} \mathrm{~S} / \mathrm{l}$. Von der zweiten Oktoberhälfte an greift die Zirkulation mit sinkender Oberflächentemperatur langsam tiefer, erreicht Ende November $15 \mathrm{~m}\left(8^{\circ} \mathrm{C}, 41 \% \mathrm{O}_{2}\right)$, und am 17 . Dezember $26 \mathrm{~m}\left(5^{\circ} \mathrm{C}\right.$ und niedrigste je gemessene $\mathrm{O}_{2}$-Sättigung von nur $5 \%$ bei $0,6 \mathrm{mg} \mathrm{O}_{2} / 1$ ).

Am 7.1.69 herrscht Vollzirkulation und der Sauerstoffgehalt hat sich auf $20 \%$ verbessert. In diesem Winter sind die Inversionen der Temperaturschichtung deutlicher, doch bildet sich auch diesmal keine durchgehende Eisdecke. Bei der letzten Probenahme am 21. März 1969 besteht Homothermie und eine $\mathrm{O}_{2}$-Sättigung von 103\%; die Sauerstoffversorgung am Ende der Zirkulation ist also besser als im Vorjahr.

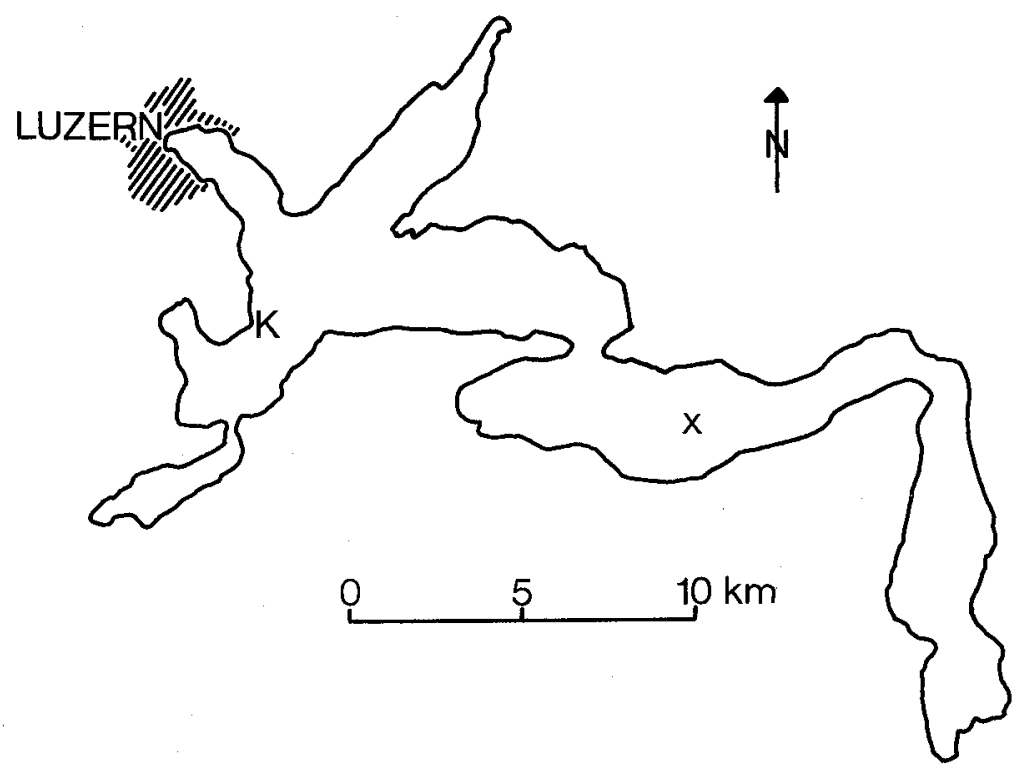

Abb. 4. Vierwaldstättersee; $K=$ Hydrobiologisches Laboratorium der ETH in Kastanienbaum, $\mathrm{x}=$ Probestelle im Gersauerbecken. 


\subsection{Gersauerbecken des Vierwaldstättersees}

\subsection{Lage und Charakterisierung}

Das Becken von Gersau ist ein Teil des Vierwaldstättersees (Abb. 4), weitgehend von hohen, steilen Felswänden eingeschlossen, ca. $10 \mathrm{~km}$ lang und $3 \mathrm{~km}$ breit. Die maximale Tiefe beträgt $214 \mathrm{~m}$.

Das Gersauerbecken kann nicht mehr als oligotroph bezeichnet werden, es befindet sich bereits auf dem Weg zum mesotrophen Zustand (AмBüHL, persönliche Mitteilung).

\subsection{Probestelle}

Die Probestelle liegt im Zentrum des Seebeckens über einer Wassertiefe von $214 \mathrm{~m}$. Im weitern Text wird sie mit "Vierwaldstättersee" bezeichnet.

\subsection{Physikalische und chemische Verhältnisse}

\subsection{Methoden}

Es wurden dieselben Methoden angewandt wie im Greifensee. Die Resultate wurden mir freundlicherweise zum grössten Teil von der EAWAG überlassen.

2.232 Resultate. Temperatur-, Sauerstoff- und Schichtungsverhältnisse (nach АмвüHL [3]), (Tab. 1 und 2)

1967 kann eine Durchmischung bis 180 m, 1968 bis $130 \mathrm{~m}$ festgestellt werden. Die Zirkulation dringt vom Spätherbst bis zum Frühjahr mit unscharfer unterer Front in die Tiefe vor (vorauslaufende Turbulenzschübe im Hypolimnion). Der Sauerstoffgehalt beträgt $1967 \mathrm{im}$ April $11 \mathrm{mg} / 1$ an der Oberfläche und $7 \mathrm{mg} / \mathrm{l}$ über Grund, 1968 $13 \mathrm{mg}$, bzw. $4 \mathrm{mg} / 1$. Unmittelbar unterhalb der trophogenen Schicht finden wir eine deutliche Zehrung (ca. $-2,5 \mathrm{mg} / \mathrm{l}$ von $20-30 \mathrm{~m}$ ). Im obern Hypolimnion ist sie schwach und steigt erst unmittelbar über dem Grund wieder an. Das Gersauerbecken erleidet den schwächsten Sauerstoffverlust aller Seebecken des Vierwaldstättersees.

Die Temperatur der bodennahen Wasserschicht änderte sich in der Untersuchungsperiode praktisch nicht $\left(5,05^{\circ} \mathrm{C}\right.$ im Winter $1967 / 68,5,15^{\circ} \mathrm{C}$ im Winter $1968 /$ 1969).

\section{Zooplankton}

\subsection{Artenliste}

Im Greifensee wurden folgende Arten gefunden:

\subsection{Phyllopoden}

Diaphanosoma brachyurum (Lievin)

Daphnia hyalina (= longispina hyalina) (Leydig)

Daphnia galeata (G.O. Sars)

Daphnia cucullata (G.O. Sars)

Eubosmina sp.

Leptodora kindtii (Focke)

Auffallend ist, dass 1961 Daphnia galeata und Daphnia cucullata noch nicht gefunden wurden (EINSLE, persönliche Mitteilung).

Im Vierwaldstättersee kommt hinzu:

Bythotrephes longimanus (Leydig) 


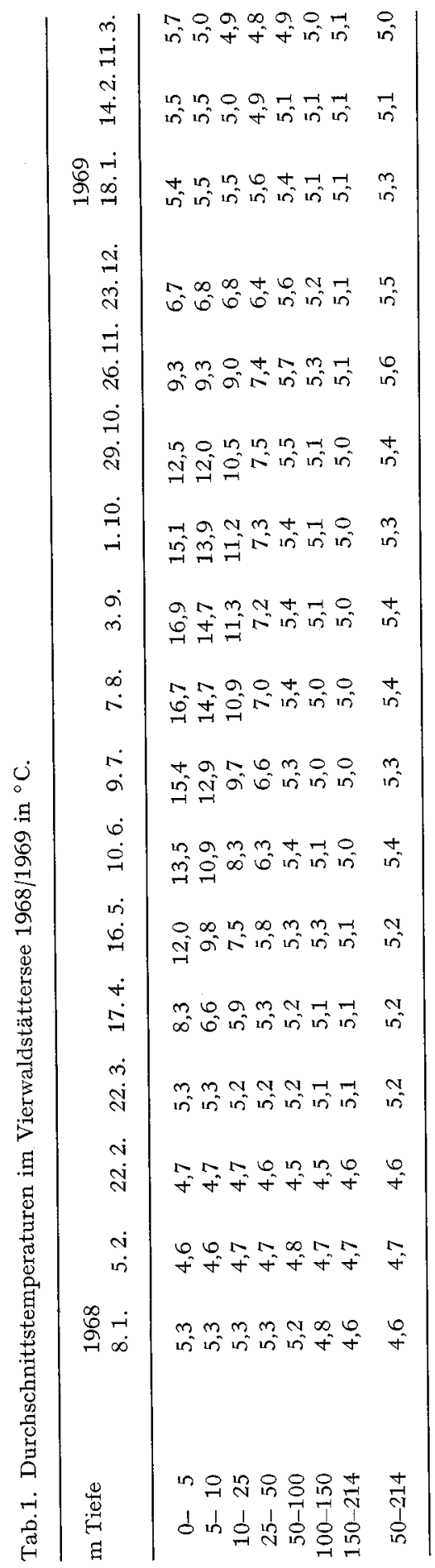

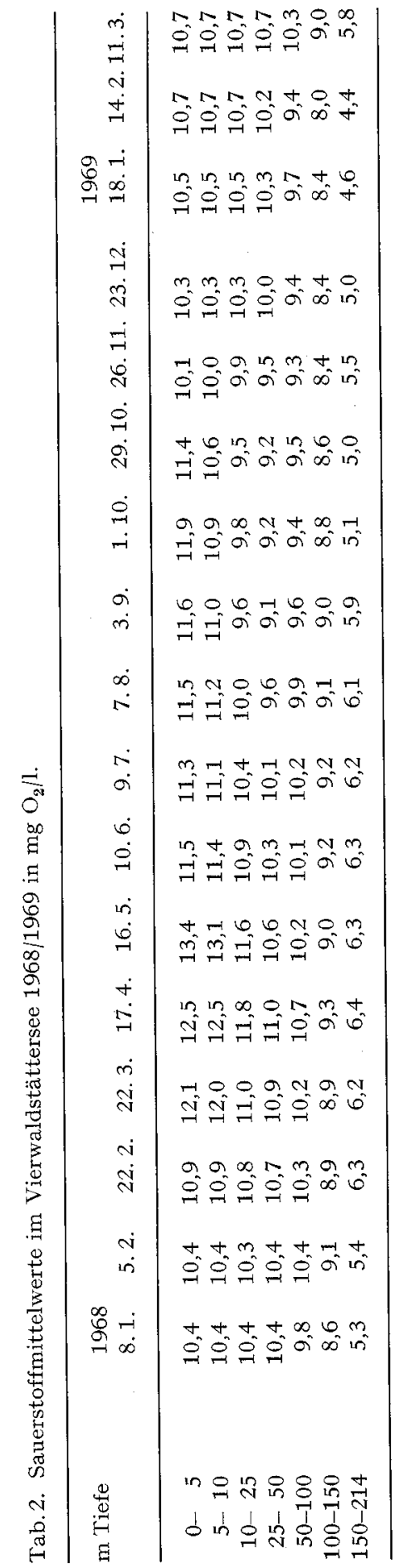




\subsection{Copepoden}

Eudiaptomus gracilis (G.O. Sars)

Mesocyclops leuckarti (Claus)

Cyclops abyssorum (Kiefer)

Cyclops bohater (Kozminski)

Cyclops vicinus (Uljanin)

Cyclops bohater ist so selten, dass er im folgenden nicht mehr behandelt wird. Selten sind im Vierwaldstättersee auch Mixodiaptomus laciniatus (Lilljeborg) und Megacyclops gigas (Claus) anzutreffen, sie spielen in der Zooplanktonpopulation keine wesentliche Rolle und wurden daher nicht berücksichtigt. Cyclops bohater fehlt im Vierwaldstättersee völlig.

\subsection{Ontogenese}

Da sich die vorliegende Arbeit hauptsächlich mit dem Crustaceenplankton befasst, sollen hier die Lebensläufe der beiden wichtigsten Gruppen, der Copepoden und der Phyllopoden kurz beschrieben werden.

\subsection{Copepoden}

Die Eier werden von den Weibchen in Eisäcken am Körper getragen, jedoch ohne physiologische Verbindung zum Muttertier. Eudiaptomus sp. haben einen Eisack, Cyclops sp. zwei (Abb.5).

Nach dem Schlüpfen folgen 5 Naupliusstadien, die jeweils durch eine Häutung voneinander getrennt sind. Der Naupliuskörper weist keine Segmentierung auf. Auf die Naupliusstadien folgen 5 wiederum durch Häutungen getrennte Copepoditstadien (C1-C5). Die Copepodite weisen ähnliche Körperformen auf wie die erwachsenen Tiere, vor allem die jüngeren Stadien sind aber plumper. Die Copepodite sind segmentiert; die Zahl der Segmente nimmt bei jeder Häutung um eins zu, beginnend mit 5 Segmenten beim C1; das Männchen hat 10 Segmente. (Nähere Angaben und Bestimmungsschlüssel sind bei KIEFER [25] und DUSSART [7] zu finden.)

\subsection{Phyllopoden}

Aus dem Ovar treten die Eier der Phyllopoden in einen Brutraum aus, der bei Daphnia und Bosmina innerhalb der Schale gelegen, bei Bythotrephes und Leptodora ein sackförmiger Anhang ist. Dort erfolgt die Embryonalentwicklung, verbunden mit einer beträchtlichen Grössenzunahme. Die benötigten Nährstoffe werden vom Muttertier geliefert.

Nach dem Austritt aus dem Brutraum ins freie Wasser besitzen die jungen Tiere sofort die Gestalt der Erwachsenen, von denen sie nur durch die geringere Grösse und das Fehlen des Brutraumes unterschieden sind.

Bei Daphnia wird nach 5 Häutungen die Geschlechtsreife erlangt, nach weiteren 5 ist die endgültige Grösse praktisch erreicht, bis zum Tod können jedoch noch weitere 10 Häutungen ablaufen [23].

Die Phyllopoden pflanzen sich haupsächlich parthenogenetisch fort. Die Befruchtung durch fakultativ auftretende Männchen führt zu Dauereiern. (Weitere Einzelheiten bei Herbst [22].)

\subsection{Untersuchungsmethodik}

Ein Zooplanktonnetzzug stellt eine sehr kleine Stichprobe aus der Population des ganzen Sees dar. Ihre Aussagekraft wird nicht nur durch den Fehler eingeschränkt, 

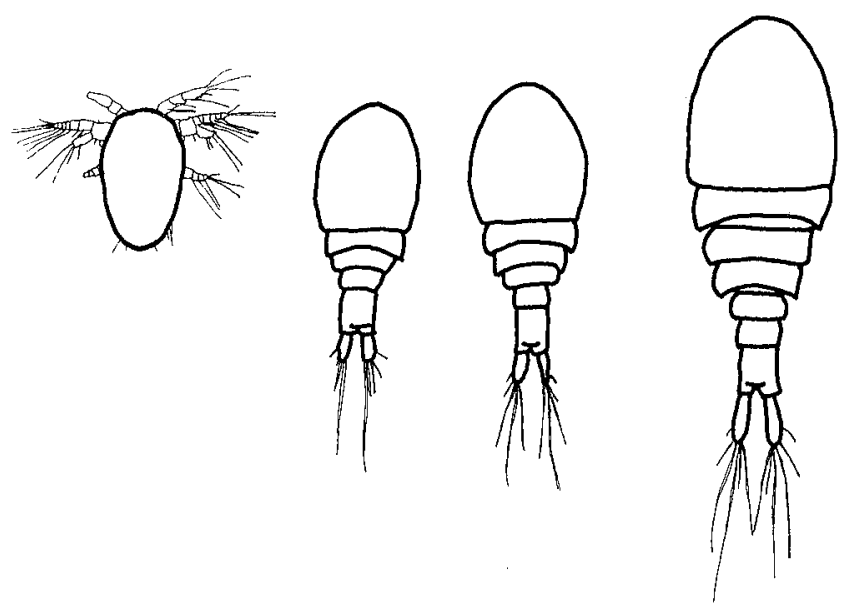

$N \quad C_{1} \quad C_{2} \quad C_{3}$

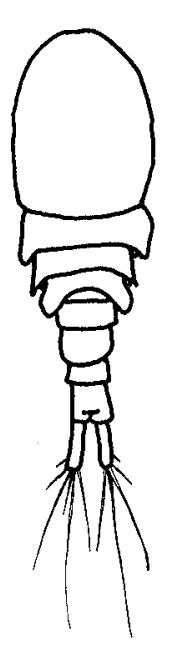

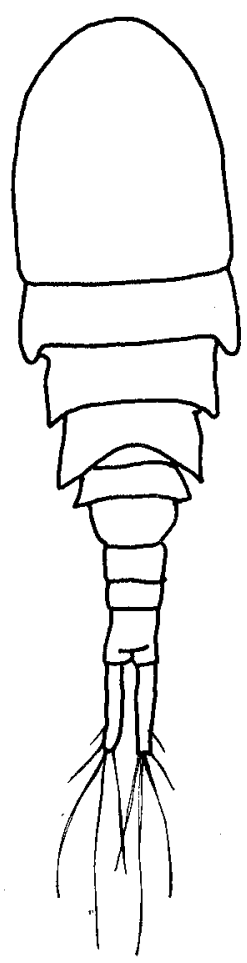

C4
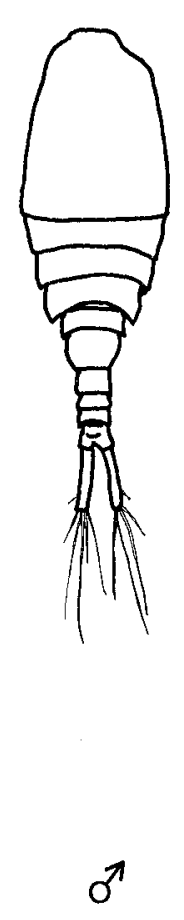

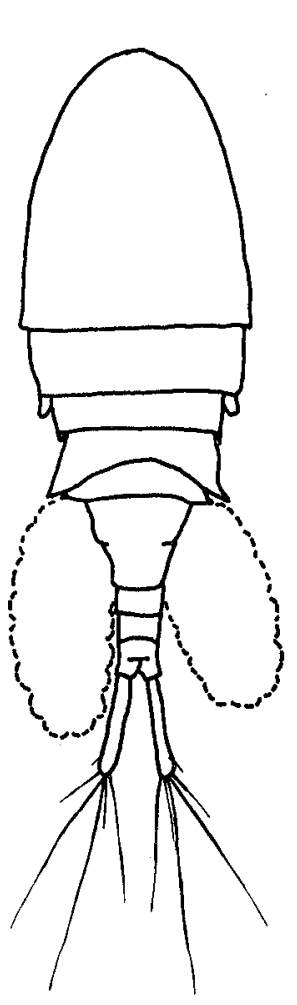

ㅇ

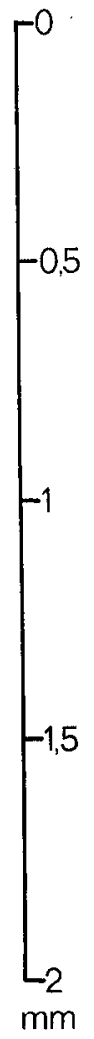

Abb.5. Cyclops vicinus: Nauplius (N), Copepoditreihe (C1-C5) und Adulte. 
der durch die Netzverstopfung entsteht, sondern vor allem durch die unregelmässige räumliche und zeitliche Verteilung des Zooplanktons [26, 38, 39]. Die Zuverlässigkeit kann gesteigert werden durch eine grosse Zahl von Proben, die entweder zur selben Zeit über den ganzen See verteilt entnommen werden, oder die an derselben Stelle in kurzen zeitlichen Abständen gefangen werden. Ich wählte den zweiten Weg, da dadurch eine gründlichere Information über die zeitliche Veränderung der Zooplanktonpopulation gewonnen werden kann.

\subsection{Netze}

Die Zooplanktonfänge erfolgten mit einem Nansen-Schliessnetz aus monofilem Nylongewebe, das keine Alterung durch Quellen der Fäden aufweist. Da dieses Netz beim senkrechten Heraufziehen in beliebiger Tiefe unter Wasser geschlossen werden kann, erlaubt es das Erfassen der dünn besiedelten tiefen Wasserschichten ohne Störung durch die dichte Bevölkerung der oberen Schichten.

Im Greifensee wurde bis zum 28.3.68 ein Netz mit $112 \mu$ Maschenweite, $0,06 \mathrm{~m}^{2}$ Eintrittsöffnung und $0,57 \mathrm{~m}^{2}$ Filterfläche verwendet. Ab 9.4.68 wurde ein neues Netz mit gleicher Maschenweite, aber $0,10 \mathrm{~m}^{2}$ Eintrittsöffnung und $0,79 \mathrm{~m}^{2}$ Filterfläche eingesetzt. Ein Vergleich der beiden Netze ergab keinerlei Unterschiede in der Fangkapazität.

Im Vierwaldstättersee wurde ein Netz von $95 \mu$ Maschenweite und gleichen Dimensionen wie das neue Netz im Greifensee gebraucht. Die Probenahmen vom 22.2. und 22.3.68 erfolgten mit demselben Netz wie im Greifensee vor dem 28.3.68.

\subsection{Entnahme und Konservierung}

Das Netz wurde mit ungefähr $0,4 \mathrm{~m} / \mathrm{s}$ hochgezogen. (TRANTER [51] verlangt weniger als $1.5 \mathrm{~m} / \mathrm{s}$ für repräsentative Werte.) Unmittelbar nach dem Fang wurden die Proben in $4 \%$ Formaldehydlösung konserviert.

\subsection{Tiefenstufung}

Um eine Verstopfung des Netzes durch Phytoplankton zu umgehen und um zusätzliche Angaben über die Aufenthaltstiefe des Zooplanktons zu erhalten, wurden die Fänge in folgenden Tiefenstufen durchgeführt:

- Greifensee: 0-5 m, 5-10 m, 10-20 m, $20 \mathrm{~m}-$ Grund bei ca. $32 \mathrm{~m}$. Während der Sommerstagnation wurden die Stufen unterhalb $10 \mathrm{~m}$ zusammengefasst, da sie kein Zooplankton mehr enthielten.

- Vierwaldstättersee: 0-10 m, 10-25 m, 25-50 m, $50 \mathrm{~m}-$ Grund bei $214 \mathrm{~m}$. Bei stark störendem Auftreten von Phytoplankton wurde die oberste Stufe geteilt in 0 $5 \mathrm{~m}$ und $5-10 \mathrm{~m}$.

\subsection{Fehlermöglichkeiten}

Eine Netzverstopfung kann im Greifensee ausgeschlossen werden, da es sich beim Phytoplankton des Greifensees um durchwegs so kleine Formen handelte, dass sie im verwendeten Netz gar nicht zurückgehalten wurden. Im Gegensatz dazu verstopfte das Vierwaldstättersee-Phytoplankton (Tabellaria fenestrata, Oscillatoria rubescens und andere grosse Formen) das Netz zeitweise in beträchtlichem Masse. Auch durch sehr eng zonierte Stufenfänge kann diese Netzverstopfung nicht völlig vermieden werden. 


\subsection{Auswertung der Proben}

\subsection{Probenteilung}

Da eine Probe während der grossen Sommerpopulation im Greifensee mindestens 20000 , oft aber über 100000 Tiere enthielt, konnte natürlich nur ein kleiner Bruchteil ausgezählt werden. Bruchteile bis zu 1/20 wurden mit einer Kolbenpipette mit erweitertem Ausfluss, die Bruchteile 1/50 bis 1/250 mit einer Stempelpipette gewonnen. Unabhängig von der Grösse des gewählten Bruchteils wird der Fehler erst beim Zählen von weniger als 20 Tieren pro Kategorie grösser als $20 \%([9,57]$, eigene Kontrollen).

\subsection{Zählen}

Bei allen Copepoden wurden folgende Kategorien getrennt gezählt: Copepoditstadien C1, C2, C 3, C4, C5, Männchen, Weibchen, eiertragende Weibchen. Die Raubcladoceren Bythotrephes longimanus und Leptodora kindtii wurden ohne Altersunterscheidung gezählt, ebenso die Nauplien.

Bei den Phyllopoden wurden eiertragende und nichteiertragende Tiere unterschieden sowie allfällig vorhandene Männchen. Die Unterscheidung zwischen jungen Tieren und ausgewachsenen, aber nicht eiertragenden wurde unterlassen, da die geringere Grösse kein eindeutiges Kriterium bildet und sich das Vorhandensein oder Fehlen eines Brutraumes bei formolfixierten Tieren nicht immer einwandfrei bestimmen lässt.

\subsection{Darstellung und Analyse der Zählresultate}

\subsection{Bestand}

Die Grundlage für die Populationsanalysen bildet die graphische Darstellung des zeitlichen Verlaufs des Gesamtbestandes einer Art unter $1 \mathrm{~m}^{2}$ Seeoberfläche. Oft lassen sich auf Grund dieser Kurven jedoch die aufeinanderfolgenden Generationen noch nicht sicher trennen: in diesen Fällen müssen noch feinere Analysenmethoden angewandt werden:

\subsection{Bestand der jüngsten und ältesten Copepodite}

Die isolierte Darstellung des Bestandes der jüngsten und ältesten Copepodite bildet eine solche Möglichkeit. (Die C1 von Cyclops vicinus und Cyclops abyssorum konnten nicht mit genügender Sicherheit unterschieden werden, weshalb alle Darstellungen und Berechnungen für diese beiden Arten erst mit den $\mathrm{C} 2$ beginnen. Bei Eudiaptomus gracilis mussten dagegen wegen zuwenig sicherer Unterscheidung die C4 und C 5 zusammengefasst werden.) Aus diesen Kurven lässt sich der zeitliche Abstand zwischen zwei aufeinanderfolgenden Generationen sehr einfach herauslesen, ebenso derjenige zwischen den ersten und letzten Copepoditstadien. (Beispiel: Abb.9. Cyclops abyssorum: Greifensee, Bestand C2 und Bestand C5, S.111.)

\subsection{Prozentualer Anteil der verschiedenen Stadien}

Für jede Probe werden die Anteile der einzelnen Copepoditstadien $\mathrm{C} 1$ bis $\mathrm{C} 5$ und der erwachsenen Tiere am gesamten Bestand berechnet und die einander entsprechenden Punkte aufeinanderfolgender Proben miteinander verbunden. Eine Zunahme der jüngern Stadien zeigt sich im Ansteigen dieser Linien, ein Älterwerden der Generation im Absinken. (Beispiel: Abb. 10. Cyclops abyssorum: Vierwaldstättersee, S.113.) 


\subsection{Analyse der Erwachsenen}

Auch die nähere Untersuchung der erwachsenen Tiere kann Aufschlüsse geben: wie im Abschnitt 3.6, Experimentelle Untersuchungen, geschildert, ist die Entwicklungsgeschwindigkeit der Männchen etwas grösser als diejenige der Weibchen. Daher ist der Anteil der Männchen zu Beginn einer Erwachsenenpopulation hoch, er sinkt ab, wenn die Weibchen in grösserer Menge auftreten. Der Anteil der eiertragenden Weibchen (\& ov.) ist zu Beginn niedrig, da zwischen dem Erwachsenwerden und dem Auftreten der ersten Eipakete auch eine gewisse Zeit verstreicht.

\subsection{Theoretische Entwicklungsdauer}

Bei den Bestandeszahlen treten oft fragliche Zwischenmaxima auf. Um entscheiden zu können, ob es sich um zufällige Schwankungen oder um eine eigene Generation handelt, verglich ich die im See gefundenen zeitlichen Abstände zwischen zwei Maxima mit der berechneten Entwicklungsdauer. Die theoretische Entwicklungsdauer wurde wie folgt berechnet:

Mitteltemperatur. Zuerst wurde das algebraische Mittel der Temperaturen folgender Tiefenstufen berechnet: Greifensee: 0-5 m, 5-10 m, 10-20 m, 20-30 m. Vierwaldstättersee: 0-5 m, 5-10 m, 10-25 m, 25-50 m, 50-214 m.

Als A ufenthaltstiefe wurde für jede einzelne Art des Zooplanktons diejenige Wasserschicht gewählt, in der zwei Drittel der ganzen Population lebt. Für diese Aufenthaltstiefe wurde aus den Stufendurchschnittstemperaturen für jede Dekade eines Monats (Greifensee), bzw. jeden halben Monat (Vierwaldstättersee) eine Mitteltemperatur berechnet, welche für die Entwicklungsgeschwindigkeit massgebend ist.

Entwicklungsdauer. Die Dauer der verschiedenen Entwicklungsstadien der Copepoden wurde experimentell bestimmt (vgl. Kap.3.6, Experimentelle Untersuchungen), sie nimmt mit sinkender Wassertemperatur zu (Abb.6, S. 107).

Berechnung der Theoretischen Entwicklungsdawer. Ausgangspunkt für die Berechnung war das Datum der maximalen Eiproduktion. Aus der Mitteltemperatur und der zugehörigen Eientwicklungsdauer wurde berechnet, an welchem Tag die Nauplien schlïpfen. Von diesem Datum ausgehend, wurde aus Mitteltemperatur und Nauplienentwicklungsdauer der Zeitpunkt berechnet, an dem die 1. Copepodite auftreten. Die Längen der verschiedenen Lebensphasen (Ei, Nauplius, Copepodit) zusammen ergeben die Entwicklungszeit von der Eiablage bis zum Auftreten erwachsener Tiere = theoretische Entwicklungsdauer.

\subsection{Eiproduktion}

Die tägliche Eiproduktion wurde nach folgender Formel berechnet:

$$
\frac{\text { Eizahl } / \mathrm{m}^{2}}{\text { Entwicklungsdauer in Tagen }}=\text { Eiproduktion } / \mathrm{Tag} \cdot \mathrm{m}^{2} \text {. }
$$

Die Eizahl $/ \mathrm{m}^{2}$ berechnete sich aus der Anzahl eiertragender Weibchen $/ \mathrm{m}^{2}$ und der Eizahl/Weibchen. Für die letzte Grösse wurden jeweils 50-100 Eisäcke zerlegt und deren Eier gezählt. Bei Mesocyclops leuckarti war dies sehr schwierig, da die Eisäcke trotz schonender Behandlung sehr leicht in kleine Teile oder sogar in einzelne Eier zerbrechen, bei den übrigen Copepoden fallen sie als ganze Säcke ab. Daher sind die für Mesocyclops leuckarti angegebenen Eiproduktionszahlen sicher zu gering, sie müssen als Minimalwerte verstanden sein. Immerhin liegen sie in derselben Grössen- 
ordnung wie diejenigen anderer Autoren $[11,34]$. Als Folge davon sind die Erfolgsraten, die auf Grund der Eiproduktion berechnet werden, zu gross, sie stellen Maximalwerte dar.

Im Vierwaldstättersee konnten nur an zwei Probetagen genügend eiertragende Mesocyclops-leuckarti-Weibchen gefunden werden, um statistisch einigermassen gesicherte Eizahlen zu erhalten. Diese Resultate liegen so gut im selben Bereich wie diejenigen der erwähnten Autoren, dass trotz seines statistischen Ungenügens der Durchschnitt der beiden Proben (10 Eier/q ov.) für die Berechnung der Eiproduktion auch an den andern Probedaten verwendet wurde. Um die Eiproduktion $/ \mathrm{m}^{2}$ für einen gewissen Zeitabschnitt $z u$ erhalten, wurden die Flächen unter der Kurve «Eiproduktion $/ \mathrm{Tag} \cdot \mathrm{m}^{2}$ ” graphisch integriert.

Die Produktionsleistung einer Population berechnet ELSTER [13] mit Hilfe des Erneuerungskoeffizienten, der eine Aussage darüber erlaubt, in welchem Zeitabschnitt die vorhandenen Eier schlüpfen und durch neue ersetzt werden. Ich gebe der Berechnung mit Hilfe der Tagesproduktion, einer konkreten, leicht vorstellbaren Grösse, den Vorzug.

Im folgenden kann gezeigt werden, dass die beiden Methoden mathematisch exakt übereinstimmen :

ELSTER [13]:

Erneuerungskoeffizient $=$ Zeitabschnitt/Entwicklungszeit, Produktion $=$ Bestand $\times$ Erneuerungskoeffizient .

(1) in (2) eingesetzt:

Produktion $=$ Bestand $\times$ Zeitabschnitt/Entwicklungszeit,

umgeformt:

Produktion pro Zeitabschnitt $=$ Bestand/Entwicklungszeit .

Mittelholzer:

Tagesproduktion $=$ Bestand/Entwicklungszeit, Produktion $=$ Tagesproduktion $\times$ Zeitabschnitt

(4) in (5) eingesetzt:

Produktion $=$ Bestand/Entwicklungszeit $\times$ Zeitabschnitt ,

umgeformt:

Produktion pro Zeitabschnitt $=$ Bestand/Entwicklungszeit, wobei (6) dasselbe ist wie (3).

\subsection{Schlammuntersuchungen}

Es ist bekannt, dass Jugendstadien von Cyclops vicimus und Mesocyclops leuckarti Ruhezeiten durchmachen, und zwar z.T. bewegungslos auf dem Seegrund $[9,34,55]$. Deshalb untersuchte ich auch die obersten Schlammschichten auf die Besiedlung durch Copepoden.

\subsection{Probenahme}

Die Schlammproben wurden mit einem Schlammstecher nach ZüLLIG [60] entnommen, der eine Probe mit praktisch ungestörter Schichtung von $9,1 \mathrm{~cm}^{2}$ Querschnitt und ca. 0,5 m Tiefe liefert, sowie ca. 0,5 m der darüberstehenden Wassersäule. Das Wasser und die obersten $20 \mathrm{~cm}$ des Schlammes, mindestens bis zur ersten festen Schlammschicht, wurden abgesaugt und unkonserviert ins Laboratorium gebracht. $90 \%$ der Copepodite wurden in den obersten $4 \mathrm{~cm}$ des Schlammes gefunden, NAU- 
WERCK [34] gibt sogar für diese Schicht 100\% an, WIERZBICKA [54]95\%. Um zuverlässigere Werte zu erhalten, wurden immer 5 Parallelproben genommen.

\subsection{Gewinnung der Crustaceen}

Die Proben wurden in einem Nylonnetz mit $160 \mu$ Maschenweite unter kräftigem Wasserstrahl ausgeschlämmt. Kontrollen zeigten, dass sämtliche Copepoden schon in einem 250- $\mu$-Netz zurückgehalten wurden, beträgt doch die grösste Körperbreite von Cyclops vicinus $\mathrm{C} 4$ mindestens $350 \pm 50 \mu$.

Unter der Lupe konnten die Copepodite zwischen den reichlich vorhandenen Sandkörnern und Pflanzenteilen bei 25facher Vergrösserung leicht gezählt werden. Die Proben des Vierwaldstättersees wurden vollständig ausgezählt, von denjenigen des Greifensees nur 1/10, wobei der daraus resultierende Fehler knapp 10\% beträgt.

\subsection{Experimentelle Untersuchungen}

Um eine genaue Populationsanalyse durchführen zu können, muss die Entwicklungsdauer der Tiere im See bekannt sein. Sie lässt sich berechnen aus der Wassertemperatur und der stark temperaturabhängigen Entwicklungsgeschwindigkeit. Nebst Temperaturmessungen im See sollten die vorliegenden Zuchtversuche die benötigten Grundlagen liefern.

\subsection{Material}

Es wurden Aufzuchten mit Nauplien von Eudiaptomus gracilis, Cyclops abyssorum und Cyclops vicinus sowie mit Copepoditen der letzten beiden Arten durchgeführt.

Von frisch gefangenen Weibchen wurden schlüpfreife Eisäcke abgestreift und in Zuchtschälchen gebracht, wo die Nauplien nach spätestens 24 Stunden schlüpften. Die Eisäcke müssen von den Weibchen getrennt werden, um zu verhindern, dass diese ihre eigenen Nachkommen restlos auffressen.

\subsection{Zuchtmethode}

Temperaturen zwischen 6 und $25^{\circ} \mathrm{C}$ konnten mit einer Konstanz von $\pm 1,0^{\circ} \mathrm{C}$ in einem Lichtbrückenthermostat hergestellt werden [58]. Beleuchtet wurde mit ca. 100 lux $8 \mathrm{~h}$ hell/16 h dunkel (die kurze Tageslänge vermeidet bei Cyclops vicinus Diapauseerscheinungen der Copepodite $[10,43])$. In Glasschälchen mit ca. $20 \mathrm{ml}$ abgekochtem Seewasser wurden maximal 20 Nauplien, bzw. 5 Copepodite gegeben (bei Copepoditen weniger, wenn an einem Tag nicht genügend $\mathrm{C} 1$ geschlüpft waren). Die Copepodite wurden einmal wöchentlich, bei starker Verschmutzung auch häufiger, in frisches Wasser transferiert, wobei sie mit einem Gemisch von Äthanol und Chloroform $(10: 1)$ möglichst schonend betäubt wurden [44].

Als Futter bewährten sich Reinkulturen von Scenedesmus oahuensis (Lemm.) Smith. und von Haematococcus pluvialis (Sammlung ZEHNDER, EAWAG). Die verwandte Art Scenedesmus obliquns kann bis zu $60 \%$ der Trockensubstanz Eiweiss enthalten, sie ergibt gleiche Wachstumsraten wie tierisches Eiweiss [32], womit auch erklärt werden kann, weshalb die karnivoren Cyclops vicinus bei Scenedesmusfütterung ausgezeichnet gediehen.

Die Erfolgsrate betrug bei 2500 Nauplien $45 \%$ und bei 1000 Copepoditen $60 \%$. Diese hohen Erfolgsraten machen wahrscheinlich, dass die angewandten Zuchtmethoden günstige Lebensbedingungen schaffen und somit zuverlässige Resultate liefern. 
Die Entwicklungszeiten der Eier wurden durch Beobachten frisch ausgetretener Eisäcke bis zum Schlüpfen der Nauplien in Wasser ohne Futter ermittelt.

\subsection{Resultate}

\subsection{Eudiaptomus gracilis (Abb.6a)}

Hier liegen nur für die Nauplien eigene experimentell ermittelte Daten vor. Angaben über die Temperaturabhängigkeit der Entwicklungsgeschwindigkeit von Eudiaptomuseiern findet man bei ELSTER [13] (Material aus dem Bodensee), für Eier, Nauplien und Copepodite bei EcKstein [8] (Schluchsee-Material). Meine eigenen Beobachtungen an Nauplien aus dem Greifensee zeigten eine sehr gute Übereinstimmung mit diesen beiden Quellen. Für die Eier und die Copepodite habe ich daher ohne Bedenken die Werte von Eckstein [8] übernommen.

\subsection{Cyclops abyssorum und Cyclops vicinus}

Die auf eigenen Zuchten basierenden Resultate sind in Abb. $6 b$ und $c$ dargestellt.

\subsection{Mesocyclops leuckarti}

Es gelang mir nicht, eigene Resultate zu beschaffen. Für Eier und Nauplien habe ich die Ergebnisse von EinsLe [12] an Bodenseematerial übernommen. Daten für die Copepodite fehlen auch bei ihm. (Abb. 6 d.)

\subsection{Dauer der einzelnen Stadien}

Nach Auvray und Dussart [4] umfasst jedes der 5 Copepoditstadien von Cyclops vicinus einen Fünftel der gesamten Copepoditentwicklungszeit. Eigene Beobachtungen an über 40 Cyclops vicinus und Cyclops abyssorum bei verschiedenen Temperaturen ergaben für die einzelnen Copepoditstadien tatsächlich zwischen 16 und $23 \%$ der gesamten Entwicklungszeit. Da keine systematischen Abweichungen erkennbar waren, wurde die sehr zeitraubende Untersuchung nicht weitergeführt. Für Acantocyclops viridis fand FAHEEM KHAN [15] ebenfalls eine gleichmässige Verteilung der Entwicklungszeit auf die 5 Copepoditstadien.

\subsection{Unterschiedliche Entwicklungsdauer männlicher und weiblicher Tiere}

Bei Temperaturen unterhalb von $17^{\circ} \mathrm{C}$ ist die Entwicklungsdauer der weiblichen Copepodite rund $20 \%$ länger als diejenige der männlichen. Bei $21^{\circ} \mathrm{C}$ betrug die Verlängerung nur noch $10 \%$ (es wurden $280 \mathrm{Cyclops}$ abyssorum und $300 \mathrm{Cyclops}$ vicinus untersucht). Nach Auvray und Dussart [4] scheint der Unterschied erst im 5. Copepoditstadium aufzutreten.

\subsection{Einfluss von Temperaturschwankungen auf die Entwicklungszeit}

Tägliche Temperaturschwankung von 15 auf $32^{\circ} \mathrm{C}$ übt auf die Copepoditentwicklungsgeschwindigkeit von Acantocyclops viridis weder eine Beschleunigung noch eine Verzögerung aus, bei den Nauplien ist eine geringe Beschleunigung zu finden [15].

Bringt man Nachkommen von an $12^{\circ} \mathrm{C}$ adaptierten Cyclops vicimus in Wasser von $20^{\circ} \mathrm{C}$, beträgt die Entwicklungsdauer nur $65 \%$ des normalen Wertes bei $20^{\circ} \mathrm{C}$. Nach 2-3 Generationen ist dann wieder der Normalwert erreicht [4]. Eine solche Akzeleration kann auch im See deutlich beobachtet werden: wenn sich im Frühjahr das Wasser 

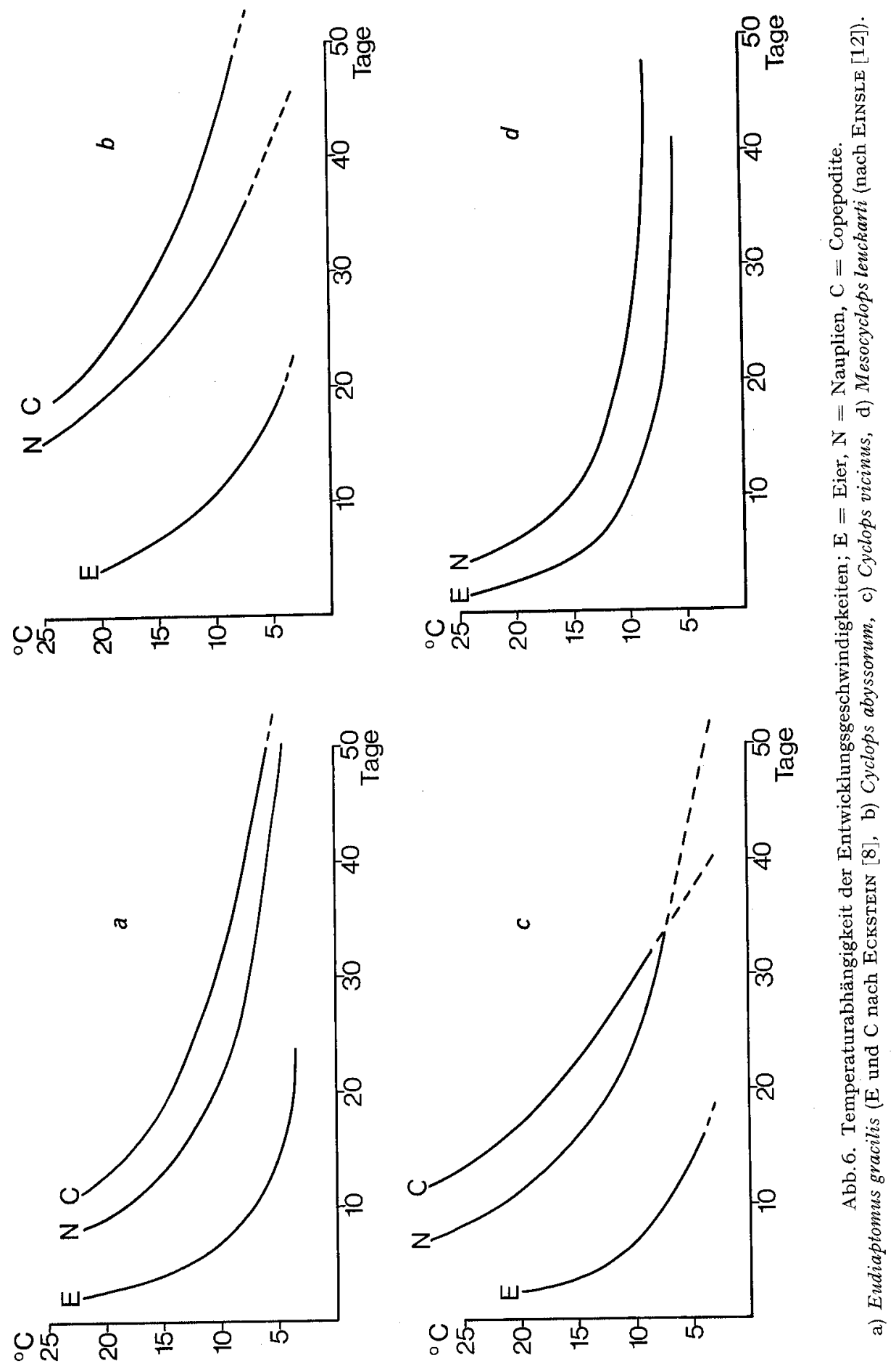
erwärmt, sind die im See gefundenen Entwicklungszeiten wesentlich kürzer als die auf Grund der Seetemperatur und der theoretisch ermittelten Entwicklungsgeschwindigkeit berechneten. Im Herbst finden wir umgekehrt eine starke Retardierung: die beobachteten Generationszeiten sind sehr viel länger als die berechneten.

Um eine bessere Übertragbarkeit der experimentell ermittelten Entwicklungsgeschwindigkeiten auf den See zu erreichen, müssen Versuchsreihen bei Temperaturen durchgeführt werden, die ähnlich wie im See langsam ansteigen, bzw. abfallen. Dabei sind besonders die Temperaturen unter $10^{\circ} \mathrm{C}$ zu berücksichtigen, da dort die grössten Effekte auftreten.

\subsection{Jahreszyklen}

\subsection{Eudiaptomus gracilis}

Greifensee (Abb. 7)

Eine Trennung der kurz aufeinanderfolgenden Generationen war nur mit Hilfe der Kurve der prozentualen Anteile der Männchen und der eiertragenden Weibchen möglich.

Im Oktober 1967 finden wir die Eiproduktion zu Beginn der Herbstgeneration 1967, die zu einem beträchtlichen Teil bis weit in den Winter hinein überlebt, ohne allerdings weitere Eier zu produzieren.

Aus den Nachkommen dieser Herbsteiproduktion (C1 Ende November, C4 und C 5 im Februar 1968) entsteht im März und April 1968 die erste, nur wenig fruchtbare Frühjahrsgeneration. Die Nachkommen dieser Tiere bilden im Mai eine zweite Frühjahrsgeneration, die erheblich mehr Eier liefert. Im Juni und in der ersten Julihälfte folgt die erste Sommergeneration, die ebenfalls grosse Eimengen hervorbringt. (Aus den Anteilen der Männchen und der eiertragenden Weibchen lassen sich für die Zeit vom 4.6. bis 16.7. Anzeichen für zwei Generationen herauslesen, was aber weder beim Erwachsenenbestand, noch bei der Eiproduktionskurve bestätigt werden kann. Die Frage, ob es sich in dieser Zeit um eine oder um zwei Generationen handelt, muss daher offengelassen werden.)

In allen Darstellungen eindeutig belegt ist der Beginn der zweiten Sommergeneration Mitte Juli. Ihr folgt ab Mitte August die dritte Sommergeneration, die die weitaus grösste Eiproduktion der ganzen Untersuchungsperiode liefert. Im Oktober und November bilden ihre Nachkommen eine Herbstgeneration, die im November produktiv ist und anschliessend ohne weitere Eiproduktion und mit geringer Individuenzahl den Winter überdauert, bis im März 1969 die erste Frühjahrsgeneration des folgenden Jahres beginnt, welche aus unterdessen erwachsenen Nachkommen der Novembereiproduktion entsteht.

Vierwaldstättersee (Abb.8)

Die Analyse der Generationsfolge ist sehr einfach:

Die Frühjahrsgeneration liefert im April eine grosse Eiproduktion, aus der im Juli die erste Sommergeneration entsteht. Deren Nachkommen bilden anfangs September die zweite Sommergeneration. Trotz einer nur mittelmässigen Eiproduktion entsteht daraus die sehr grosse Herbstgeneration vom November und Dezember.

Die rechnerisch aus Entwicklungsgeschwindigkeit und Seemitteltemperatur bestimmten Generationsdauern stimmen gut mit den tatsächlich beobachteten überein, 

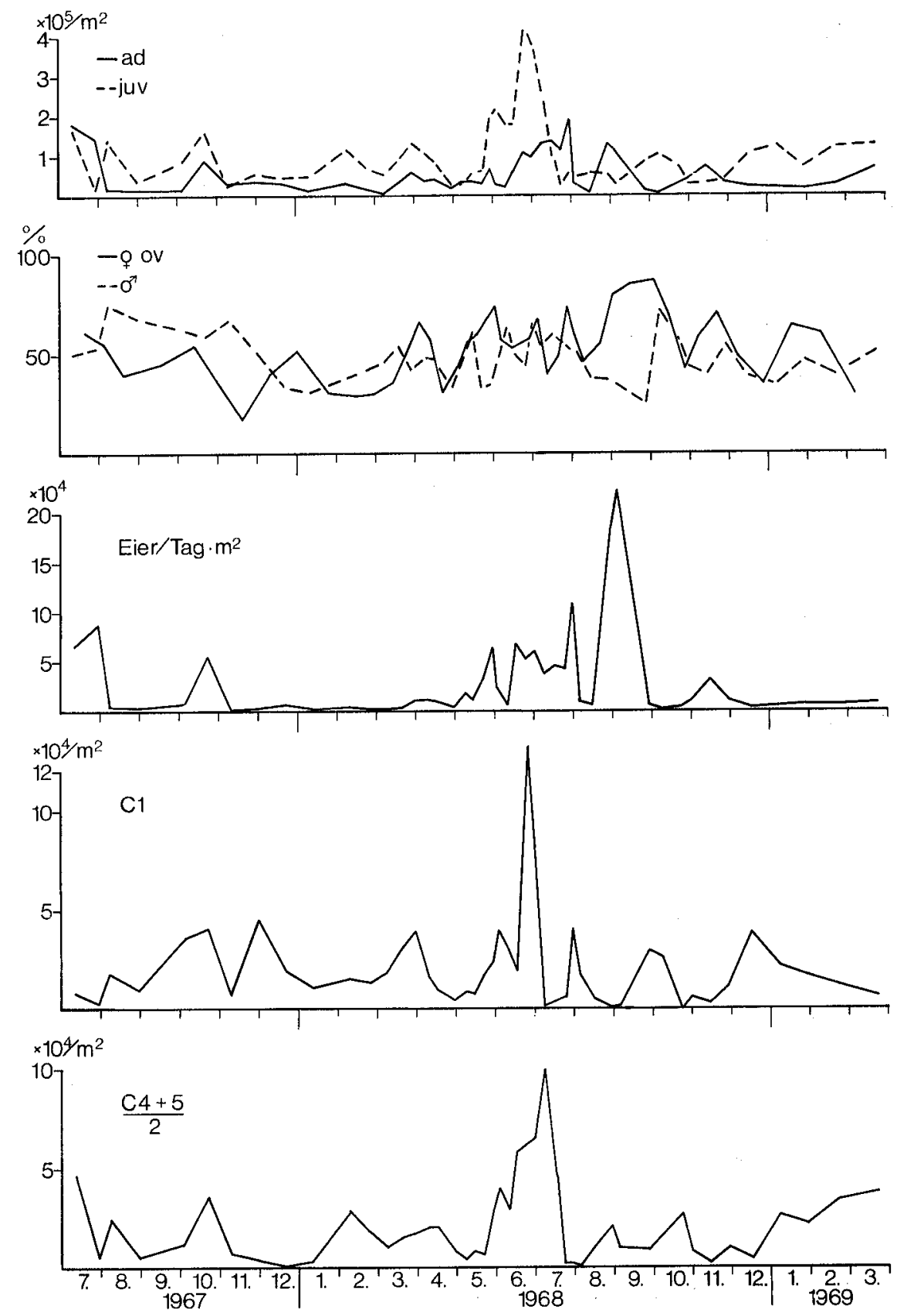

Abb.7. Eudiaptomus gracilis: Greifensee (Bestand, prozentualer Anteil der Männchen und eiertragenden Weibchen, Eiproduktion, Bestand $\mathrm{C} 1$, Bestand $\left.\frac{\mathrm{C} 4+\mathrm{C} 5}{2}\right)$. 

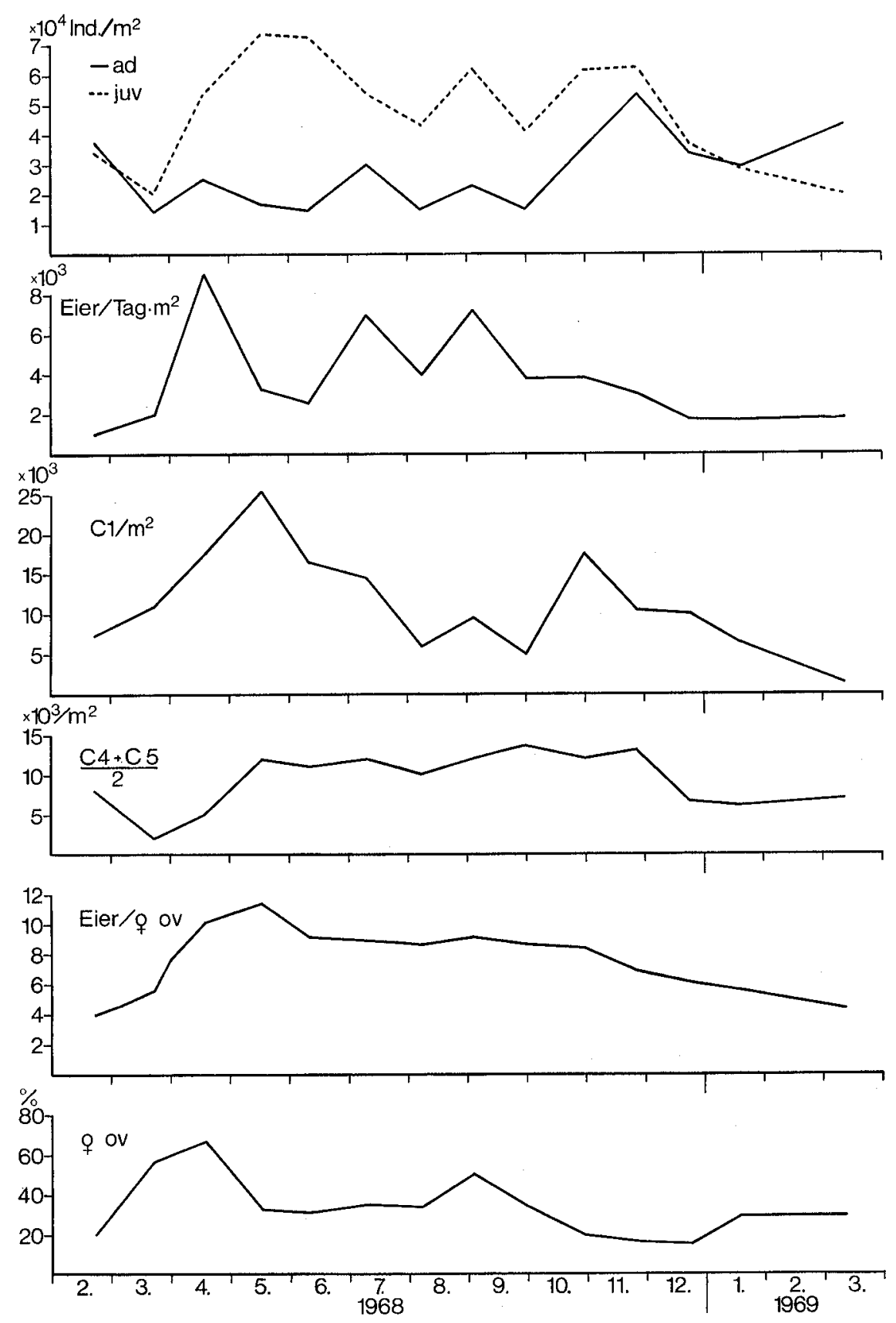

Abb.8. Eudiaptomus gracilis: Vierwaldstättersee (Bestand, Eiproduktion, Bestand C1, Bestand $\frac{\mathrm{C} 4+\mathrm{C} 5}{2}$, Eizahl pro $O$ ov., prozentualer Anteil eiertragender Weibchen). 
nur die Herbstgeneration"zeigt eine Verspätung von 14 Tagen, was mit der Retardierung wegen der abnehmenden Seetemperatur erklärt werden kann.

Zur Eiproduktion: Die Eizahl/o ov. steigt mit der Frühjahrsgeneration auf über 10 und sinkt dann sehr gleichmässig während des Jahres ab bis auf 4 Eier/P ov. am Ende der Untersuchungsperiode. Die Höhe der Eiproduktion wird vor allem durch den Anteil der eiertragenden Weibchen reguliert. In der Frühjahrsgeneration steigt er auf $70 \%$, was zusammen mit der hohen Eizahl/9 ov. die grösste Eiproduktion der Untersuchungsperiode verursacht. Auffällig ist das fast vollständige Fehlen der Eiproduktion der grossen Herbstgeneration. Dies ist vor allem auf den äusserst geringen Prozentsatz eiertragender Weibchen zurückzuführen, wobei die niedrige Eizahl/q ov. diesen Effekt noch verstärkt.

\subsection{Cyclops abyssorum}

Greifensee (Abb.9)

Die Auftrennung der Population in die aufeinanderfolgenden Generationen war auch hier nur dank der Analyse der erwachsenen Tiere ohne grosse Zweifel möglich.

Während des Winters finden wir sehr wenige Copepodite und keine Erwachsenen. Im März treten gleichzeitig mit der ersten Erwärmung des Seewassers zahlreiche Copepodite auf; da keine Eiproduktion vorausgeht, müssen wir annehmen, dass Cyclops abyssorum vor allem als Nauplius überwintert. Aus diesen Nauplien entstehen im Frühling Copepodite und wenig Erwachsene, die kaum Eier produzieren. Der grösste Teil der Copepodite wird erst im Mai erwachsen, wie die Bestandeskurve der Adulten deutlich zeigt.

Diese Erwachsenen liefern beträchtliche Mengen von Eiern, aus denen im Juli die nächste Generation und deren Eiproduktion folgt. Daraus entsteht die erste Herbsterwachsenengeneration, die Ende August beginnt und bis Mitte Oktober dauert. Dann wird sie von der zweiten Herbstgeneration abgelöst, die - im Gegensatz zum Vorjahr nicht ausstirbt, sondern während des ganzen Winters an Bestand zunimmt. Im Jahre 1967 fehlen die Herbst- und Wintergenerationen praktisch vollständig. Es ist allerdings ausserordentlich schwierig, in der im Winter rund 100 mal grösseren Zahl von Cyclops-vicinus-Copepoditen die paar wenigen, sehr ähnlich aussehenden Cyclopsabyssorum-Tiere zu finden: daher besteht die Möglichkeit, dass der Bestand von Cyclops abyssorum nicht vollständig erfasst wurde.

Vierwaldstättersee (Abb. 10)

Die Copepodite im April und Mai, die sich vor allem in der Darstellung der prozentualen Verteilung auf die einzelnen Stadien sehr deutlich als neue Generation zeigen, sind Tiere aus einer Eiproduktion vom Herbst 1967, die als Eier und Nauplien überwintert haben.

Aus ihnen entsteht die sehr langlebige Sommererwachsenengeneration vom Juni bis September, die im Juni und im August je einen Eischub liefert. Diese Zweigipfligkeit zeigt sich auch noch bei den $\mathrm{C} 2$, während bei den $\mathrm{C} 5$ und den Erwachsenen nur noch ein einziges Maximum vorhanden ist. Die Nivellierung ist bedingt durch die grossen individuellen Unterschiede in der Entwicklungsgeschwindigkeit: Bei Zuchten hat es sich gezeigt, dass die langsamsten Tiere für ihre Entwicklung doppelt soviel Zeit benötigen als die schnellsten. Die Herbstgeneration liefert nur am Anfang (im 

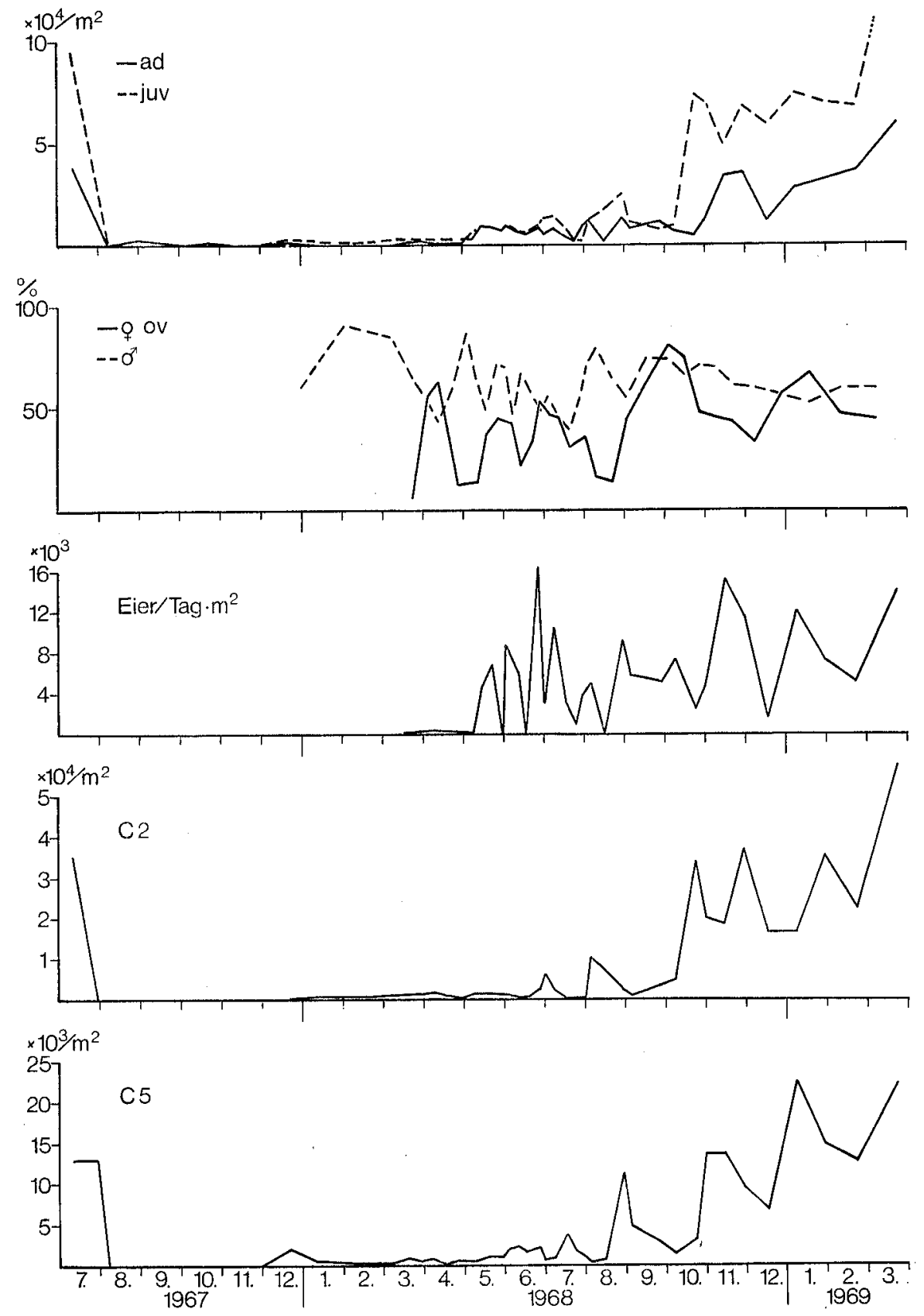

Abb.9. Cyclops abyssornm: Greifensee (Bestand Adulte und Copepodite, Prozentualer Anteil der Männchen und eiertragenden Weibchen, Eiproduktion, Bestand C2, Bestand C5). 

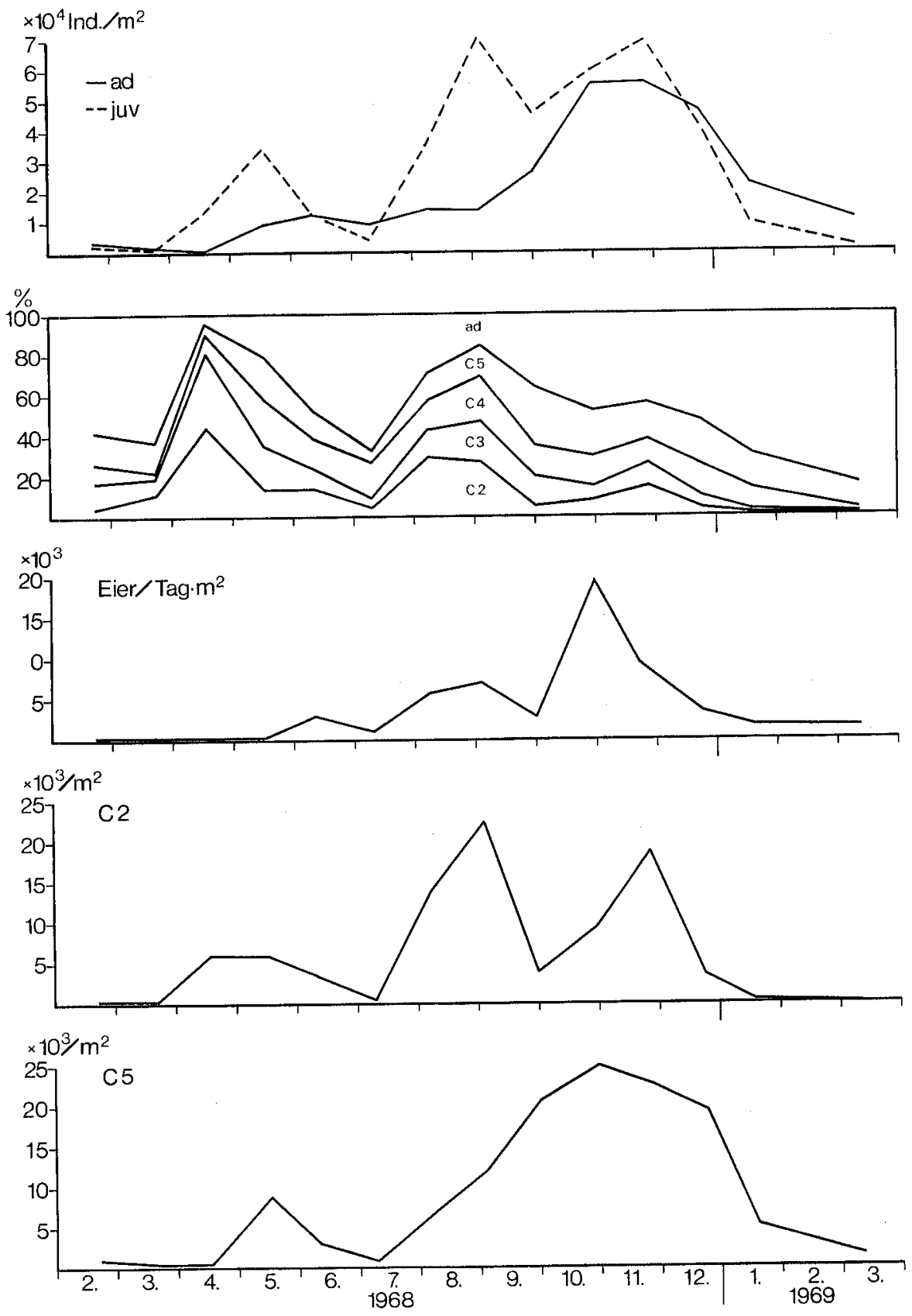

Abb.10. Cyclops abyssomm: Vierwaldstättersee (Bestand Adulte und Copepodite, Prozentualer Anteil der einzelnen Stadien, Eiproduktion, Bestand C2, Bestand C 5). 
November) eine wesentliche Eiproduktion. Die daraus entstehenden Nachkommen häuten sich erst im folgenden Frühjahr zu Copepoditen und bauen die Sommergeneration 1969 auf. Die Generationsdauern scheinen ausserordentlich lang zu sein. Da sich aber ein Grossteil der Cyclops-abyssorum-Population tagsüber tiefer als $25 \mathrm{~m}$ aufhält (s. Kap.3.8: Aufenthaltstiefe), steigt die Durchschnittstemperatur der von ihnen bewohnten Wasserschicht nicht über $9^{\circ} \mathrm{C}$ an, was theoretische Generationslängen von mindestens 3 Monaten ergibt, im Winter sogar mehr als 4 Monate.

Im Greifensee kann die Population wegen des sauerstofflosen Hypolimnions höchstens bis $7 \mathrm{~m}$ hinuntergehen, während sie im Vierwaldstättersee bis $50 \mathrm{~m}$ tief geht. Von Mitte Juni bis Ende September (während der Sommerstagnation) liegen die durchschnittlichen Aufenthaltstemperaturen daher immer zwischen 15 und $17^{\circ} \mathrm{C}$. Das erklärt die im Greifensee wesentlich kürzeren Generationszeiten.

\subsection{Cyclops vicinus}

Greifensee (Abb.11)

Während des Winters 1967/68 finden wir eine schwache Population aus Copepoditen und erwachsenen Tieren. Die im Frühjahr sehr plötzlich entstehende Erwachsenengeneration muss - da keine vorausgehende Copepoditentwicklung festzustellen ist - aus 4. Copepoditen stammen, die aus der Diapause erwachen. Diese Frühjahrserwachsenengeneration liefert zwei Eischübe: Ende März und Ende April. 30\% der Nachkommen dieser Eiproduktion finden wir im Juli als ruhende C 4 auf dem Seegrund. Aus dem ersten Eischub werden 7\% der Tiere erwachsen, ehe gegen Ende Mai der Stimulus wirksam wird, der die Tiere zur Diapause zwingt, beim zweiten, rund einen Monat späteren Eischub sind es sogar nur 1,25\%.

Diese beiden unbedeutenden Sommergenerationen liefern die Eier, aus denen die Herbstgenerationen von anfangs September und anfangs Oktober entstehen. Diese Tiere haben allerdings für die im See herrschenden Temperaturen eine ausserordentlich lange Entwicklungszeit, was dadurch erklärt werden könnte, dass diese Copepodite zwar nicht in Diapause fallen, in ihrer Entwicklung jedoch eine wesentliche Verzögerung erleiden.

Die Eiproduktion der Herbstgenerationen bleibt ohne Folgen, abgesehen von vereinzelten C 2 im Oktober, die sich mit den aus der Diapause erwachenden Tieren vermischen. Auch 1967 ergibt die gewaltige Eiproduktion der Herbstgeneration nur sehr wenige C 2: nur rund 2\% der produzierten Eier, gegenüber ungefähr $20 \%$ aus der Frühjahrseiproduktion 1968.

Im Dezember steigen aus der Diapause erwachte 4. Copepodite aus dem Schlamm ins freie Wasser auf, wo sie sich zu C5 und ab Ende Januar zu Erwachsenen entwickeln. Damit ist der Jahreszyklus geschlossen.

Praktisch verhält sich Cyclops vicinus im Greifensee monozyklisch. Die Einschaltung von zwei parallel laufenden Sommergenerationen ist unbedeutend, da deren Bestand nie mehr als $2 \%$ der im Schlamm ruhenden Copepodite ausmacht.

Vierwaldstättersee (Abb.12)

Hier ist die Generationsfolge sehr einfach zu übersehen, da sich die Art streng monozyklisch verhält: im April 1968 finden wir eine starke Eiproduktion, daraus ent- 

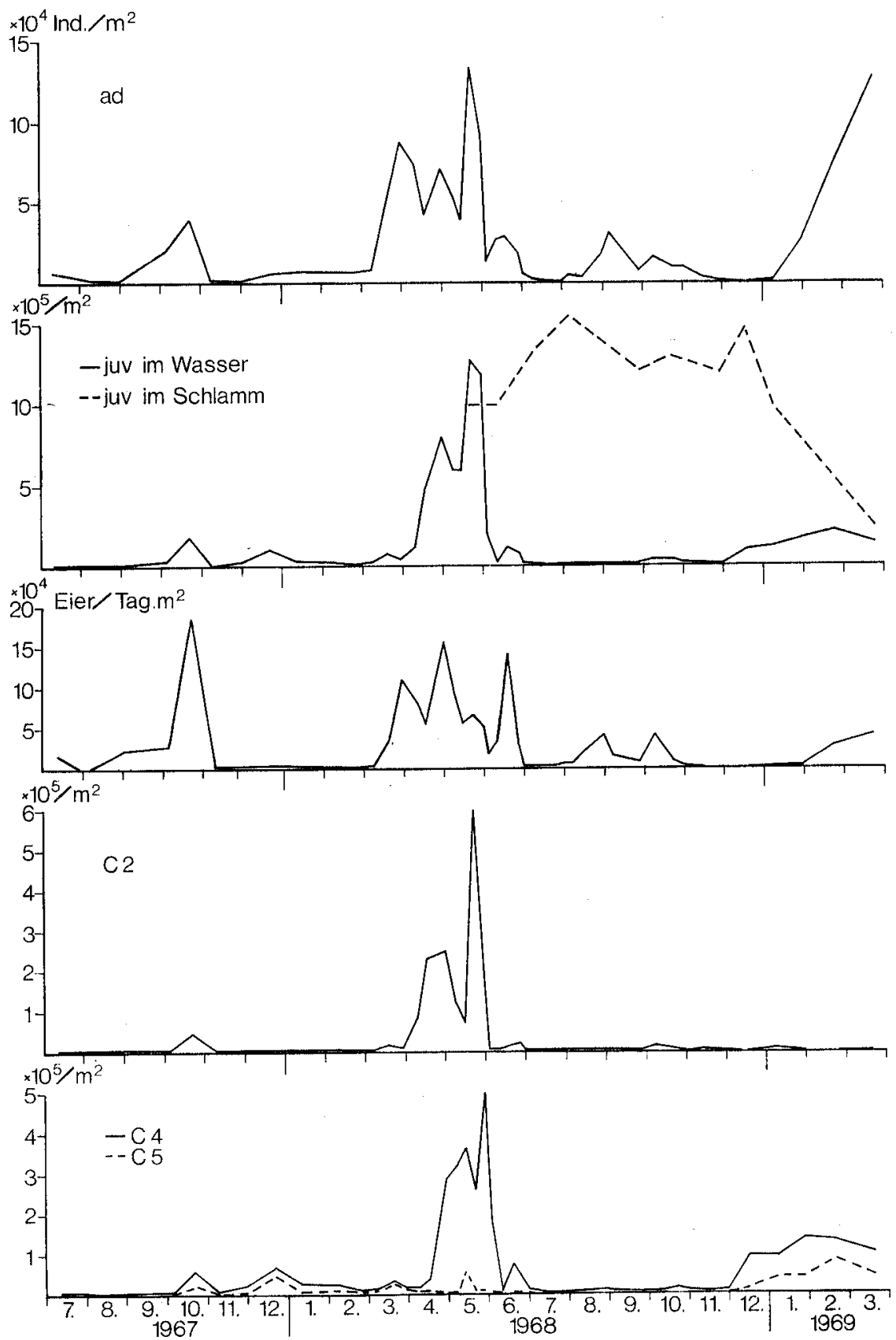

Abb.11. Cyclops vicinus: Greifensee (Bestand Adulte, Bestand Copepodite im Wasser und im Schlamm, Eiproduktion, Bestand C2, Bestand C4 und C 5). 
steht die Maipopulation der Copepodite, die im Juni aus dem freien Wasser verschwinden. Während des Sommers sind diese Copepodite als ruhende C4 in $214 \mathrm{~m}$ Tiefe im Schlamm wiederzufinden, während nur ganz vereinzelte Tiere im Wasser aktiv sind. Im November erscheinen wieder C4 im freien Wasser, im Dezember wird der Anteil der C5 immer grösser und Mitte Januar sind die ersten Erwachsenen zu sehen. Mit dem Beginn der Frühjahrseiproduktion ist der Jahreskreislauf geschlossen.

Ohne Diapause müssten die Tiere aus der Frühjahrseiproduktion $1968 \mathrm{im}$ Juli erwachsen werden. Da sie aber erst im Januar 1969 so weit sind, können wir sagen, dass die Diapause eine Entwicklungsverzögerung von rund 6 Monaten verursacht.
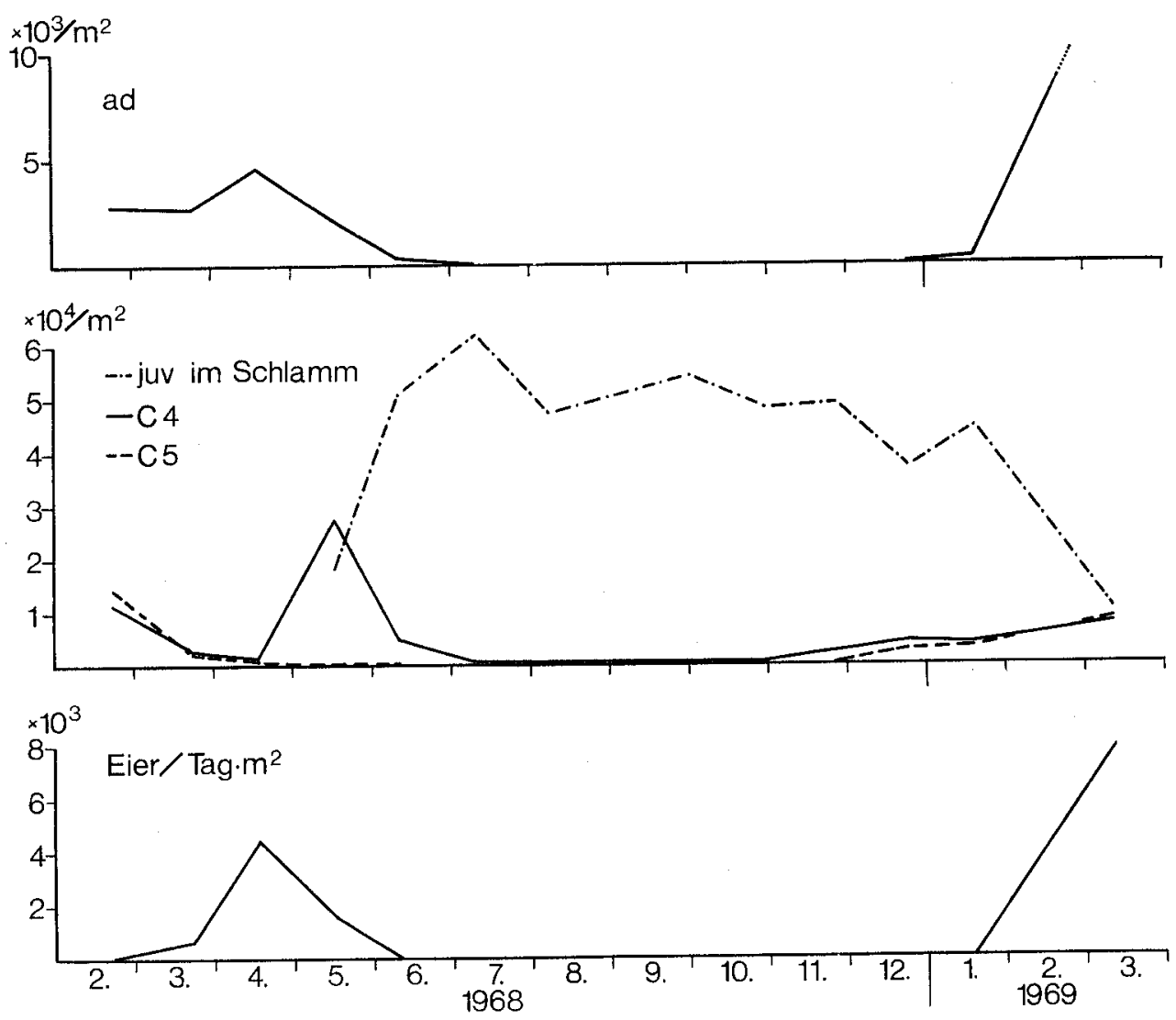

Abb.12. Cyclops vicinus: Vierwaldstättersee (Bestand Adulte, Bestand aktive und ruhende Copepodite, Eiproduktion).

\section{Zur Diapause}

Der Beginn der sommerlichen Diapause wird eindeutig durch die Tageslänge festgelegt. Experimentelle Untersuchungen $[10,43]$ ergaben als auslösenden Faktor eine Tageslänge von 15 Stunden oder mehr. Sowohl im flachen, eutrophen Greifensee als auch im sehr tiefen und oligo- bis mesotrophen Vierwaldstättersee mit ganz andern 
Temperatur- und Sauerstoffverhältnissen beginnt die Diapause von Cyclops vicinus Ende Mai, d.h. tatsächlich bei einer natürlichen Tageslänge von rund 15 Stunden.

Für die Beendigung der Diapause kommt als exogener Faktor die Zirkulation in Frage [48]. Die Diapause von Cyclops-vicinus-Copepoditen, die in $\mathrm{O}_{2}$-freiem Milieu liegen, kann experimentell durch Sauerstoffzufuhr beendet werden, nicht aber durch Temperaturerhöhungen $[54,55]$.

Im Stary-Dwor-See (ähnliche Zirkulations- und Stagnationsverhältnisse wie im Greifensee) beobachtete Szlauer [48] den Eintritt der Diapause im Juni, das Ende in einem ersten Schub während der Herbstzirkulation und in einem zweiten Schub während der Frühjahrszirkulation. Diese Befunde können am Greifensee bestätigt werden: die Zahl der wegen der herbstlichen Zirkulation aufsteigenden Cyclopsvicinus-Copepodite steigt proportional zum Anteil des Seebodens, der von der tiefergreifenden Zirkulation erreicht und mit Sauerstoff versorgt wird. Im Winter 1967/68 werden allerdings nur $8 \%$ dieser Copepodite erwachsen, der Rest geht grösstenteils zugrunde, so dass anfangs März nur wenige Erwachsene im Wasser zu finden sind. Gleichzeitig mit der ersten thermischen Schichtung nach der Frühjahrszirkulation im März tauchen nochmals ungefähr gleich viele Copepodite auf wie im Herbst. Dieser zweite Schub entwickelt sich sehr rasch und praktisch ohne Verlust zu erwachsenen Tieren, die die Frühjahrsgeneration bilden.

Im Winter 1968/69 sieht der Verlauf deutlich anders aus: zwar beginnt das Auftauchen der Copepodite ebenfalls mit dem Eintritt der Zirkulation, die Population erleidet aber keine winterliche Depression, sondern die Zahl der Erwachsenen steigt bis zum Abbruch der Untersuchungsreihe am 31. März 1969 kontinuierlich an. Eine Erklärung für diesen Unterschied konnte nicht gefunden werden, dazu wären jahrelange Beobachtungen nötig.

\subsection{Mesocyclops leuckarti}

Greifensee (Abb.13)

Aus einer gewaltigen Eiproduktion vom September 1967 entstehen noch im September die C1, im Oktober die C5. Anfangs November verschwinden die fast 100000 Tiere $/ \mathrm{m}^{2}$ schlagartig aus dem Wasser und während des ganzen Winters sind weder junge noch erwachsene Mesocyclops leuckarti im See zu finden. Der Bestand im Herbst 1967 wurde in der Abb.13 nicht eingezeichnet, da diese Kurve so hoch würde, dass daneben vom Geschehen im Jahre 1968 nichts mehr zu sehen wäre.

Ein Nachweis der überwinternden Mesocyclops-Copepodite ist schwierig, da sie sich z. T. aktiv in den extrem bodennahen Schichten aufhalten, ohne sich im Schlamm einzugraben und daher weder mit dem Schliessnetz noch mit dem Schlammstecher zu erfassen sind $[12,42]$.

Im April und Mai 1968 erscheinen zwei Schübe von 5. Copepoditen. Da vorher keine jüngeren Copepoditstadien zu finden sind, muss es sich um C5 handeln, die überwintert haben. (Die im April und Mai auftretenden wenigen $\mathrm{C} 1$ dürften aus Eiern und Nauplien entstanden sein, die den Winter trotz den niedrigen Temperaturen im Wasser überlebt haben). Aus diesen C5 baut sich von April bis Juni eine Erwachsenengeneration auf. Der erste Teil im April/Mai fällt durch das vollständige Fehlen von eiertragenden Weibchen und damit auch der Eiproduktion auf. (Auch Einste [12] fand im Bodensee-Obersee eine auffallend geringe Eiproduktion der 
$\times 10^{4} / \mathrm{m}^{2}$

10
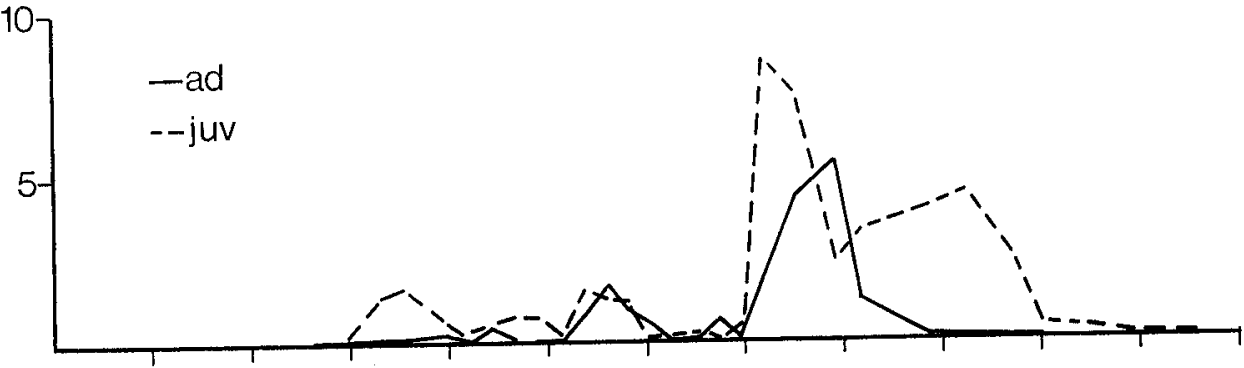

$\times 10^{3}$

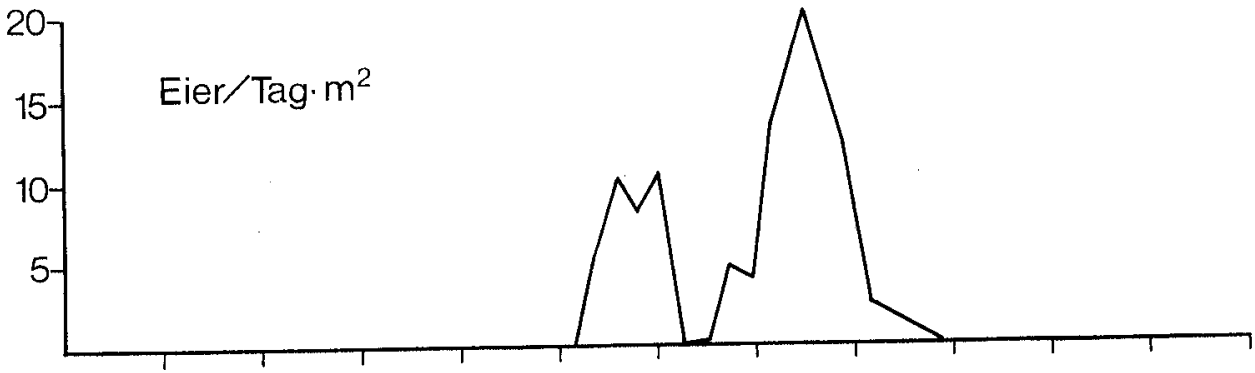

$\times 103 / \mathrm{m}^{2}$

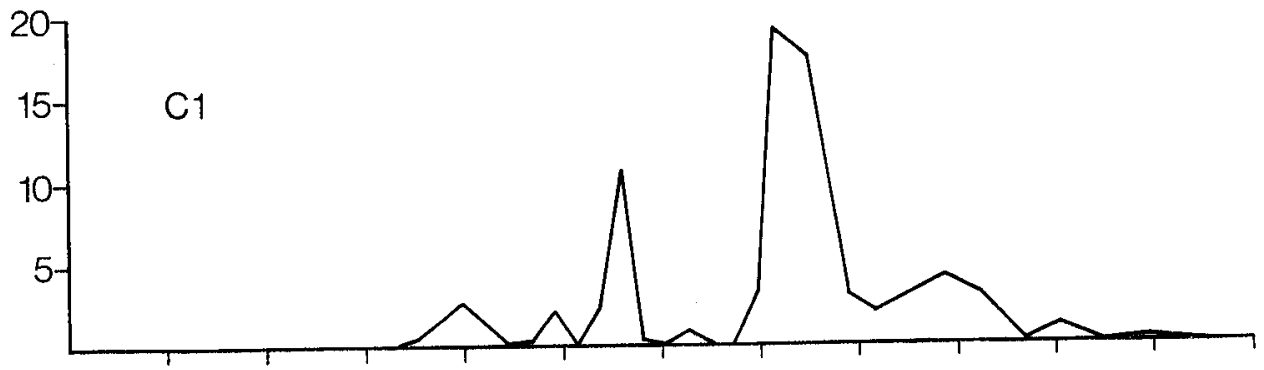

$\times 10^{3} / \mathrm{m}^{2}$

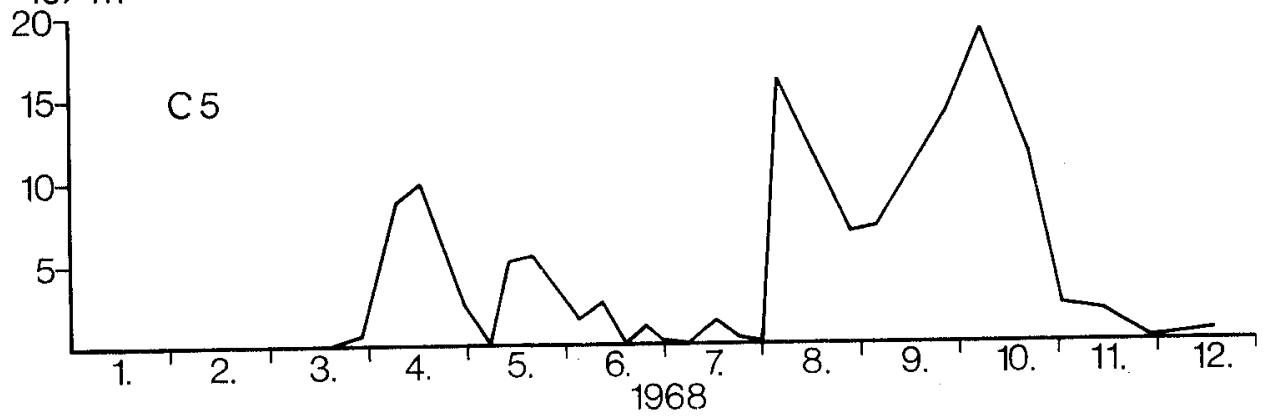

Abb.13. Mesocyclops leuckarti: Greifonsee (Bestand Adulte und Copepodite, Eiproduktion, Bestand ( 1, Bestand C5). 

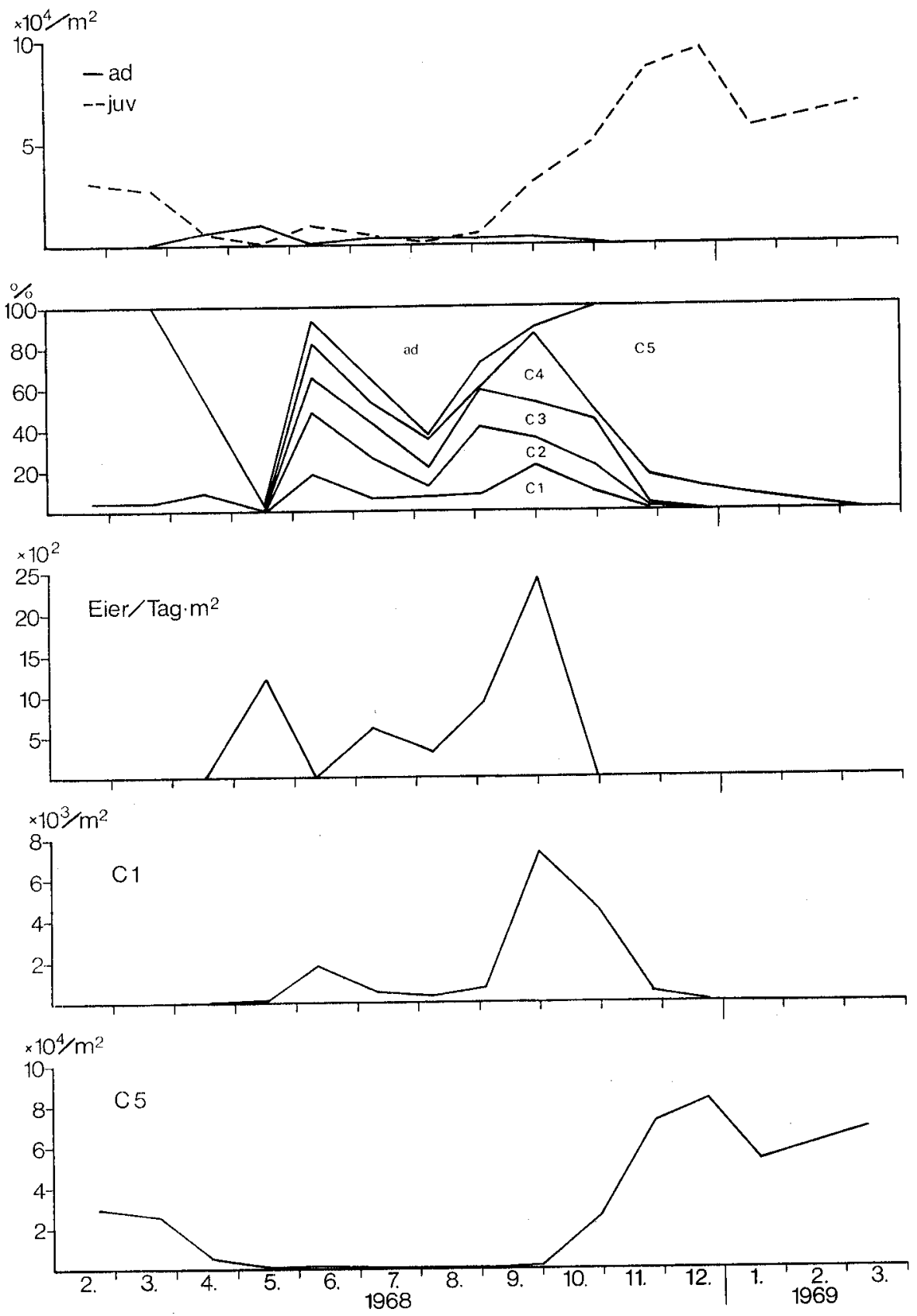

Abb.14. Mesocyclops leuckarti: Vierwaldstättersee (Bestand Adulte und Copepodite, Prozentualer Anteil der cinzelnen Stadien, Eiproduktion, Bestand C1, Bestand C 5). 
Frühjahrsgeneration 1963, die er dort mit der Seegfrörne des vorangegangenen Winters zu erklären versucht). Der zweite Teil im Juni liefert dann eine schwache Eiproduktion. Daraus entstehen rasch die C1 und im August schliesslich die Erwachsenen. Dabei kann es sich auf Grund der Generationslänge um eine einzige Generation handeln und nicht wie bei EINSLE [10] um zwei, die er nur dank der sich ändernden Körpergrösse für die Mindelseepopulation trennen konnte.

Diese Augustgeneration liefert die grösste Eiermenge des Jahres 1968, die C1 daraus entstehen wiederum sehr rasch, die C5 folgen im Oktober und verschwinden wie im Vorjahr abrupt; Erwachsene entstehen während der untersuchten Zeit keine daraus.

Vierwaldstättersee (Abb.14)

Vom Dezember bis März finden wir nur Copepodite im Wasser (96\% C5, 4\% C4). Sehr wahrscheinlich handelt es sich bei diesem Entwicklungsstillstand nicht um eine echte Diapause, sondern um eine Kältehemmung. EINSLE [12] beobachtete, dass sich Mesocyclops-Copepodite bei weniger als $12^{\circ} \mathrm{C}$ nicht mehr weiterentwickeln können, für die Nauplien liegt diese Grenze bei $8^{\circ} \mathrm{C}$, für die Eier bei $6^{\circ} \mathrm{C}$.

Die ersten Erwachsenen treten im April schon auf, sobald die Wassertemperatur an der Oberfläche auf über $10^{\circ} \mathrm{C}$ ansteigt. Hier führt die Akzeleration der Entwicklungsgeschwindigkeit bei steigender Temperatur dazu, dass die Entwicklung schon bei weniger als $12^{\circ} \mathrm{C}$ weitergehen kann, wenn die Tiere an noch tiefere Temperaturen adaptiert waren.

Mitte Mai besteht die gesamte Population aus Erwachsenen. Die Nachkommen dieser Frühjahrserwachsenengeneration bilden den verhältnismässig geringen Copepoditbestand des Sommers und die sehr langlebige Sommererwachsenengeneration vom Juli bis September. Die Nachkommen der Herbstgeneration bauen bis zum Dezember einen gewaltigen Copepoditbestand auf, der wie im vorhergehenden Winter zu mindestens 90\% aus C5 und dem Rest aus C4 besteht. Bis zum Ende der Freilanduntersuchungen am 11.3.69 treten keine erwachsenen Tiere auf.

\section{Zur Diapause}

Leider lässt sich die Zahl der überwinternden Copepodite von Mesocyclops leuckarti aus den obenerwähnten Gründen nicht mit genügender Genauigkeit ermitteln. Dazu kommt, dass SzLauer [48] ruhende Mesocyclops-Copepodite nur in Ufernähe bei weniger als $8 \mathrm{~m}$ Tiefe beobachtete; EINSLE [11] weist darauf hin, dass Mesocyclops leuckarti in kleinen Seen nicht rein pelagisch, sondern z.T. im Litoral lebt. SMyLy [42] beobachtete den Eintritt der "resting stages» beim Beginn der Vollzirkulation und bei $10^{\circ} \mathrm{C}$ Wassertemperatur, SzLAUER [48] 3 Wochen vor der Herbstzirkulation bei mehr als $8,9^{\circ} \mathrm{C}$. In beiden Fällen handelte es sich um echte «resting stages» mit Körperstarre und Unempfindlichkeit für äussere Reize.

Im Greifensee beginnt die winterliche Entwicklungsstagnation mit genauer Übereinstimmung in den Jahren 1967 und 1968 jeweils am 20. Oktober bei $14^{\circ} \mathrm{C}$ Wassertemperatur. Die Zirkulation erreicht zu diesem Zeitpunkt $8 \mathrm{~m}$ Tiefe und versorgt ungefähr 17\% des ufernahen Seebodens mit Sauerstoff, die tiefere Seemitte ist noch sauerstofflos. Da Mesocyclops leuckarti nicht in sauerstofflosem Wasser leben kann $[48]$, werden die Tiere sich im Greifensee nur in den ufernahen Zonen im Schlamm 
eingraben. Die Probestelle jedoch liegt in der Seemitte: dies ist ein weiterer Grund für die geringe Anzahl Copepodite, die während der Diapause gefunden wurden. Das Wiedererwachen im Frühjahr kann nach SMYLY |42] durch den ersten Temperatur-
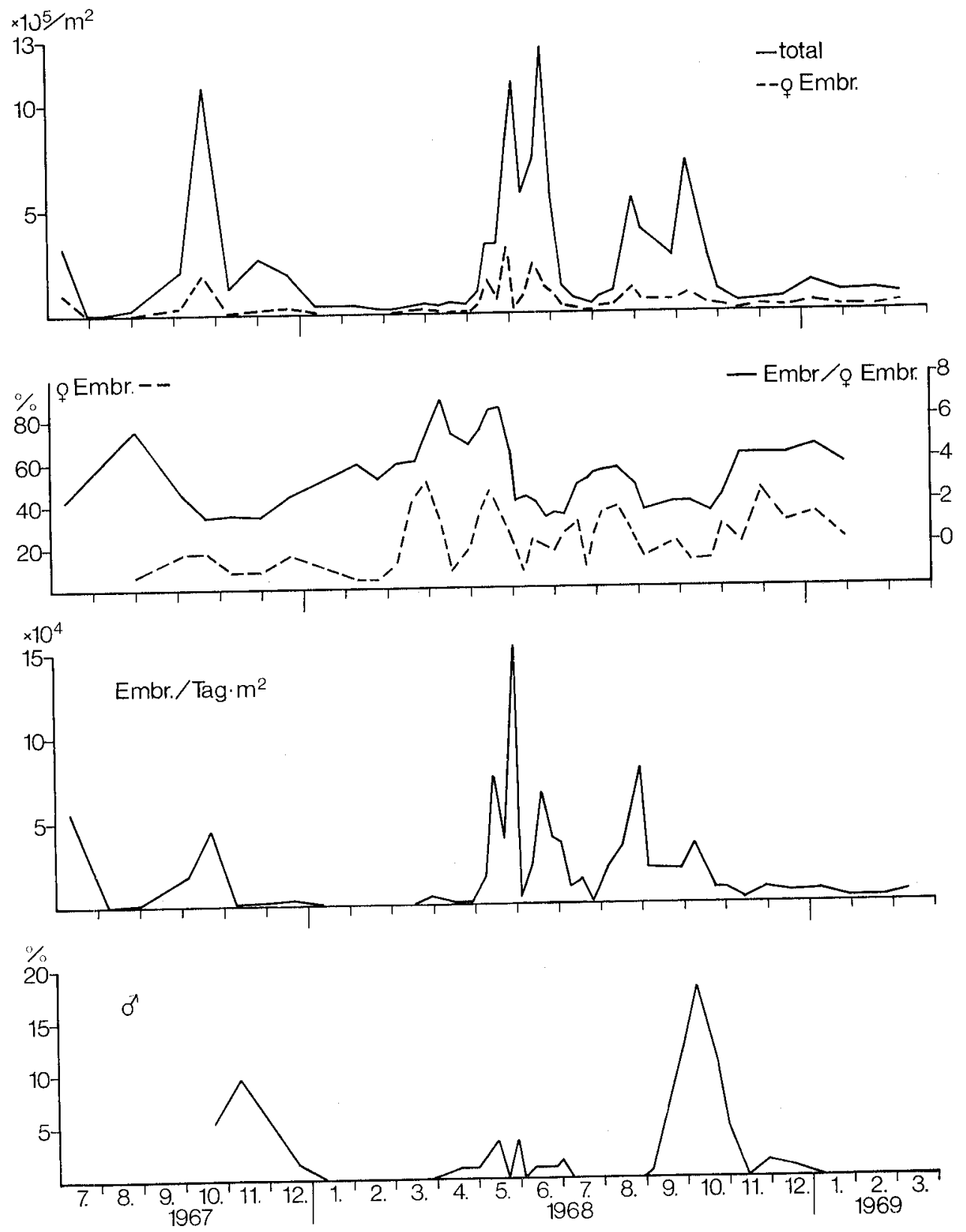

Abb. 15. Daphnia sp.: Greifensee (Bestand, Prozentualer Anteil der Weibchen mit Embryonen und Embryonenzahl pro Weibchen, Embryonenproduktion, Prozentualer Anteil der Männchen). 
anstieg und die beginnende thermische Schichtung des Wassers verursacht werden oder aber durch Sauerstoffmangel.

Im Greifensee findet das Ende der Winterruhe deutlich in zwei Schüben statt. Der erste anfangs April fällt mit dem Ansteigen der Temperatur der bodennahen Wasserschichten zusammen, der zweite anfangs Mai mit dem Beginn der Sauerstofflosigkeit. Im Greifensee scheinen also beide in der Literatur erwähnten Faktoren nebeneinander zu wirken.

\subsection{Daphnien sp.}

Bei den Daphnien lässt sich im Gegensatz zu den Copepoden keine eindeutige Populationsanalyse durchführen, da sie sich parthenogenetisch vermehren und eine Population daher nicht in deutlich getrennte Generationen autgeteilt werden kann.

Greifensee (Abb. 15)

Die Daphnienpopulation zeigt zwei scharf getrennte Perioden mit starker Bevölkerungsentwicklung, die erste im Juni, die zweite im September/Oktober. Berïcksichtigen wir die Begrenzung des Lebensraumes nach unten durch das sauerstofflose Hypolimnion, crgeben sich in beiden Perioden Bevölkerungsdichten von ungefähr 60 Tieren/l.

Auffallend sind die Schwankungen der Embryonenzahl pro embryotragendem Weibchen: vor Beginn der grossen Populationsdichte liegt sie hoch (3-6 Embryonen/ Weibchen), sinkt während des Höhepunktes rasch ab und steigt erst nach Zusammenbruch der Population wieder an. Hier scheint ein Regulationsmechanismus vorzuliegen, der eine noch stärkere Bevölkerungsexplosion verhindert. Er wird zudem dadurch verstärkt, dass bei steigender Populationsdichte immer weniger Weibchen Embryonen tragen. Die Abbildung "Prozentualer Anteil der Weibchen mit Embryonen und Embryonenzahl pro Weibchen» zeigt die ausserordentlich strenge Parallelität der beiden Kurven. (Die Basislinie für die Embryonenzahl pro Weibchen musste erhöht werden, um ein ständiges Überschneiden der beiden Kurven zu vermeiden).

Die Sommerpopulation weist nur wenige Männchen auf, während gegen Ende der Herbstpopulation der Anteil der Männchen an der Gesamtzahl auf 9\% (November 1967) bzw. 18\% (Olktober 1968) steigt.

Die Entwicklungsgeschwindigkeiten, die für die Berechnung der Embryonenproduktion/Tag $\cdot \mathrm{m}^{2}$ benötigt wurden, sind von ELSTER |14] übernommen worden.

Vierwaldstättersec (Abb.16)

In Winter finden wir nur ganz vereinzelte Daphnien. Ab Mitte Mai bringt ein sehr starkes Wachstum die Population auf den höchsten Stand am 10.6.68. Trotz gleichbleibender Zahl von Weibchen mit Embryonen und trotz weiteren Anstiegen der Embryonenproduktion sinkt der Bestand anschliessend auf ungefähr die Hälfte $\mathrm{ab}$. Ab anfangs August nimmt die Produktionsleistung beträchtlich ab, sie wird vor ihrem Aufhören Ende November nur am 29. Oktober nochmals leicht erhöht. Dieses Anstcigen ist ausschliesslich auf die starke Zunahme der Embryonenzahl pro Weibchen zurückzuführen.

Der grosse Verlust im Juni, der trotz einer Steigerung der Embryonenproduktion/ Tag $\cdot \mathrm{m}^{2}$ entsteht, muss durch Zehrung verursacht sein. 
Mit einer Ausnahme beträgt die Zahl der Embryonen pro embryotragendes Weibchen bei allen Proben zwischen 2 und 3, nur am 29.10.68 sind es 5. Der Prozentsatz der embryotragenden Weibchen schwankt zwischen 40 und 60\%, nur am Anfang und am Ende der Population sinkt er tiefer.
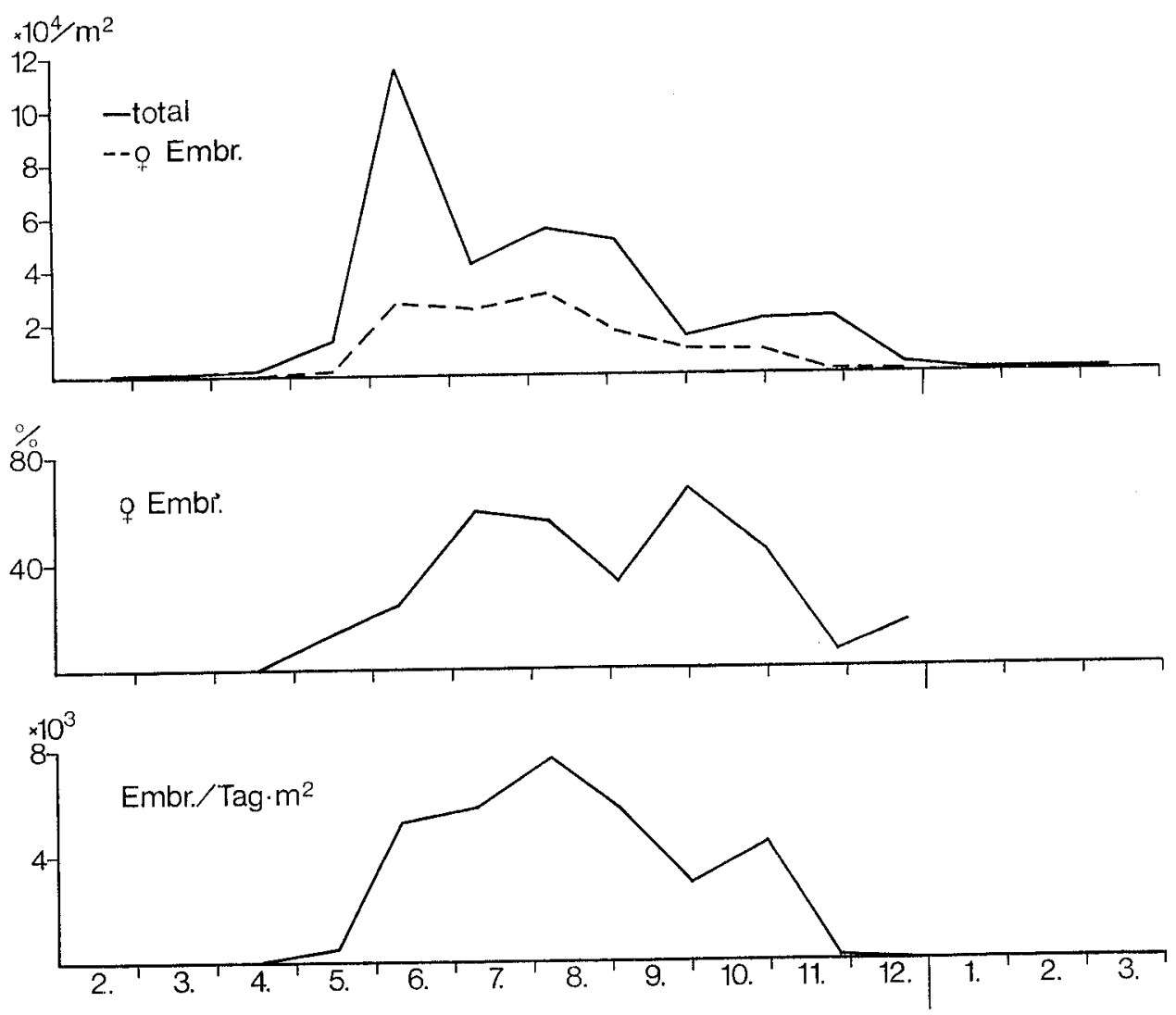

Abb. 16. Daphnia sp.: Vierwaldstättersec (Bestand, Prozentualer Anteil embryotragender Weibchen, Embryonenprocluktion).

Die Regulierung der Vermehrungsleistung der Vierwaldstätterseepopulation erfolgt durch die Veränderung des Prozentsatzes von Weibchen mit Embryonen. Diese Kurve verläuft sehr schön gegenläufig zur Bestandeskurve, d.h. bei hohem Bestand ist die Vermehrungsleistung pro Individuum gering. Männchen wurden keine gefunden; da nur aus befruchteten Eiern Dauereier entstehen, bedeutet das, dass die Vierwaldstätterseepopulation der Daphnien den Winter ohne solche überstehen muss.

\subsection{Bosmina sp.}

Wie bei den Daphnien ist eine Populationsanalyse wegen der parthenogenetischen Fortpflanzung nicht möglich. 
Greifensee (Abb.17)

Im Mai und Juni besteht eine gewaltige Bosmina-Population (1967 wurde nur noch deren Ende erfasst). 1967 ist im Oktober noch eine kleinere Population zu finden, während sich im nächsten Jahr keine Herbstgeneration entwickelt.

Vierwaldstättersee (Abb.18)

Von einer kleinen Wintergeneration ausgehend, vermehrt sich die Population im April und Mai sehr stark. Der Anteil der Weibchen mit Embryonen beträgt 40-50\% und sinkt im Juni auf 0 zurück. Gleichzeitig beginnt die Zahl der Individuen $/ \mathrm{m}^{2} \mathrm{ab}$ zunehmen und anfangs November ist nur noch die geringe Menge der überwinternden Tiere vorhanden.

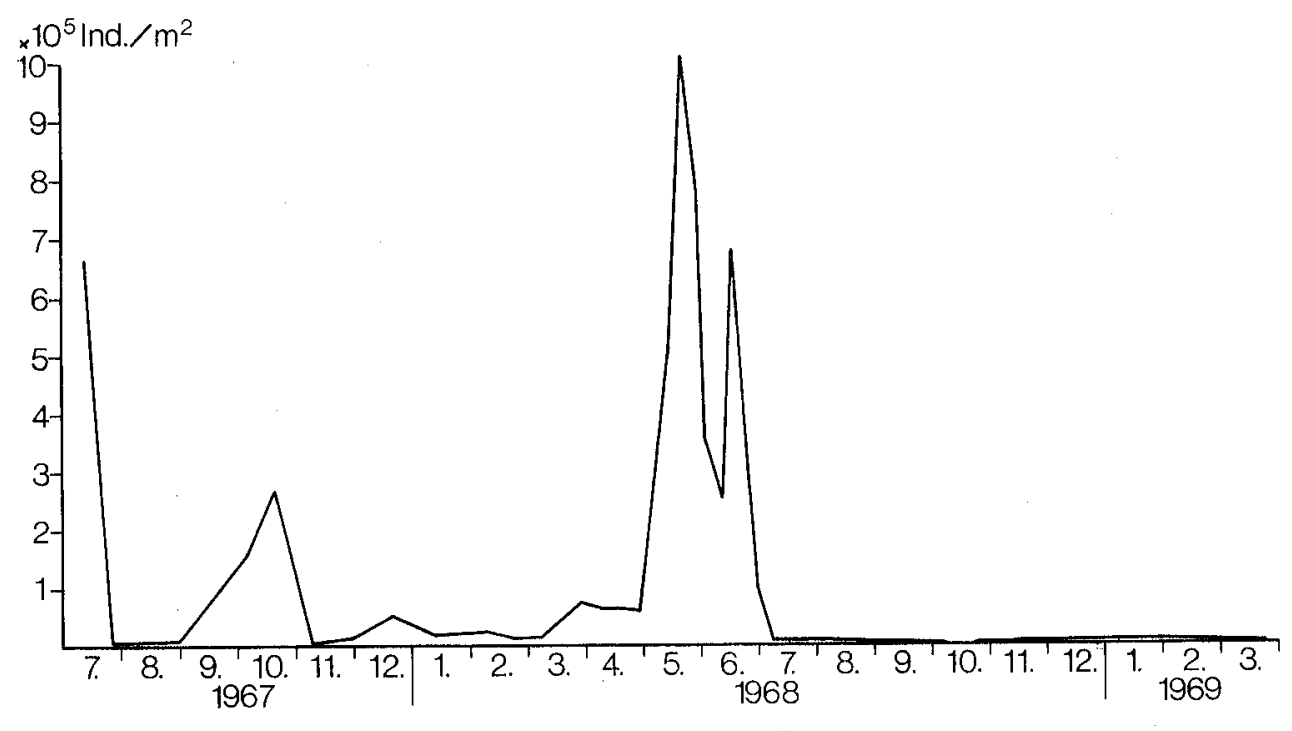

Abb. 17. Bosminasp.: Groifensee.

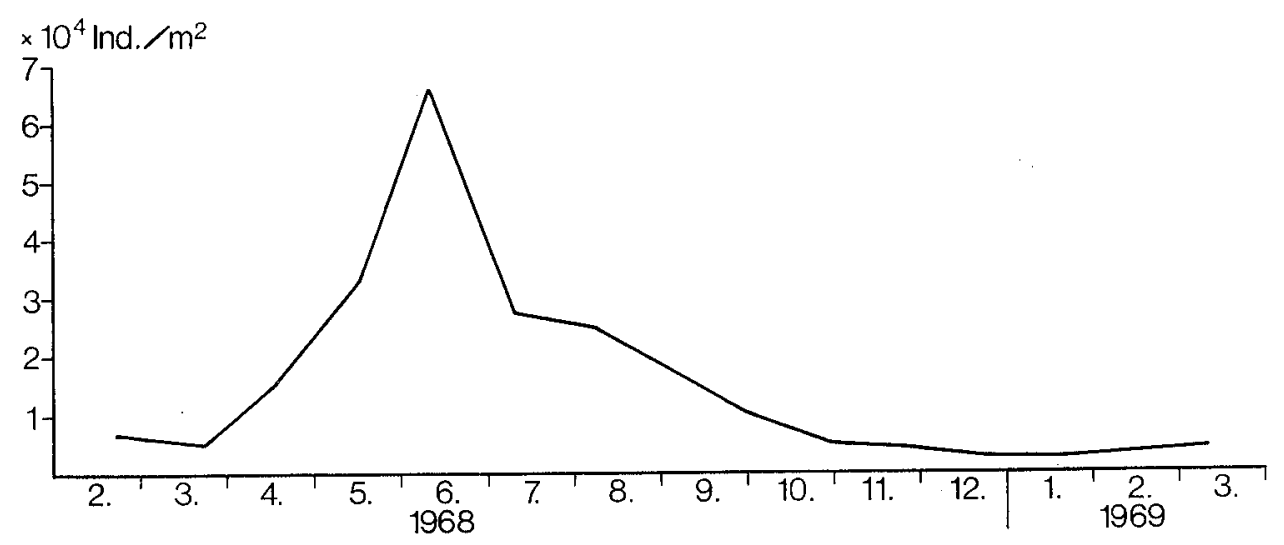

Abb. 18. Bosmina sp.: Vierwaldstättersee. 


\subsection{Diaphanosoma brachyurum (Abb.19)}

Das Vorkommen dieser Art ist streng auf die Sommermonate beschränkt. 1967 erreicht die Population ihren Höhepunkt Ende August, Mitte Oktober ist sie wieder verschwunden. 1968 kommt sie praktisch nur im August vor und erreicht nur ungefähr einen Drittel der Individuenzahl des Vorjahres.

Im Vierwaldstättersee wurden keine Diaphanosoma gefunden.

$\times 10^{4} \mathrm{Ind} . / \mathrm{m}^{2}$

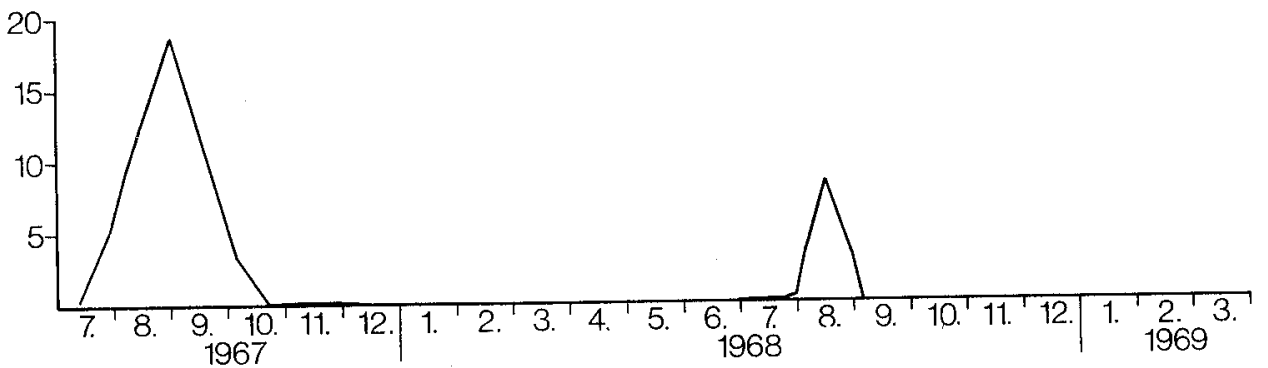

Abb. 19. Diaphanosoma brachyurum: Greifensee.

\subsection{Leptodora kindtii und Bythotrephes longimanus}

Diese beiden Arten sind grosse, räuberisch lebende Cladoceren. Trotz ihrer Körpergrösse spielen sie für die Zooplanktonpopulation keine wesentliche Rolle, da sie nur in geringer Anzahl vorkommen.

3.781 Leptodora kindtii (Abb. 20). Die Bestandeskurve für Leptodora kindtii verläuft im Greifensee sehr ähnlich, wie diejenige für Bythotrephes longimanus im Vierwaldstättersee: ein sehr rascher Anstieg führt zum Bestandesmaximum von 8000 Ind. $/ \mathrm{m}^{2}$ anfangs Juli, dem ein ebenso rascher Abstieg folgt. Ein bescheidener Rest kann sich noch einige Zeit halten, bis die Art Mitte November endgültig verschwindet.

1968 tritt im September ein Zwischenmaximum auf, das allerdings nur durch eine einzige Probe belegt ist, die Entsprechung 1967 fehlt. Da keine Daten über die Entwicklungsgeschwindigkeit vorliegen, kann nicht entschieden werden, ob es sich um eine oder um zwei aufeinanderfolgende Generationen handelt.

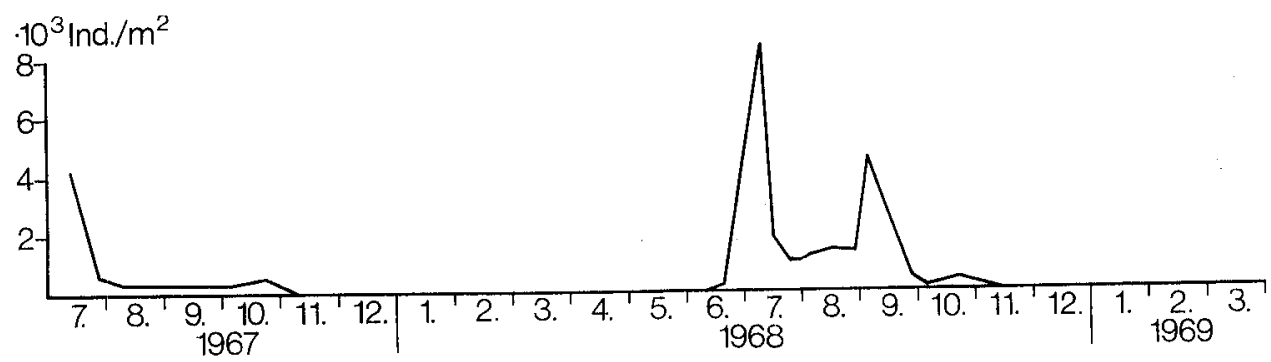

Abb. 20. Leptodora kindtii: Greifensee. 
3.782 Bythotrephes longimanus (Abb.21). Im Vierwaldstättersee finden wir diese Art in den warmen Sommermonaten und bis in den Herbst hinein, im Greifensec fehlt sie vollständig.

Den höchsten Bestand erreicht die Population im Juli mit bescheidenen 4500 Tieren $/ \mathrm{m}^{2}$. Nach einer raschen Abnahme im August hält sie sich mit weniger als 1000 Tieren $/ \mathrm{m}^{2}$ bis Ende des Jahres. Vor dem endgültigen Verschwinden der Art treten im Dezember plötzlich Dauercier auf, aus denen im nächsten Jahr die neue Population entsteht.

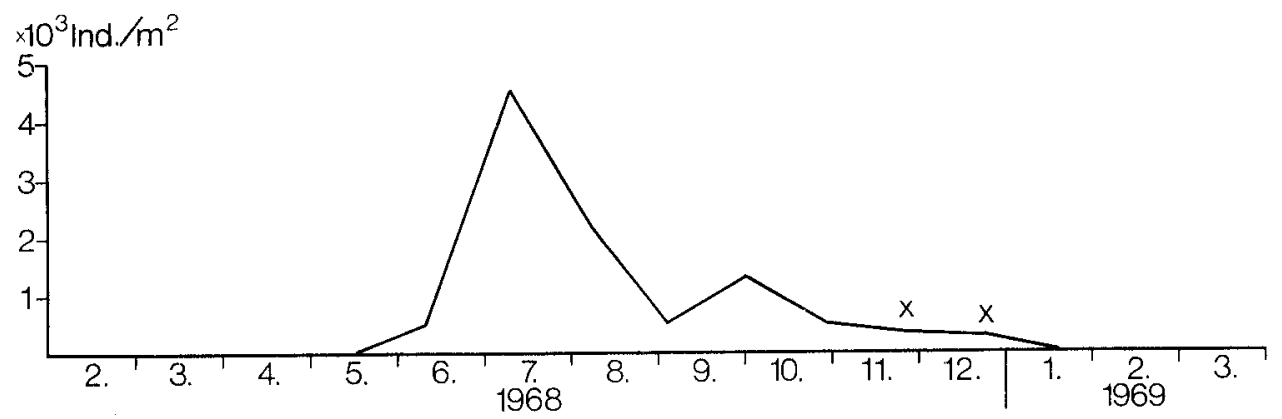

Abb.21. Bythotrephes longimanus: Vierwaldstättersee $(\mathrm{x}=$ Auftreten von Dauereiern).

\subsection{Aufenthaltstiefe des Zooplanktons}

In der Zielsetzung dieser Arbeit war eine Aussage über die Tiefenverteilung des Zooplanktons nicht als wesentlicher Punkt enthalten. Dank der z.T. eng zonierten Stufenfänge konnte ich dennoch einige Beobachtungen machen, von denen die bedeutendsten hier zusammengestellt sind.

\section{Greifensee}

Beide Jahre der Untersuchungsperiode ergaben dasselbe Verhalten: Mit Eintritt der herbstlichen Vollzirkulation verteilen sich die Tiere aller gezählten Kategorien gleichmässig über die gesamte Seetiefe.

Während der inversen Temperaturschichtung (im Februar 1969) werden die obersten Schichten leicht gemieden, während Cyclops abyssorum sie als einzige Kategorie vorzieht.

Ab Mitte März, mit den Einsetzen der Erwärmung der obersten Wasserschichten, beginnt deren Bevorzugung. Nauplien und Cyclops vicinus machen damit den Anfang. Im April wird diese Tendenz immer stärker; dennoch sind auch die untersten Schichten besiedelt.

Im Mai und Juni finden wir ein eigenartiges Phänomen: neben demjenigen an der Oberfläche besteht ein zweites Volksdichtemaximum in 10-20 m Tiefe, das sicher dadurch zustande kommt, dass die Tiere die untersten Schichten wegen der dort beginnenden Sauerstofflosigkeit nicht mehr aufsuchen können und an der $\mathrm{O}_{2}$-Grenze gestaut werden. Nur Cyclops vicinus, Bosmina sp. und Nauplien leben noch im sauerstoffreien Tiefenwasser. 
Im Juli sind nur noch die obersten $10 \mathrm{~m}$ besiedelt, einzig Bosmina sp. ist tiefer anzutreffen. Dabei zeigt sich die eindeutige Tendenz, dass Eudiaptomus gracilis und Mesocyclops leuckarti die oberen $5 \mathrm{~m}$, Cyclops abyssorum, Daphnia sp. und die Nauplien die Schicht 5-10 $\mathrm{m}$ bevorzugen.

Dieses Bild bleibt unverändert, bis im November die Herbstzirkulation beginnt. Von diesem Zeitpunkt an ist das ganze Epilimnion wieder gleichmässig besiedelt.

\section{Vierwaldstättersee}

Da weder sehr engzonierte Stufenfänge, noch über den Tag verteilte Fänge gemacht wurden (alle Fänge zwischen 12 und $15 \mathrm{Uhr}$ ), kann über die Vertikalwanderung der verschiedenen Arten im Vierwaldstättersee keine eindeutige Aussage gemacht werden.

Normalerweise reicht die Aufenthaltstiefe aller Arten bis gegen $50 \mathrm{~m}$ hinunter. Vom 9.7.-3.9.68 sind die obersten $10 \mathrm{~m}$ stark mit Phytoplankton durchsetzt. Ausser einigen Mesocyclops leuckarti werden in dieser Schicht keine Copepoden gefunden. Ob es sich dabei um ein Nichterfassen infolge Netzverstopfung handelt, oder ob die Tiere die phytoplanktonreiche Schicht tatsächlich meiden, kann nicht entschieden werden.

Interessant ist noch die Verteilung am 23.12.68: Alle Arten sind von $0-50 \mathrm{~m} \mathrm{zu}$ finden, Cyclops vicinus bevorzugt jedoch die höheren, Mesocyclops leuckarti (nur als C5 zu finden!) die tieferen Schichten dieses Bereiches. Auch bei der letzten Probe (11.3.69) ist ähnliches zu sehen: Cyclops vicinus von 0-25 m, Mesocyclops leuckarti von 10 bis unterhalb $50 \mathrm{~m}$.

Im April und Mai besteht die Tendenz, nur die obersten Schichten bis $25 \mathrm{~m} z \mathrm{u}$ besiedeln, was sicher mit den dort herrschenden höhreren Wassertemperaturen zusammenhängt. In sämtlichen Proben sind die Nauplien die einzige Zählkategorie, die unterhalb vo: $50 \mathrm{~m}$ in grösserer Menge angetroffen wird. Es dürfte sich dabei um absinkende, nicht mehr vitale Individuen handeln. Die Phyllopoden und Rotatorien verteilen sich mehr oder weniger unregelmässig zwischen 0 und $50 \mathrm{~m}$. Die Daphnien sind auch in der algenreichen Oberflächenschicht des Sommers zu finden, Bosmina sp. jedoch verschwindet zu jener Zeit praktisch vollständig aus dem Wasser.

\section{Produktion}

Die Produktion im Sinne dieser Arbeit umfasst die vom Zooplankton synthetisierte organische Substanz. Sie errechnet sich aus der Anzahl der produzierten Erwachsenen, multipliziert mit der zugehörigen Biomasse pro adultem Tier und aus der Biomasse der von diesen Erwachsenen produzierten Eier. Hinzu kommt die Biomasse derjenigen Tiere, die schon als Nauplien oder Copepodite zugrunde gingen.

Als Grundlage für alle Berechnungen diente die Anzahl der produzierten Tiere und nicht die Bestandeszahlen ("standing crop»). Bei kurzer Lebensdauer eines Entwicklungsstadiums kann das Bestandesmaximum zwischen zwei Probenahmen liegen und daher die erfassten Zahlen zu gering sein, bei langer Lebensdauer hingegen erscheint dasselbe Stadium möglicherweise in mehreren Proben, die Bestandeszahl wird dadurch zu hoch. Mit der nachstehenden Formel wurden die Bestandeszahlen zur wirklichkeitsnahen Grösse "Anzahl produzierte Individuen» verarbeitet: 


$$
\text { Produktion pro Zeitabschnitt }=\text { Bestand } \frac{\text { Zeitabschnitt (in Tagen) }}{\text { Entwicklungsdauer (Tage) }}
$$

Diese Formel ist im Kapitel 3.42, Eiproduktion, S. 103 erläutert.

Bei den erwachsenen Tieren ist diese Methode nicht anwendbar, dazu müsste die tatsächliche Lebensdauer unter Freilandbedingungen bekannt sein. Hier müssen die Bestandeszahlen verwendet werden : Erwachsenenproduktion = Bestandesmaximum minus vorhergehendes Bestandesminimum. Der dadurch entstehende Fehler dürfte aber klein sein, da die Lebensdauer der Adulten sicher länger ist als der Abstand zwischen zwei Probenahmen, weshalb das Bestandesmaximum erfasst wird.

\subsection{Erfolgsraten}

Die gründliche Analyse der Bestandeszahlen ermöglichte die Aufteilung des Bestandes in aufeinanderfolgende Generationen. Für jede dieser Generationen wurde die Anzahl produzierter Tiere berechnet, und zwar aufgeteilt in Nauplien, Copepodite und Adulte. Diese Erfolgsraten wurden ausgedrückt in Prozent der Eiproduktion der vorhergehenden Generation.

Die Nauplien mussten aus diesen Erfolgsberechnungen ausgeschlossen werden, da sie mangels Unterscheidungsmerkmalen nicht den einzelnen Arten zugeteilt werden konnten. Auch war es nur in Ausnahmefällen möglich, die Produktion eines einzelnen Copepoditstadiums zu berechnen, oft war die Entwicklungsdauer des Stadiums kürzer als der Abstand zwischen zwei Probenahmen.

In den nachfolgenden Tabellen wird deutlich sichtbar, dass der grösste Verlust auf dem Weg vom Ei zum ersten Copepoditstadium erlitten wird.

Die offensichtlich am wenigsten verlustreiche Phase ist das Schlüpfen der Nauplien aus den Eiern. NAUWERCK [34] fand für Eudiaptomus gracilis eine Verlustrate beim Schlüpfen von nur 2-3\%. Eigene Beobachtungen bei der Zucht ergaben für Cyclops abyssorum und Cyclops vicinus ebenso gute Schlüpferfolge.

Hingegen konnte häufig festgestellt werden, dass die Häutung vom letzten Naupliusstadium zum ersten Copepoditstadium nicht vollendet werden konnte: die Tiere gingen ausnahmslos daran zugrunde. Auch spätere Häutungen sind kritisch, sie blieben ebenfalls oft unvollendet. Dagegen wurde keine nicht geglückte Häutung vom letzten Copepoditstadium zum erwachsenen Tier beobachtet.

\subsection{Eudiaptomus gracilis}

Der Erfolg der Frühjahrsgeneration im Greifensee ist sehr hoch, die Sommer- und die Herbstgeneration ist nur ein Viertel so erfolgreich. Die niedrigste Erfolgrate weist die Wintergeneration 1968/69 auf. Der grosse Unterschied zwischen der Wintergeneration 1967/68 und derjenigen von 1968/69 ist auf die stark abweichenden Eiproduktionen von 0,9 bzw. 5,2 Millionen Eier zurückzuführen. Die Absolutzahlen der $\mathrm{C} 4+\mathrm{C} 5$ und der Adulten stimmen hingegen bei diesen beiden Generationen auffallend gut überein.

Im Vierwaldstättersee sind die Eiproduktionen aller vier Generationen gleichmässig gross, hier hat aber die Herbstgeneration den grössten Erfolg. Die durch- 
Tab. 3. Erfolgsraten von Eudiaptomus gracilis

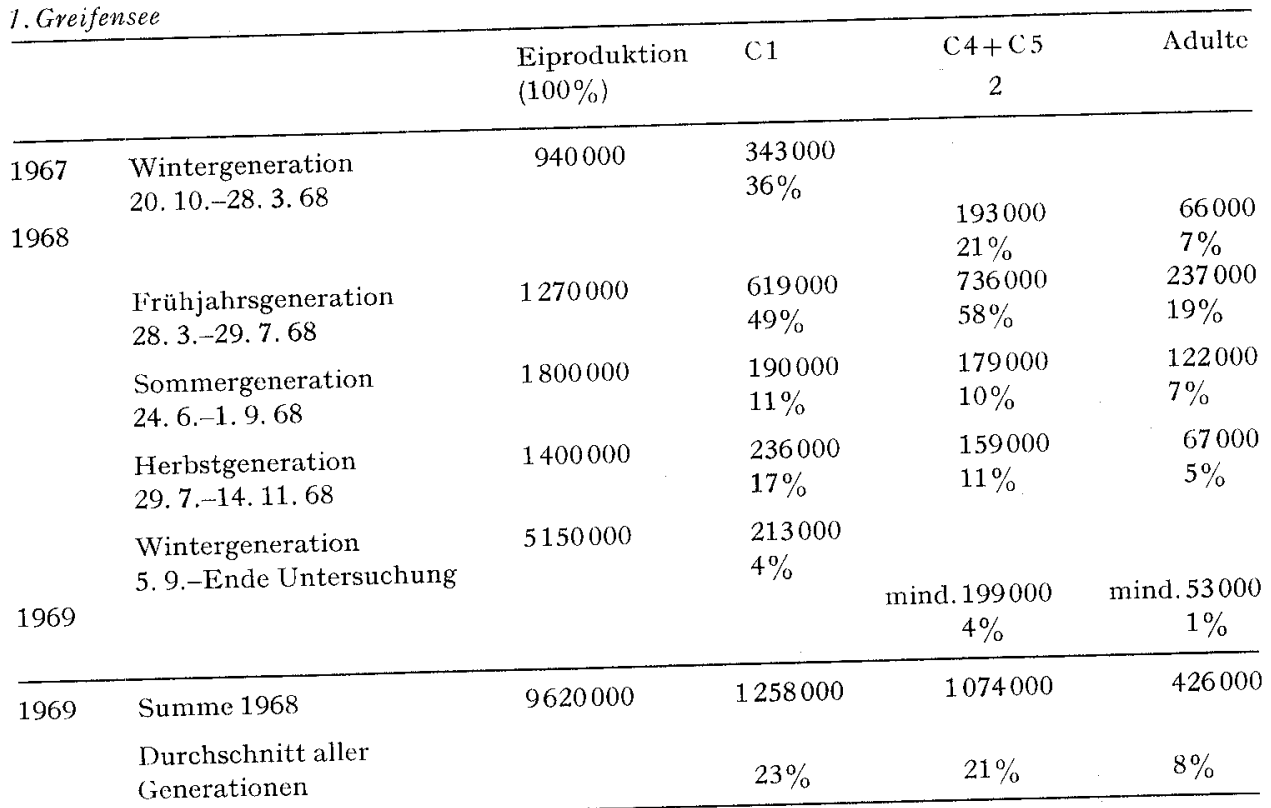

2. Vievwaldstättersee

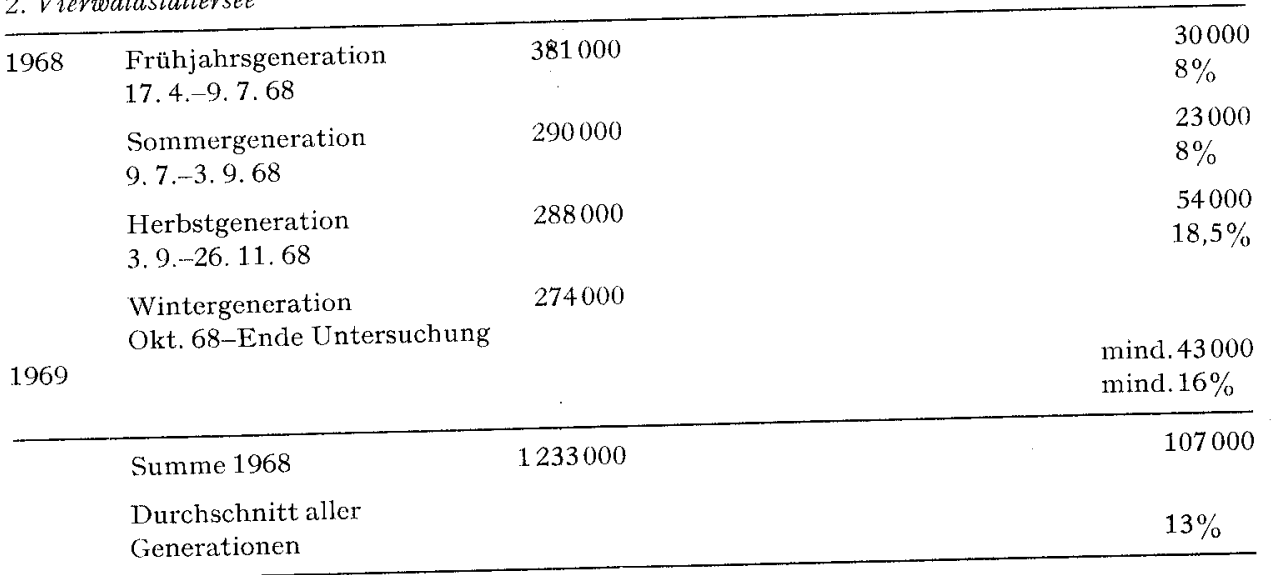

schnittliche Erfolgsrate beträgt im Vierwaldstättersee $13 \%$ gegenüber $8 \%$ im Greifensee.

\subsection{Cyclops abyssorum}

Die Eiproduktion der Sommergeneration 1968 im Vierwaldstättersee ist deutlich in zwei Schüben erfolgt, während die daraus resultierenden Erwachsenen nur ein Maximum gebildet haben. 
Tab.4. Erfolgsraton von Cyclops abyssorum

1. Greifensee

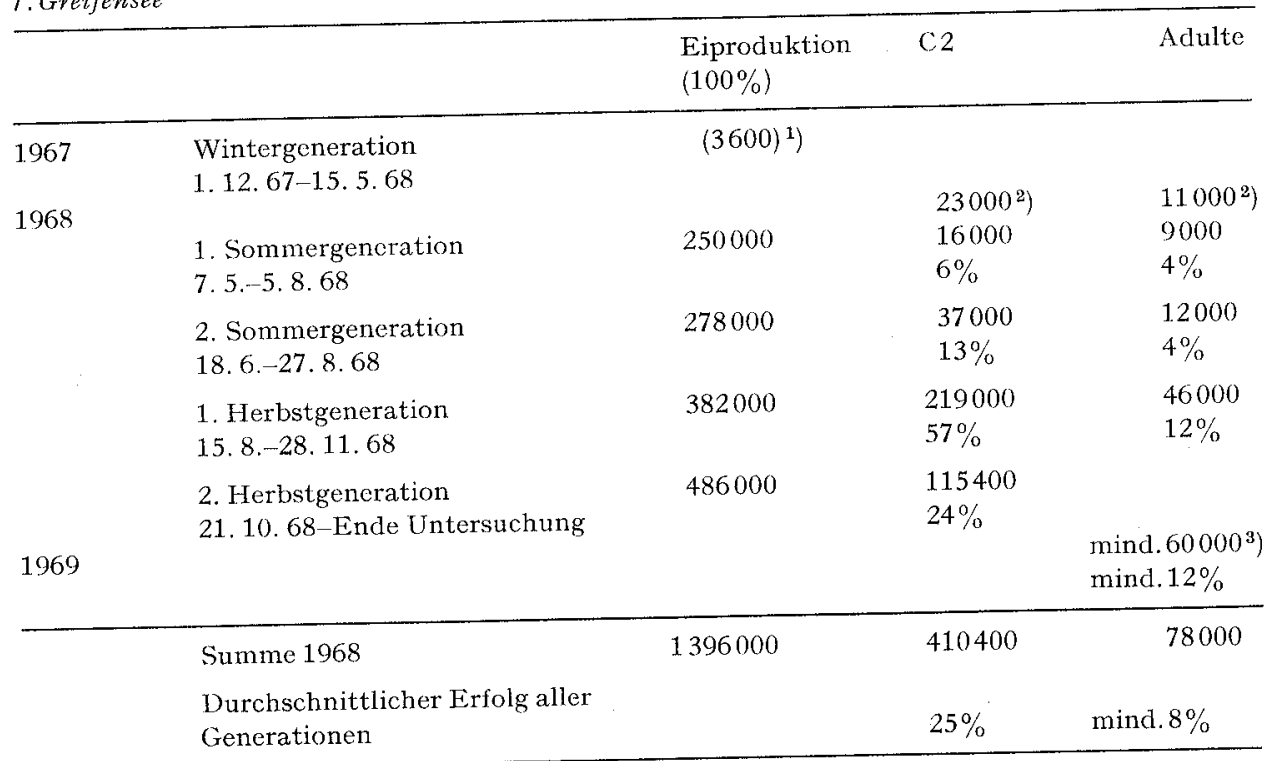

\section{Vierwaldstättersee}

\begin{tabular}{|c|c|c|c|}
\hline 1967 & $\begin{array}{l}\text { Wintergeneration } \\
\text { Herbst } 67 \text {-Frühjahr } 68\end{array}$ & - & $\left.12000^{2}\right)$ \\
\hline 1968 & $\begin{array}{l}\text { Sommergeneration } \\
\text { Juni } \\
\text { August }\end{array}$ & $\left.\begin{array}{l}120000 \\
500000\end{array}\right\}$ & $\begin{array}{l}46000 \\
7,5 \%\end{array}$ \\
\hline 1969 & $\begin{array}{l}\text { Wintergeneration } \\
\text { Oktober-Dezember }\end{array}$ & 884000 & $\begin{array}{l}\left.\text { mind } 11000^{3}\right) \\
\text { mind } 1,2 \%\end{array}$ \\
\hline & Summe 1968 & 1504000 & 46000 \\
\hline
\end{tabular}

1) Wahrscheinlich zu klein, am Anfang der Untersuchung waren die Abstände zwischen den Probenahmen zu gross.

2) Nicht bestimmbar, da Eiproduktion nicht bekannt.

3) Wegen Ende der Untersuchung nicht mehr vollständig erfasst.

\subsection{Cyclops vicinus}

Bei den Eiproduktionen im Greifensee lassen sich deutlich eine 1. und eine 2. Frühlingsgeneration, wie auch eine 1. und eine 2. Sommergeneration abgrenzen, während die Erwachsenen dieser Generationen je zu einem einzigen Maximum verschmelzen.

Die Erfolgsrate der Erwachsenen, die im direkten Entwicklungsgang (ohne Diapause) aus dem Ei entstehen, ist sehr bescheiden. Aber auch ihre Anzahl ist gering: 
Tab. 5. Erfolgsraten von Cyclops vicinus.

1. Greifensee

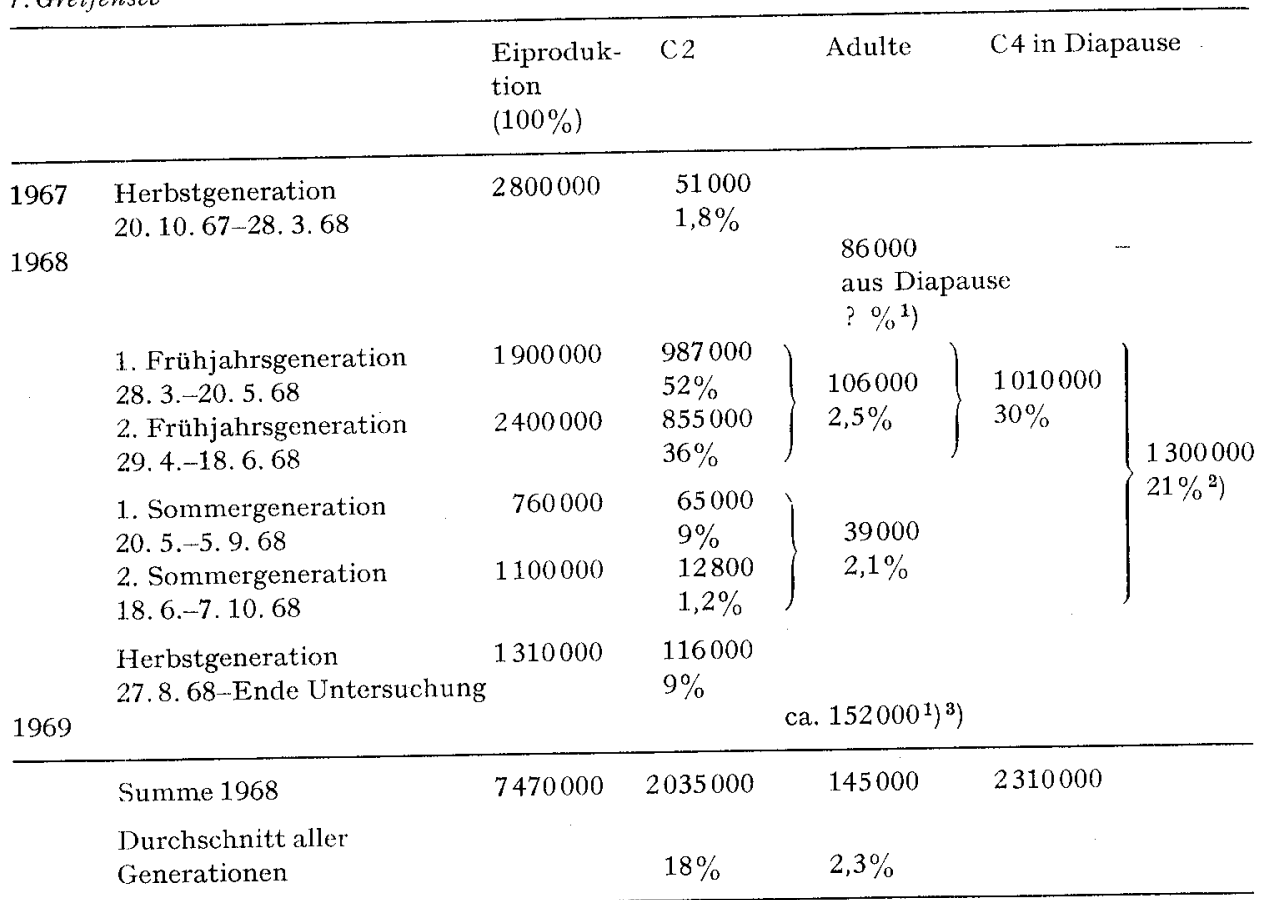

\section{Vierwaldstättersee}

\begin{tabular}{llcl}
\hline 1968 & April-9.7.68 & 227000 & 62000 \\
& & & $27 \%$ \\
1969 & bis Ende Untersuchung & ca. $\left.36000^{3}\right)$ & \\
$16 \%$ & \\
\hline
\end{tabular}

1) Nicht bestimmbar, da vermischt mit aus der Diapause erwachenden Tieren.

2) Wegen der langen Dauer der Diapause (rund 6 Monate) ist es nicht möglich, die C4 im Schlamm auf die einzelnen Generationen zu verteilen, es kann nur die Summe aus sämtlichen vorangegangenen Generationen festgestellt werden.

3) Extrapolation.

$10 \times$ mehr Tiere gehen in Diapause. Vor allem die Copepoditerfolgsrate dieser «Durchbrenner»-Generationen ist ausserordentlich gering, offenbar sind die Lebensbedingungen im Sommer für Cyclops vicinus ungünstig. Der Weg über die Diapause ist erfolgreicher, obwohl im Greifensee auch hier grosse Verluste erlitten werden: von den 1,3 Millionen C4 zu Beginn der Diapause werden nur $27 \%$ wieder aktiv und $12 \%$ erwachsen.

Im Vierwaldstättersee dagegen werden beinahe $60 \%$ der in Diapause gefundenen Tiere wieder aktiv und die Hälfte davon sind am Ende der Untersuchung erwachsen. 


\subsection{Mesocyclops lenckarti}

Tab.6. Erfolgsraten von Mesocyclops leuckarti.

1. Greifensee

\begin{tabular}{|c|c|c|c|c|}
\hline & & $\begin{array}{l}\text { Eiproduktion } \\
(100 \%)\end{array}$ & $\begin{array}{l}\mathrm{C} 4+\mathrm{C} 5 \\
\text { in Diapause }\end{array}$ & Adulte \\
\hline 1967 & Herbstgeneration & 2225000 & 154000 & \multirow{4}{*}{$\begin{array}{l}21000 \text { nach Diapause } \\
1 \% \\
54000 \\
23 \%\end{array}$} \\
\hline \multirow[t]{5}{*}{1968} & August-Oktober 67 & & $7 \%$ & \\
\hline & Sommergeneration & 234000 & 1) & \\
\hline & Juni-August 67 & & & \\
\hline & Herbstgeneration & 558000 & 30000 & 2) \\
\hline & August-Oktober 67 & & $5,5 \%$ & \\
\hline & Summe 1968 & 792000 & 84000 & 2) \\
\hline
\end{tabular}

2. Vievwaldstättersee

\begin{tabular}{|c|c|c|c|c|}
\hline \multirow[t]{3}{*}{1968} & $\begin{array}{l}\text { Herbst-Wintergeneration } \\
\text { bis Frühjahr } 68\end{array}$ & & $\left.31000^{3}\right)$ & $\left.9000^{3}\right)$ \\
\hline & $\begin{array}{l}\text { Sommergeneration } \\
\text { Mai-Juli } 68\end{array}$ & 36000 & 1) & $\begin{array}{l}3000 \\
8 \%\end{array}$ \\
\hline & $\begin{array}{l}\text { Herbstgeneration } \\
\text { Juli-Oktober } 68\end{array}$ & 30000 & 1) & $\begin{array}{l}3400 \\
11 \%\end{array}$ \\
\hline \multirow[t]{2}{*}{1969} & $\begin{array}{l}\text { Herbst-Wintergeneration } \\
\text { September-Frühjahr } 69\end{array}$ & 147000 & $\begin{array}{l}95000 \\
65 \% \\
68000 \\
46 \%\end{array}$ & $\left.9)^{2}\right)$ \\
\hline & Summe 1968 & 213000 & 101400 & \\
\hline
\end{tabular}

1) Nicht feststellbar, da Stadiendauer der Copepodite im Vergleich zu den Abständen zwischen den Probenahmen zu kurz. Erfassung nur in der Diapause möglich.

2) Diese Generationen wurden erst nach Abschluss der Untersuchung erwachsen.

3) Nicht bestimmbar, da Eiproduktion vor Beginn der Untersuchung.

Zuchtversuche mit Mesocyclops leuckarti führten zu keinem Erfolg, weshalb mir keine Entwicklungsgeschwindigkeit für die Copepodite bekannt ist. Die Erfolgsberechnungen der Copepodite basieren hier auf den Bestandeszahlen.

Die Sommergeneration hat einen sehr grossen Erfolg: 23\% der Tiere werden erwachsen. Bei den Herbstgenerationen hingegen gelingt es nur $6 \mathrm{bzw}$. 7\% als C4 oder C5 in Diapause zu gehen. EinsLe [12] fand bei Mesocyclops leuckarti eine Verlustrate vom Ei bis zum 1. Copepoditstadium von 95\%. Meine Zahlen stimmen damit gut iberein, da sicher die Naupliusphase die weitaus verlustreichste ist:

Rechnet man, ausgehend von der Eiproduktion, eine Sollbestandeskurve für das 1. Copepoditstadium (aus experimentell bestimmter Entwicklungsgeschwindigkeit 
der Eier und Nauplien und der Seemitteltemperatur) und vergleicht diese mit der tatsächlich gefundenen Bestandeskurve (Abb.22), so sieht man, dass nur die frühesten C1 die Naupliusphase überstehen, während diejenigen, die später folgen sollten, verlorengehen. Als Hauptursache dieses Verlustes kommt zweifellos Frass durch die Erwachsenen der eigenen Art, die unterdessen ihr Maximum erreicht haben, sowie durch die ältern Geschwister in Frage.

Zum Verlust während des Winters: Im Vierwaldstättersee sind während der $2 \frac{1}{2}$ Monate der winterlichen Kältehemmung, die in der Untersuchungsperiode erfasst wurden, $28 \%$ der ruhenden C4 und C5 zugrunde gegangen.

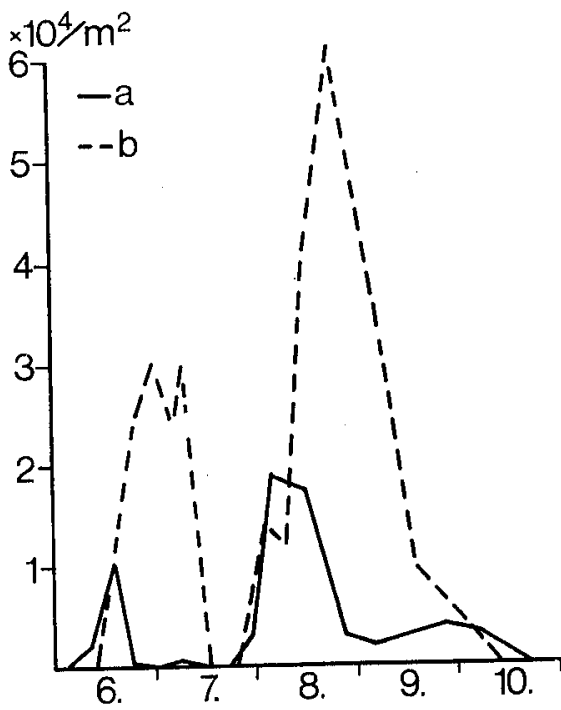

Abb. 22. Mesocyclops leuckarti im Greifensee: Vergleich des effektiven (a) mit dem theoretisch $z u$ erwartenden (b) Bestand.

\subsection{Biomassebestimmung}

Die Bestimmung der Biomasse von Zooplanktern stellt ein bisher nicht befriedigend gelöstes Problem dar. Dabei ist dies eine Schlüsselgrösse zur Beurteilung der Wichtigkeit einer Art für den Stoffumsatz im See. Das Zählen der vorhandenen Individuen ist schon deshalb ungenügend, weil dabei die unterschiedliche Grösse der Tiere unberücksichtigt bleibt, die zwischen $0,1 \mu \mathrm{g}$ bei Nauplien und $10 \mu \mathrm{g}$ bei grossen Daphnien schwanken kann.

\subsection{Methodik}

Folgende Methoden zur Bestimmung der Biomasse wurden bisher versucht:

Volumenbestimmung. LOHMANN [31] schlug die Herstellung von maßstabgetreuen Modellen vor, deren Volumen auf einfache Weise bestimmt werden kann. Das führt bei Phytoplanktern mit geometrisch relativ einfachen Körperformen zu annähernd richtigen Resultaten, bei Crustaceenplankton mit stark gegliedertem Körper und feinverzweigten Gliedmassen können aber auf diese Weise sicher keine genauen Resultate gefunden werden. 
Frischgewicht. Das Zooplankton wird meist auf einem Filterpapier vom anhaftenden Wasser befreit und ohne weiteres Trocknen gewogen. Dabei verfälscht eine nicht bestimmbare Menge von Haftwasser innerhalb der Schale und in Körpereinbuchtungen das Resultat. Auch sagt das Frischgewicht über die vorhandene Menge an organischem Material nichts aus, falls der Anteil an Trockensubstanz am Frischgewicht nicht bekannt ist, und dieser schwankt von Fall zu Fall (NAUwerck [34] gibt $5-10 \%$ an).

Trockengewicht. Die genaueste Aussage über die Menge an organischem Material gibt das Gewicht völlig wasserfreier Tiere, korrigiert mit dem Aschegewicht. Dabei bereitet aber in noch weit grösserem Masse als bei der Bestimmung des Frischgewichtes die Beschaffung von genügend Tieren Mühe. Bei Rotatorien ist sie praktisch unmöglich, hingegen liefert diese Methode bei Monokulturen auf einfachste Weise zuverlässige Werte.

"The best method for estimating organic particulate matter consists of filtration, followed of the use of specific or semispecific microanalytical procedures" [45]. Die drei Stoffklassen Eiweiss, Fett und Kohlehydrate machen ohne Zweifel die Hauptmenge des organischen Materials von Crustaceenplankton aus, daher kann ihre Summe in guter Näherung als Biomasse angenommen werden. Die Bestimmung der einzelnen Komponenten ergibt zusätzlich sehr wertvolle Informationen, insbesondere über die Anlage von Reservestoffen.

Für die Bestimmung der Eiweissmenge liegen 2 Methoden vor:

a) Bestimmung des Gesamtstickstoffes und Multiplikation mit dem konventionellen Faktor 6,25.

b) Spezifisch und einfach ist die Eiweissbestimmung mit der Biuretmethode, wie sie in der klinischen Chemie üblich ist.

Die Gesamt-N-Methode wurde der Biuretmethode vorgezogen, da es sich um eine weitverbreitete Methode handelt, mit der man zudem an der EAWAG grosse Erfalirung hat.

Nach Krause [28] und Biaska [5] beträgt der Anteil des Gesamtstickstoffs, der vom Chitin geliefert wird, 23\%. Der dadurch bei der Biomasse auftretende Fehler ist vernachlässigbar klein. (Chitin $=4-7,5 \%$ des Trockengewichtes nach KRAUsE [28]).

Der Fettgehalt von biologischem Material wird meist durch Extraktion mit Äther, Trocknen und Wägen des Rückstandes bestimmt. Dabei ist die Gefahr, dass Nichtlipide die Bestimmung verfälschen, gross. Auch sind grössere Mengen von Material nötig, als in meinem Fall zur Verfügung standen. Wegen der höheren Spezifität und der viel grösseren Empfindlichkeit ist die Bestimmung mit Hilfe einer Farbreaktion vorzuziehen. Bisher fehlte eine für Reihenuntersuchungen geeignete Methode. Seit kurzer Zeit wird in der klinischen Chemie mit Erfolg die SulfophosphovanillinMethode angewandt, die Charbol [6] zur Bestimmung der Gesamtlipide im Blutserum einführte. Die Intensität der kolorimetrisch ausgewerteten Farbreaktion ist proportional zur. Anzahl Doppelbindungen der Fettsäuren [59]. Die Übereinstimmung mit der gravimetrischen Methode ist gut, die Präzision der Sulfophosphovanillin-Methode ist aber bedeutend besser [52].

Für die Kohlehydrate wird üblicherweise die Annahme gemacht: Kohlehydrat := ätherunlöslicher Nichtproteinanteil der Trockensubstanz minus Aschegewicht. Aus 
denselben Gründen wie beim Fett ist auch bei den Kohlehydraten die Bestimmung durch eine spezifische Farbreaktion andern Methoden vorzuziehen. Gebräuchlich ist die Anthronmethode, die sich dank ihrer Einfachheit für die routinemässige Untersuchung grosser Probezahlen eignet.

Durch Erhitzen mit Säure werden Polysaccharide zunächst zu Monosacchariden hydrolysiert. Daraus entsteht durch Wasserentzug ein Furanderivat, das mit dem Anthron zu einem intensiv gefärbten Farbstoff kondensiert [36].

Die Resultate geben alle Hexosen (Mono- oder Polysaccharide) und Methylpentosen als äquivalente Mengen von Glucose wieder. Pentosen und Hexuronide erscheinen nur als Bruchteile des Glucosegewichtes, Hexosamine (z.B. Chitin) reagieren überhaupt nicht [46].

Mit der Biuret-, der Anthron- und der Sulfonphosphovanillin-Methode liegen somit drei einfache Routinemethoden vor, die nebst einer zuverlässigen Gesamtbiomassebestimmung noch Aussagen über die Physiologie der Tiere liefern. Als weiterer grosser Vorteil ist die Tatsache zu werten, dass alle Methoden so empfindlich sind, dass sie schon mit der kleinen Menge von 50 Tieren zuverlässige Resultate liefern.

4.211 Material. Jeweils 50 Tiere der betreffenden Kategorie wurden aus frisch gefangenem Zooplankton herausgelesen und bis zur Analyse tiefgefroren aufbewahrt.

\subsection{Methoden.}

Eiweiss. Die Eiweissmenge wurde durch Multiplikation der Stickstoffmenge mit dem Faktor 6,25 berechnet. Die Bestimmung des Stickstoffs erfolgte mit einer MikroKjehldahl-Methode nach Schmid [37]. Deren mittlerer Fehler beträgt bei $10 \mu \mathrm{g}$ Einwaage $\pm 10 \%$.

Fett. Standard: Um möglichst wirklichkeitsgetreue Resultate zu erhalten, übernahm ich nicht den Standard aus der klinischen Chemie, sondern stellte einen eigenen, auf das vorliegende Material abgestimmten, zusammen.

FARKAS [16] gibt als Hauptbestandteile des Fettes von Crustaceenplankton aus dem Balatonsee an: Öl-, Linol-, Palmitolein-, Myristin-, Palmitin-, Stearin- und in geringerer Menge Linolensäure. Der Anteil der gesättigten Fettsäuren anı Gesamtfett beträgt zwischen 20 und 30\% [18]. Etwa 70\% der gesättigten Fettsäuren haben eine Kettenlänge von $16 \mathrm{C}$. Die Verteilung der ungesättigten Fettsäuren auf die verschiedenen Kettenlängen ist wie folgt: $1 \%$ C $14,8 \%$ C 16, 37\% C 18, 25\% C 20, 31\% C 22 . Die C16- und C18-Ketten sind hauptsächlich Mono- oder Diensäuren, die C20 und C22-Ketten Di-, Tri- oder Tetraensäuren. (Nach STRICkLANd [45] ist das Fettsäurespektrum von Zooplankton und auch von Fischen demjenigen mariner Pflanzen sehr ähnlich, ebenso das Aminosäurenspektrum).

In Anlehnung an diese Angaben setzte ich meinen Standard wie folgt zusammen: 25\% Palmitinsäure und 75\% Linolsäure in alkoholischer Lösung.

Arbeitsvorschrift: Das Analysenmaterial wird in einem absolut fettfreien Reagensglas im Vakuum getrocknet. Nach Zugabe von $2 \mathrm{ml}$ konzentrierter Schwefelsäure wird 10 Minuten im kochenden Wasserbad inkubiert, anschliessend rasch in kaltem Wasser auf Zimmertemperatur abgekühlt. $5 \mathrm{ml}$ Phosphovanillinreagens werden zu- 
gegeben und nach 30 Minuten Stehenlassen bei Zimmertemperatur die entstandene Farbe bei $530 \mathrm{~nm}$ in einer 1-cm-Küvette gemessen.

Phosphovanillinreagens: 1 Teil $0,6 \%$ wässrige Vanillinlösung und 4 Teile konzentrierte Phosphorsäure.

Kohlehydrate (nach RICHTERICH [36]). Das Untersuchungsmaterial wird in einem peinlich sauberen Reagensglas am Vakuum zur Trockene eingedampft. Es werden $10,0 \mathrm{ml}$ Anthronreagens zugegeben, 15 Minuten im kochenden Wasserbad inkubiert, anschliessend rasch in kaltem Wasser auf Zimmertemperatur abgekühlt. Nach 15 Minuten wird bei $620 \mathrm{~nm}$ in einer 2-cm-Küvette abgelesen. Diese Werte werden auf einer Eichkurve interpoliert, die bis unterhalb $5 \mu \mathrm{g}$ linear verläuft.

Die Resultate werden als Glucoseäquivalente angegeben, da Glucose der hauptsächlichste Zuckeranteil in allem untersuchten Meeresplankton ist [45]. Diese Angabe können wir ohne Bedenken auf Süsswasserplankton übertragen.

\subsection{Resultate}

Ich habe über die wichtigsten Zooplankter des Greifensees eigene Untersuchungen vorgenommen. Obwohl es sich meist um Einzelbestimmungen handelt, scheint es mir sehr wichtig, diese Resultate vorzulegen, um die spärlichen, in der Literatur zu findenden Angaben zu ergänzen und um die Anwendung der einfachen und spezifischen Methoden zu fördern. Die Úbernahme von Resultaten anderer Autoren, die mit verschiedenen Methoden und unterschiedlichem Material gewonnen wurden, ist infolge der grossen Differenzen nicht möglich.

\section{Zur Tabelle 7}

Vergleichen wir die durchschnittliche Biomasse der erwachsenen Tiere, finden wir bei Eudiaptomus gracilis 3,1 $\mu \mathrm{g}$, bei Cyclops vicinus 5,4 $\mu \mathrm{g}$ und bei Cyclops abyssorum 7,4 $\mu g$.

Für Eudiaptomus gracilis, Cyclops abyssorum, Cyclops vicinus und Daphnia sp. aus dem eutrophen Greifensee wurden Werte gefunden zwischen 17-32\% Eiweiss, $30-65 \%$ Fett und 14-40\% Kohlehydrate. (Zum Vergleich: Farkas [16]: 33\%/36\%/ $30 \%$; BLASKA [5] $73 \% / 13 \% / 14 \%$ ).

Eudiaptomus gracilis. Die gesamte Biomasse ist deutlich kleiner als diejenige von Cyclops vicinus. Verglichen mit diesen ist der Anteil des Eiweisses auf Kosten der Kohlehydrate vergrössert.

Cyclops abyssorum. Das geringe Trockengewicht der Männchen kann daher rühren, dass diese Probe 2 Monate später gefangen wurde als diejenige der Weibchen und dass die Tiere in diesem Zeitraum infolge der Temporalvariation wesentlich kleiner geworden sind. Auffallend ist in allen 3 Kategorien von Cyclops abyssorum der hohe Fettgehalt, der rund $2 / 3$ des Trockengewichtes ausmacht.

Cyclops vicinus. Die chemische Zusammensetzung ändert von Stadium zu Stadium wenig, einzig die Weibchen und vor allem die Eierweibchen weisen erhöhte Fettgehalte auf. Diese hängen sicher mit der Eibildung zusammen, die Eier enthalten ja auch einen auffallend hohen Prozentsatz an Fett. Die Trockensubstanz der Eisäcke ist sehr gross, sie liegt bei 2 Eisäcken in derselben Grössenordnung wie ein erwachsenes Tier. 
Tab.7. Trockengewicht pro Individuum und prozentualer Anteil der drei Hauptstoffklassen.

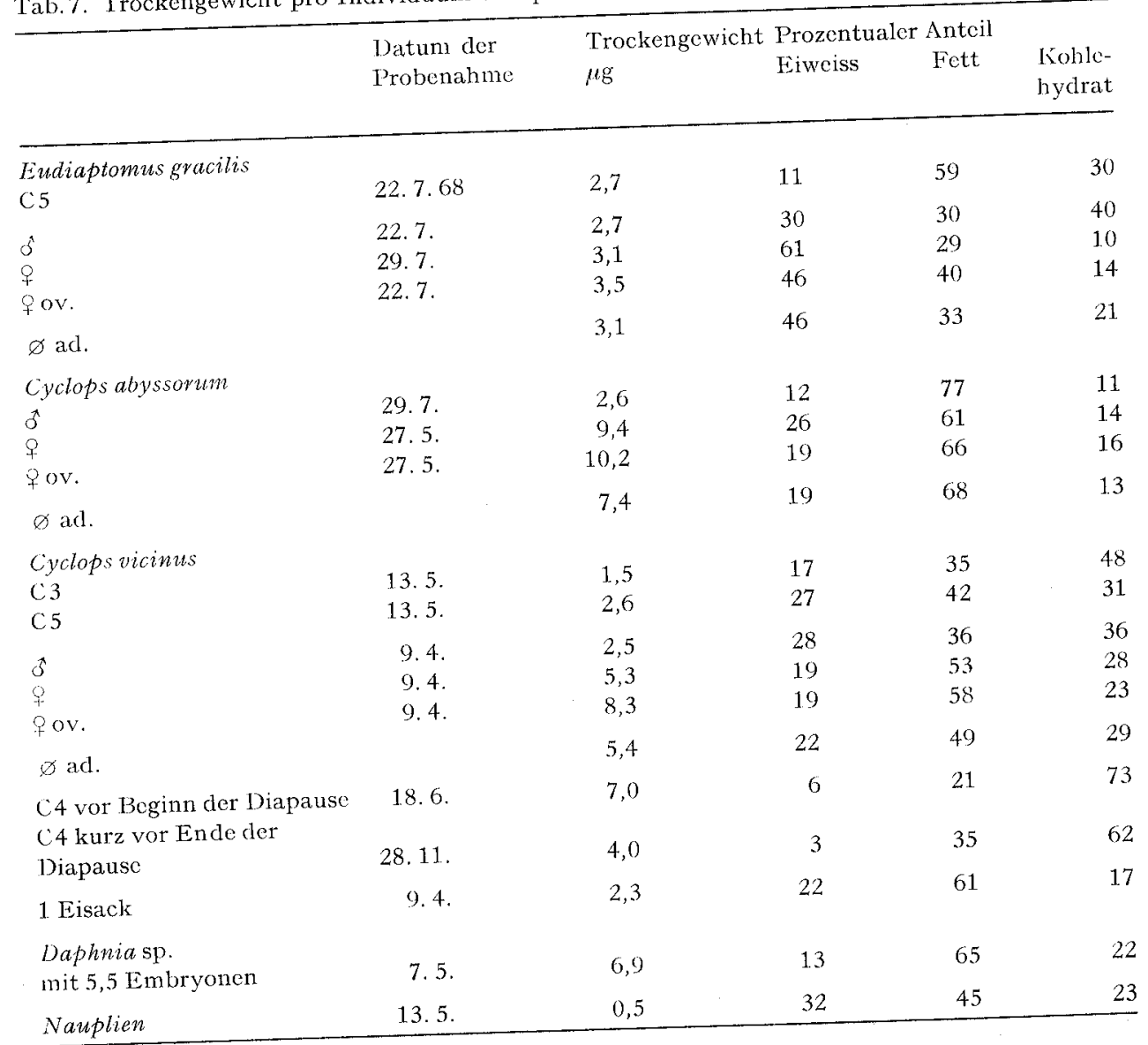

Trockengewicht $=\Sigma \mu \mathrm{g}$ Eiweiss $+\mu \mathrm{g}$ Fictt $+\mu \mathrm{g}$ Kohlehydratc.

Eiweiss als Gesamt-N $\times$ 6,25.

Fett als Äquivalente des Standards 25\% Palmitinsäure $+75 \%$ Linolsäure.

Kohlchydrate als Glucoseäquivalent.

Eine Sonderstellung nehmen die im Schlamm ruhenden 4. Copepodite von $C y$ clops vicinus ein: 5\% Eiweiss, 28\% Fett, 68\% Kohlehydrate, womit ganz eindeutig zum Ausdruck kommt, dass der Reservestoff der diapausierenden Copepodite von Cyclops vicinus Kohlehydrate und nicht etwa Fette sind. Während der fünf Monate Diapause bleibt die Fettmenge auf gleicher Höhe, während vom Kohlehydratdepot ungefähr die Hälfte verbraucht wird. Diese Feststellung wird dadurch bestätigt, dass auch BLASka [5] bei Cyclops vicinus im Sommer, also zur Zeit der Diapause, einen dreimal höheren Kohlehydratanteil fand als normal.

Von andern Autoren sind nur wenige und stark abweichende Angaben über Süsswasserzooplankton bekannt: FARKAS [16] macht nur eine Aussage über die prozentualen Anteile der drei Hauptstoffklassen Eiweiss, Fett und Kohlehydrate in Misch- 
plankton, Blaska [5] gibt sowohl die absolute Summe der drei Stoffklassen pro Individuum für einzelne Arten als auch ihre prozentuale Zusammensetzung an. NAUWERCK 134] und SEBestyen [40] geben Volumina einzelner Arten an, MoshiRi [33] veröffentlichte Trockengewichte für Leptodora kindtii. KREY [29] und KrishnAMURTHY [30] untersuchten marines Zooplankton, letzterer veröffentlichte eine Zusammenstellung von Resultaten zahlreicher Autoren.

Vergleicht man die Biomasseangaben dieser verschiedenen Autoren, fallen die grossen Differenzen auf. Grösse und physiologischer Zustand der Tiere schwanken mit dem Alter der Population, bzw. Generation sowie auch mit der Jahreszeit [17]. Daher können die Resultate nicht ohne weiteres verglichen werden; dennoch sollen hier die wichtigsten Differenzen kurz hervorgehoben werden.

Sebestyen 40$]$ erhält im Durchschnitt nur $43 \%$ der Biomasse von NAUWERCK 134], obwohl beide nach der Volumenmethode von LoHmann [31] arbeiteten. Diese Differenz ist nur durch unterschiedliches Ausgangsmaterial erklärbar. Noch verschiedener sind die Angaben über die prozentuale Verteilung der drei Hauptstoffklassen. So finden verschiedene Autoren (in Krishnamurthy [30]) 9-11\% Gesamtstickstoff am Jrockengewicht, entsprechend 56-69\% Eiweiss, BLAskA $[5] 73 \%$, FARKAS |16] 33\%, meine eigenen Werte: 26\%. Der Vergleich der Resultate von BLASKA [5] und meinen eigenen ist besonders interessant, da in beiden Fällen sowohl die absolute Biomasse als auch ihre prozentuale Verteilung bestimmt wurde. Auch sind zwei der drei Methoden identisch: Eiweiss (als 6,25 $\times$ Stickstoff nach Kjeldahl), Glucose (mit der Anthronmethode). Den Fettgehalt bestimmte Braska [5] durch Extraktion und anschliessende Oxydation mit Kaliumdichromat, ich selber benutzte die Sulfophosphovanillinmethode. Bei BLAska liegen die gefundenen Absolutwerte der Gesamtbiomasse rund dreimal höher, die Verteilung: 73\% Eiweiss, 13\% Fett, 14\% Kohlehydrate, eigene Werte: 26\% Eiweiss, 52\% Fett und 22\% Kohlehydrate. Die Differenzen sind vor allem auf die unterschiedlichen Eiweisswerte zurückzuführen. Dabei findet BLASKa die höchsten von mir in der Literatur gefundenen Eiweissresultate, andererseits scheint die Fettmenge zu niedrig zu sein: FARKas [16] findet immerhin 20-40\% Fett. Gerade bei der Fettbestimmung dürften methodische Fehler bisher eine grosse Rolle gespielt haben, sind doch sowohl die Extraktion der Fette als auch die anschliessende Oxydation oder Wägung kleinster Mengen fehleranfällige Methoden, während die Sulfophosphovanillinmethode sehr empfindlich ist und weitaus besser reproduzierbare Resultate gibt |52].

\subsection{Biomasseberechnung}

Die Resultate der Biomasseberechnungen sind in nachstehender Tabelle zusammengefasst. Die als Berechnungsgrundlage dienenden Zahlen sind den Tab. 3-6 (Erfolgsraten) und der Tab.7 (Trockengewicht pro Individuum) entnommen. Die Anzahl geschlüpfter Nauplien wurde der Menge produzierter Eier gleichgestellt, da beim Schlüpfen der Nauplien praktisch keine Verluste auftreten.

Für Mesocyclops leuckarti war nur eine Abschätzung der maximal produzierten Biomasse auf Grund des Bestandes an erwachsenen Tieren möglich, da die genaue Erfassung der Populationsdynamik nicht gelang. Dafür fehlten die Entwicklungsgeschwindigkeiten von Nauplien und Copepoditen. 
Tab.8. Im Jahre 1968 im Greifensee produzierte Biomasse.

Anzahl produzicrter Trockengewicht produ-

Tiere unter $1 \mathrm{~m}^{2}$

Seeoberfläche in $\mu$ g pro Tier zierte

Bio-

masse

in $\mu \mathrm{g}$

pro $\mathrm{m}^{2}$
1. Eudiaptomus gracilis

Geschlüpfte Nauplien

Als Nauplius gestorben

Als C 1, C 2 oder C 3 gestorben

$\mathrm{Als}$ C 4 oder C 5 gestorben

Adulte

Eiproduktion

Am Ende des untersuchten Jahres

als $C 1$ vorhanden

Am Anfang des untersuchten Jahres

von C $5 \mathrm{zu}$ Adult gewachsen

2. Cyclops abyssorum

Geschlüpfte Nauplien

Als Nauplius gestorben

Als Copepodit gestorben

Adulte

Eiproduktion

Am Ende des untersuchten Jahres

als C 2 vorhanden

Am Anfang des untersuchten Jahres

von C 2 zu Adult gewachsen

3. Cyclops vicinus

Geschlüpfte Nauplien

Als Nauplius gestorben

Als C 2 und C 3 gestorben

Als 4. Copepodit in Diapause

Adulte

Eiproduktion dieser Adulten

4. Mesocyclops leucharti

Abschätzung der maximalen Produktion

5. Daphniasp.

6. Bosminasp.

7. Diaphanosoma brachyurum $\left.2792000^{5}\right)$

9620000

8362000

184000

648000

426000

9620000

213000

66000

$\left.0,44^{1}\right)$

3700000

1,6

2, 7

2,9

0,06

290000

1750000

1240000

580000

190000

0,9

13200

7763200

1396000

1008600

320400

67000

1396000

115400

11000

$\left.0,48^{1}\right)$

475000

4,1

6,0

1300000

400000

0,02

28000

266000

2,3

$\left.3,7^{3}\right)$

40700

2509700

7470000

5435000

$-$

2174000

145000

3170000

$\left.0,45^{1}\right)$

2000000

1., 5

$5,5^{4}$ )

3,9

11900000

565000

0,05

158000

14623500

226000

19200000

$1507000^{5}$ )

$\left.6,9^{6}\right)$

4150000

$\left.83000^{5}\right)$

249000

1) Naupliusgewicht abzüglich Eigewicht.

2) Erwachsenengewicht abzüglich Gewicht des 5. Copepoditen.

3) Erwachsenengewicht abzüglich Gewicht des 2. Copepoditen.

4) Mittel des Gewichtes der 4. Copepodite zu Beginn und am Ende der Diapause.

5) Auf Grund des Bestandes berechnet: Bestandesmaximum abzüglich vorhergehendes Bestandesminimum.

6) Trockengewicht nach NAUWERcK [34]. 
Die Phyllopodenpopulationen lassen sich wegen der parthenogenetischen Fortpflanzung nicht in sauber getrennte Generationen aufteilen. Die Biomasse wurde daher nicht populationsdynamisch, sondern auf Grund der Bestandeszahlen berechnet.

Die im Vierwaldstättersee produzierte Biomasse konnte nicht auf dieselbe Weise berechnet werden wie im Greifensee, wo die engen Abstände zwischen den Probenahmen eine Erfassung der Populationsdynamik erlaubten. Deshalb berechnete ich aus den Greifenseeresultaten, wieviel der im ganzen Jahr produzierten Biomasse auf 1. erwachsenes Tier entfällt. In dieser Zahl ist der Anteil der als Nauplius, bzw. Copepodit gestorbenen Tiere eingeschlossen. Dieser Koeffizient wurde mit der entsprechenden Anzahl erwachsener Tiere im Vierwaldstättersee multipliziert. Bei den $C y$ clops vicinus wurde die Gesamtbiomasse auf die in Diapause ruhenden C4 verteilt, um die in beiden Seen stark unterschiedlichen Verluste auszuschalten.

Die Schlussresultate für beide Seen sind in folgender Tabelle zusammengefasst:

Tab.9. Produzierte Biomasse (Zusammenfassung).

\begin{tabular}{lccrr}
\hline & Greifensee & & \multicolumn{2}{c}{ Vierwaldstättersec } \\
& $\mu \mathrm{g}$ Biomasse $/ \mathrm{m}^{2}$ & $\%$ & $\mu \mathrm{g}$ Biomasse $/ \mathrm{m}^{2}$ & $\%$ \\
\hline Eudiaptomus gracilis & 7763200 & 16 & 1950000 & 36 \\
Cyclops abyssorum & 2509700 & 5 & 1720000 & 32 \\
Cyclops vicinus & 14623500 & 30 & 393000 & 7 \\
Mesocyclops leuckarti & 226000 & 0,5 & 274000 & 5 \\
Daphnia sp. & 19200000 & 39 & 889000 & 16 \\
Bosmina sp. & 4150000 & 8,5 & 189000 & 4 \\
Diaphanosoma brachyurum & 249000 & 0,5 & - & - \\
\hline & 48721400 & 99,5 & 5415000 & 100 \\
\hline
\end{tabular}

Der im Greifensee geerntete Fischertrag macht demgegenüber $4,12 \mathrm{~g} / \mathrm{m}^{2}$ aus. Er verteilt sich wie folgt auf die einzelnen Arten: Rotaugen 41,7\%, Hecht 22,1\%, Barsch 9,2\% und Schleien 9,1\% 24$]$.

\section{Diskussion}

\subsection{Entwicklungsgeschwindigkeit}

Der Vergleich von Zuchtresultaten mit Beobachtungen im See zeigten, dass die Entwicklungsgeschwindigkeit der Copepodite im See im Frühjahr zu kurz, im Herbst $z u$ lang ist. Zuchtergebnisse von Auvray und Dussar'T [4] legen den Verdacht nahe, dass allmählich sinkende Wassertemperaturen eine Retardierung (sinkende Temperatur bewirkt übermässige Verlängerung der Entwicklungsdauer), allmählich steigende Temperaturen eine Akzeleration (steigende Temperatur bewirkt übermässige Beschleunigung der Entwicklungsgeschwindigkeit) zur Folge haben.

\subsection{Bythotrephes longimanus und Leptodora kindtii}

Bythotrephes longimanus erreicht maximal 2,5\% des gesamten Crustaceenplanktons, Leptodora kindtii höchstens 1,5\%. Damit dürften sie trotz ihrer Grösse gegen- 
über den ebenfalls räuberisch lebenden $C y c l o p s$ vicimus und Mesocyclops leuckarti von sehr geringer Bedeutung sein.

\subsection{Daphnia}

Sowohl im Greifensee wie auch im Vierwaldstättersee verläuft der Prozentsatz embryotragender Weibchen entgegengesetzt zur Bevölkerungsdichte, im Greifensee auch die Anzahl Embryonen pro embryotragendem Weibchen. Hier dürfte ein wirksamer Regulationsmechanismus vorliegen, der eine noch stärkere Bevölkerungsexplosion verhindert.

\subsection{Mesocyclops leuckarti}

Mesocyclops leuckarti überdauert im Vierwaldstättersee die Entwicklungshemmung, welche durch die tiefen Wassertemperaturen im Winter verursacht wird, als 5. Copepodit aktiv schwimmend im Pelagial. Im Greifensee sind im Winter weder im Wasser noch im Schlamm Mesocyclops-Copepodite zu finden. Da sie mit den verwendeten Methoden sowohl im Wasser wie auch im Schlamm sicher erfasst worden wären, müssen wir annehmen, dass sie tatsächlich aus der Seemitte verschwunden sind. Im Frühling tauchen plötzlich wieder grosse Mengen von 5. Copepoditen auf, die ohne Zweifel im See überwintert haben. Am ehesten kommen dafür die ufernahen Schlammflächen in Frage, sie sind schon bei Beginn der Diapause im Oktober durch die Herbstzirkulation mit Sauerstoff versorgt $[12,55]$.

\subsection{Eutrophierung und Cyclops vicimus}

Die maximale Bevölkerungsdichte von Cyclops vicinus beträgt im Greifensee 1,3 Millionen Ind. $/ \mathrm{m}^{2}$, im Vierwaldstättersee $62000 \mathrm{Ind} . / \mathrm{m}^{2}$. Da Cyclops vicinus nach KozMINsKI [27] vornehmlich in eutrophen Gewässern $\mathrm{zu}$ finden ist, beweist die Tatsache, dass im Greifensee zwanzigmal mehr C. vicinus vorhanden sind als im Vierwaldstättersee die viel stärkere Eutrophierung des ersteren.

Einen deutlichen Hinweis auf die zunehmende Eutrophierung des Vierwaldstättersees gibt der steigende Anteil von Cyclops vicinus am Gesamtfang: in den Jahren 1934-37 wurde kein einziges Tier gefangen, 1962 und 1963 maximal 1\% [47] 1968 schon $7 \%$.

In beiden Seen liegt Cyclops vicinus während eines halben Jahres in einer echten Diapause bewegungslos auf dem Seegrund. Der Aufenthalt der Copepodite in $214 \mathrm{~m}$ im Vierwaldstättersee wird von $2 / 3$ der Tiere überlebt, während im Greifensee bei nur $32 \mathrm{~m}$ Tiefe $60 \%$ der diapausierenden Tiere zugrundegehen. Dieser hohe Verlust wird allerdings verständlich, wenn man bedenkt, dass die C4 während der ganzen Zeit im anaeroben Schlamm liegen und dabei noch Schwefelwasserstoffkonzentrationen bis $1,0 \mathrm{mg} / 1$ ertragen müssen. Für die wenigen sich im Sommer direkt fortpflanzenden Cyclops vicinus sind die Lebensbedingungen offenbar noch viel schlechter, denn der Entwicklungserfolg der Sommergenerationen beträgt nur wenige Prozent.

\subsection{Biomasse}

Im Greifensee wird rund zehnmal mehr Zooplankton-Biomasse produziert als im Vierwaldstättersee $\left(48,7\right.$ resp. $\left.5,4 \mathrm{~g} / \mathrm{m}^{2}\right)$, was die unterschiedlichen Trophiegrade der beiden Seen widerspiegelt. Zudem unterscheidet sich der Anteil der einzelnen Arten in den beiden Seen in bezeichnender Weise: im eutrophen Greifensee produzieren die 
Daphnien 39\% der gesamten Biomasse (vgl. die Daphnia-«Monokulturen» in stark verschmutzten Teichen), die eutrophieliebenden Cyclops vicinus 30\%. Im oligo- bis mesotrophen Vierwaldstättersee liefert Daphnia nur noch $16 \%$, Cyclops vicimus gar nur noch $7 \%$ der Gesamtbiomasse, während hier der Hauptanteil von Eudiaptomus gracilis mit 36\% und Cyclops abyssorum mit 32\% gestellt wird.

\subsection{Phytoplankton}

Das Phytoplankton der Proben von Juni bis Dezember 1968 wurde im Umkehrmikroskop nach Utermöhl [53] gezählt. Schon aus dieser Zeitspanne ergab sich, dass unmöglich ein Zusammenhang zwischen den Phytoplanktonfressern und dem Hauptanteil des Phytoplanktons, den $\mu$-Algen (kleine kugelige Grünalgen [35]) und Microcystis sp. gefunden werden kann. Wie schon NAUwERCK [34] zeigte, ist auch nur in ganz vereinzelten Fällen eine Korrelierung möglich. Hierzu wären zuerst experimentelle Untersuchungen über die Selektivität bei der Nahrungsaufnahme der Zooplankter und über den Nährwert der entsprechenden Plytoplankter nötig, dann auch Freilanduntersuchungen an einfachen Modellbiozoenosen mit wenig Zoo- und Phytoplanktonarten.

\section{Zusammenfassung}

Ziel dieser Arbeit war die Erfassung der im Jahre 1968 vom Zooplankton produzierten Biomasse. Die dafür nötigen Freilanduntersuchungen wurden an zwei Schweizer Seen durchgeführt, am Greifensee $(10 \mathrm{~km}$ östlich von Zürich) und am Vierwaldstättersee (Kastanienbaum bei Luzern). Bei jeder Probenahme wurde ein Temperatur- und Sauerstoffprofil erstellt, das Aufschluss iiber die Begrenzung des Lebensraumes der Zooplankter gab. Das Zooplankton wurde mit einem Schliessnetz aus eng zonierten Tiefenstufen gefangen und die fixierten Proben ausgezählt.

Diese Zählungen ergaben vor allem für die Sommermonate im Greifensee sehr grosse Besiedlungsdichten (bis 335000 Zooplankter $/ \mathrm{m}^{3}$ ), da die Aufenthaltstiefe wegen Sauerstoffmangels stark eingeschränkt war.

Schlammproben vom Grund beider Seen wurden auf die dort ruhenden Stadien von Cyclops vicimus und Mesocyclops leuckarti untersucht. Die Besiedlungsdichte betrug im Greifensee 1300000 C. vicinus $/ \mathrm{m}^{2}$, im Vierwaldstättersee $62000 / \mathrm{m}^{2}$. In der Seemitte wurden an beiden Orten keine Mesocyclops leuckarti gefunden.

Die Jahreszyklen der in den untersuchten Seen vorkommenden Crustaceen wurden graphisch dargestellt und gründlich analysiert. Besondere Beachtung wurde dabei der halbjährigen Diapause von Cyclops vicinus und der Entwicklungshemmung von Mesocyclops leuckarti geschenkt.

In vitro wurde die Entwicklungsgeschwindigkeit der Eier, Nauplien und Copepodite von Copepoden ermittelt. Die Entwicklungsdauer verlängert sich mit sinkender Wassertemperatur.

Mit einfach durchzuführenden chemischen Analysen wurde die Biomasse der Zooplankter als Summe von Eiweiss, Fett und Kohlehydraten bestimmt. Folgende Methoden wurden dabei verwendet: Eiweiss: N-Gehalt nach Kjehldahl $\times 6,25$; Fett: Sulfophosphovanillinmethode; Kohlehydrate: Anthronmethode. Überraschenderweise zeigte sich deutlich, dass der Diapausereservestoff bei Cyclops vicinus nicht Fett, sondern Kohlehydrate sind. 
Auf Grund der Anzahl produzierter Individuen und der Biomasse pro Individuum wurde die im Greifensee von den einzelnen Arten im Jahre 1968 produzierte Biomasse berechnet. Von den Copepoden lieferte Cyclops vicinus weitaus am meisten $\left(14,6 \mathrm{~g} / \mathrm{m}^{2}\right)$, Mesocyclops leuckarti hingegen unbedeutend wenig (etwa $0,2 \mathrm{~g} / \mathrm{m}^{2}$ ).

Die Summe der von den einzelnen Arten produzierten Substanzmengen ergab die gesamte im Greifensee vom Zooplankton produzierte Biomasse: $48,7 \mathrm{~g} / \mathrm{m}^{2}$ Seeoberfläche. Dabei entfielen auf Daphnia sp. 39\%, Cyclops vicinus 30\%, Eudiaptomus gracilis $16 \%$, Bosmina sp. 8,5\%, Cyclops abyssorum 5\%, Mesocyclops leuckarti $0,5 \%$, Diaphanosoma brachyurum $0,5 \%$. Im Vierwaldstättersee entfielen von total $5,4 \mathrm{~g} / \mathrm{m}^{2}$ auf die einzelnen Arten: Eudiaptomus gracilis 36\%, Cyclops abyssorum 32\%, Daphnia sp. $16 \%$, Cyclops vicinus $7 \%$, Mesocyclops leuckarti $5 \%$, Bosmina sp. $4 \%$.

Im Greifensee wurden im Jahre 1968 4,1 g/m² Fische gefangen.

\section{SUMMARY}

The aim pursued in this study was to determine the biomass produced by the zooplankton in 1968. Appropriate field investigations were carried out at two Swiss lakes, namely the Greifensee (10 km east of Zurich) and the Lake of Lucerne (at Kastanienbaum near Lucerne). At each sampling a temperature and oxygen profile was made in view of obtaining information on the delimitation of the habitat of the zooplankton organisms. The zooplankton was collected from narrowly zoned depth areas and the fixed samples were counted.

Counting showed large densities of populations in the Greifensee, especially in the summer months (up to 335000 zooplankton organisms per $\mathrm{m}^{3}$ ); this was due to the fact that the depth at which they held themselves was strongly limited owing to oxygen scarcity.

Sludge samples from the bottom of both lakes were examined with regard to the Cyclops vicinus and Mesocyclops leuckarti stages that rest there. The density of population amounted to 1300000 C. vicinus per square meter in the Greifensee and $62000 / \mathrm{m}^{2}$ in the Lake of Lucerne. No Mesocyclops leuckarti at all were found in the centre of both lakes.

Graphs and thorough analyses were made of the annual cycles of the crustaceans living in the two lakes, special attention being given to the half year resting stage of Cyclops vicinus and to the development inhibition of Mesocyclops leucharti.

The development velocity of the eggs, nauplii and copepodites of copepods was determined in vitro. The duration of development increased as the water temperature decreased.

By means of uncomplicated chemical analyses it was possible to determine the biomass of the zooplankton organisms as the sum of the protein, fat and carbohydrates. The methods applied were:

protein: $\quad \mathrm{N}$ content after Kjehldahl $\times 6,25$,

fat: Sulphophospho-vanilline method,

carbohydrate: Anthron method.

Surprisingly, it was observed that the substance stored up by Cyclops vicinus for its resting stage is not fat, but carbohydrates.

The biomass produced in 1968 in the Greifensee by the different species was calculated from the number of individuals produced and from the biomass produced per individual. Among the copepods, Cyclops vicinus produced by far the largest amount $\left(14,6 \mathrm{~g} / \mathrm{m}^{2}\right)$, whereas the amount produced by Mesocyclops lenckarti was extremely small $\left(0,2 \mathrm{~g} / \mathrm{m}^{2}\right)$.

The total biomass produced in the Greifensee by the zooplankton, i. e. $48,7 \mathrm{~g} / \mathrm{m}^{2}$ of the surface of the lake, was obtained by adding up the amounts of substances produced by the different species. Of the total biomass, Daphnia sp. produced 39\%, Cyclops vicinus 30\%, Eudiaptomus gracilis $16 \%$, Bosmina sp. 8,5\%, Cyclops abyssomm 5\%, Mesocyclops leucharti $0,5 \%$ and Diaphanosoma brachyurum $0,5 \%$. In the Lake of Lucerne, the total production amounted to $5,4 \mathrm{~g} / \mathrm{m}^{2}$, of which Eudiaptomus gracilis produced 36\%, Cyclops abyssorum 32\%, Daphnia sp. 16\%, Cyclops vicinus $7 \%$, Mesocyclops leuckarti $5 \%$ and Bosmina sp. $4 \%$.

In the Greifensee 4,1 $\mathrm{g}$ fish were caught per square meter of the lake surface in 1968. 


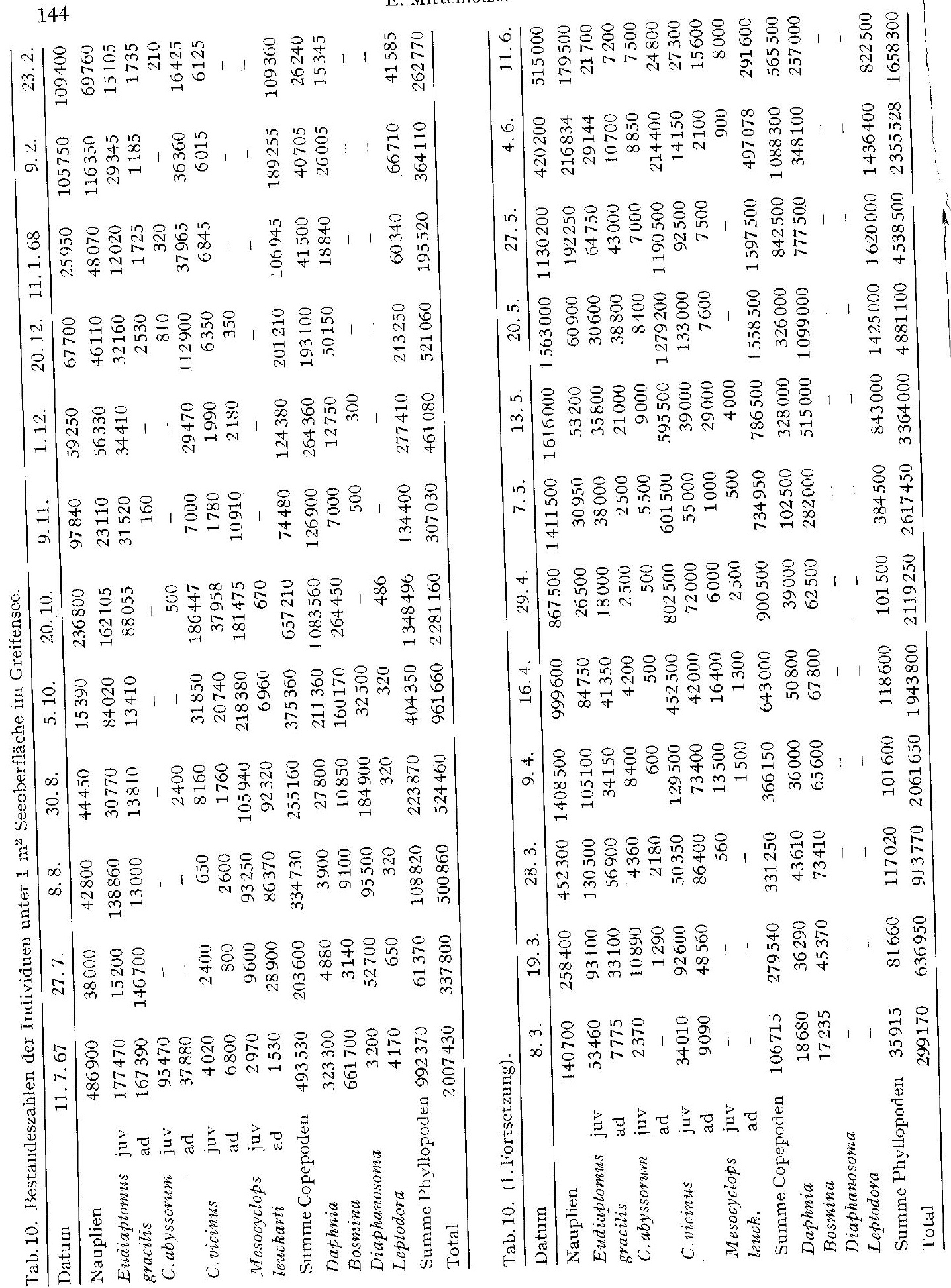


$\mid \begin{aligned} & 0 \\ & \text { | }\end{aligned}$ 讨

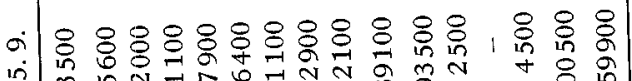

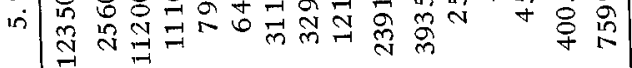

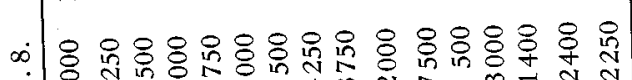

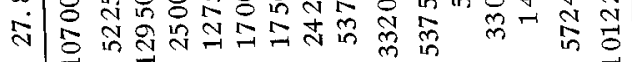

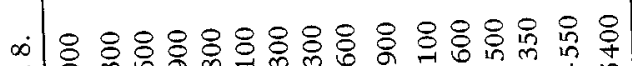
党|

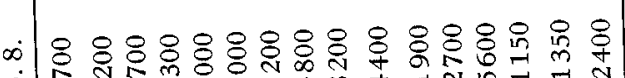

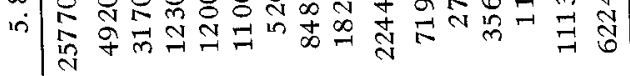

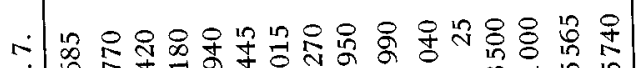

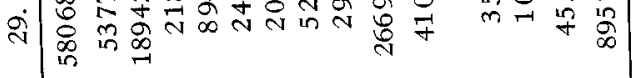

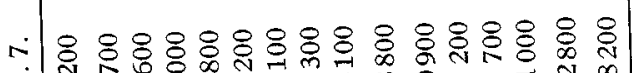

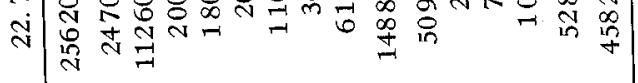

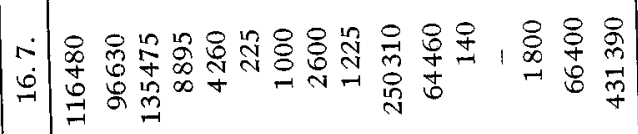

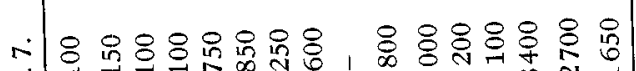

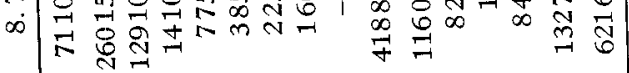

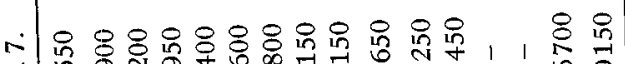

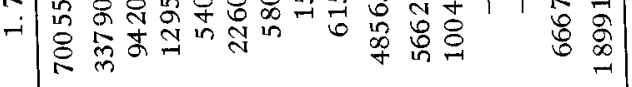

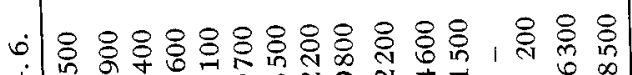
ป๋

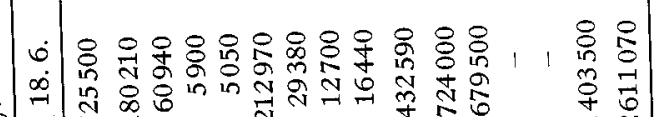

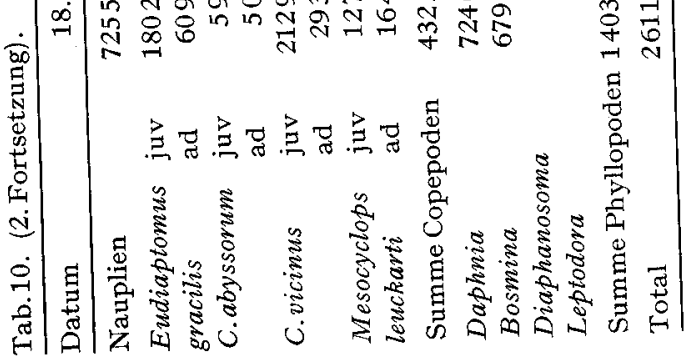

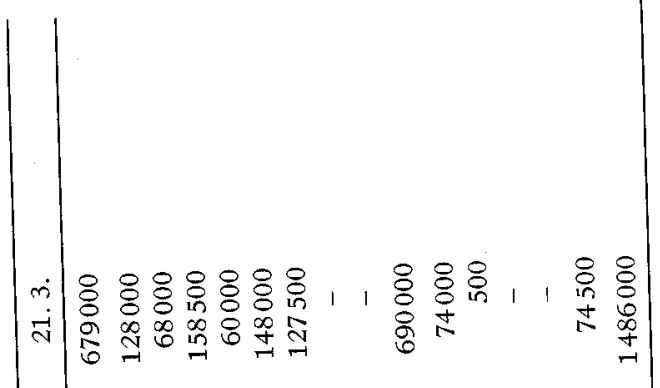
ن तี -

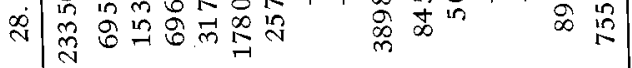

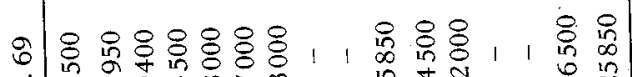
-i்

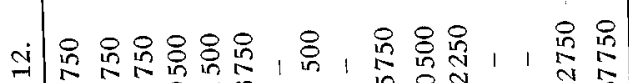

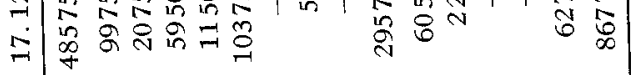

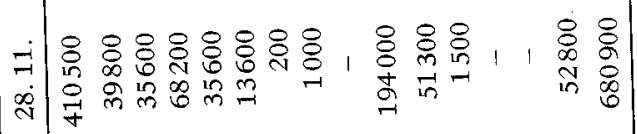
-

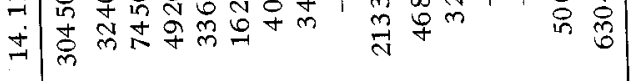

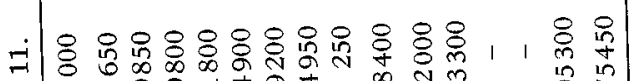

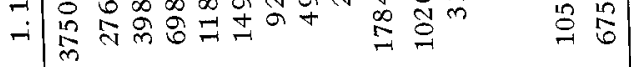

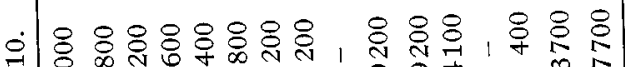
तो

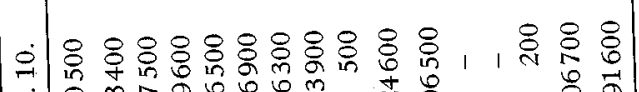

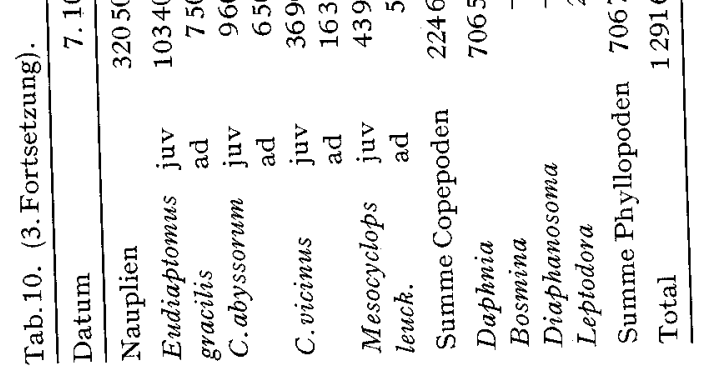




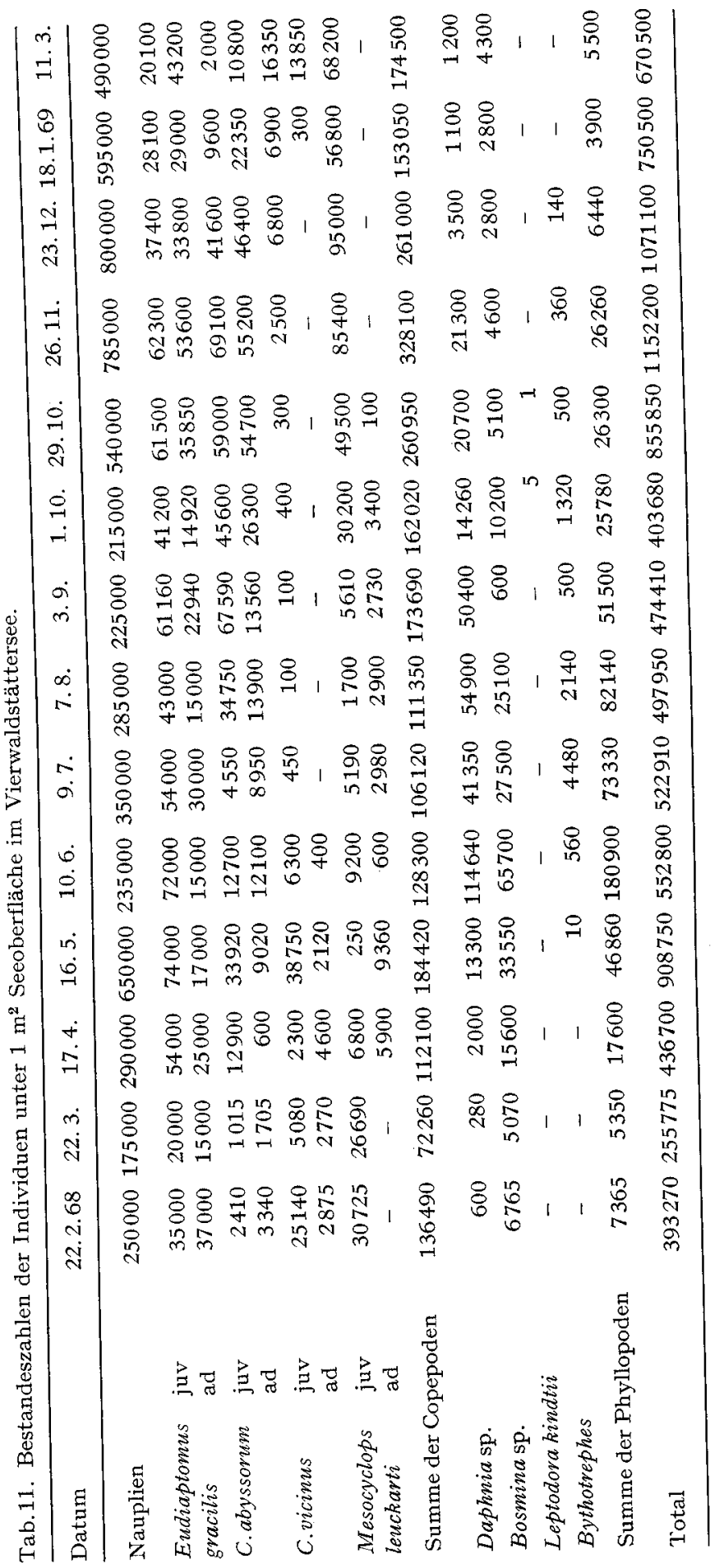




\section{LITERATURVERZEICHNIS}

[1] Alsterberg G., Die Winklevsche Bestimmungsmethode für in Wasser gelösten, elementaven Sauerstoff sowie ihve Anwendung bei Anwesenheit oxydierbaver Substanzen, Biochem. Z. 170 (1926).

[2] AмвuенL H., Die praktische Anwendung der Elektrochemischen Sauerstoffbestimmung im Wasser, Schweiz. Z. Hydrol. 22, 23-39 (1960).

[3] Амв Verein. Limnol. 77, 219-230 (1969).

[4] Auvray G., und Dussart B., Rôle de quelques facteurs du milieu sur le développement postembryonnaive des cyclopides (Crustacées copépodes). II. Cas des Cyclops et influences des facteurs extérieurs, Bull. Soc. Zool. France 1, 11-22 (1967).

[5] Blaska P., The Ratio of Crude Protein, Glycogen and Fat in the Individual Steps of the Production Chain, Hydrobiological studies 1, Prague (1966).

[6] Chabrol E., und Charonnat R., Une nouvelle véaction pour l'Etude des Lipides, Presse Med. 96,1713 (1937).

[7] Dussart B., Les Copépodes des eaux continentales. I. Calanoides et Harpacticoides, Edition N, Doubée \& Cie. (1967).

[8] EcksteIN H., Untersuchungen über den Einfluss des Rheinwassers auf die Limnologie des Schluchsees, Arch. Hydrobiol. Suppl. 23, 47-118 (1963).

[9] Einsle U., Die Gattung Cyclops s.str. im Bodensee, Arch. Hydrobiol. 60, 133-199 (1964 a).

[10] EinsLe U., Lavvalentwicklung von Cyclopiden und Photoperiodik, Die Naturwissenschaften 51, 345-346 (1964. b).

[11] Einsle U., Die Buchenseen bei Radolfzell (Bodensee) undihr Zooplankton, Mitt. bad. Landesver. Naturkde. u. Naturschutz 9, 27-63 (1966).

[12] Einsle U., Die Gattung Mesocyclops im Bodensee, Arch. Hydrobiol. 64, 131-169 (1968).

[13] Elster H.J., Ủber die Populationsdynamik von Eudiaptomus gracilis Sars und Heterocope borealis Fischer im Bodensee-Obersee, Arch. Hydrobiol. Suppl. 20, 546-614 (1954).

14] Erster H.J., Daphnien-Populationsdynamik und Eutrophierung im Bodensee (in Vorbereitung).

15] Faheem Khan M., The Effect of Constant and Varying Temperatures on the Development of Acanthocyclops viridis (Juvine), Proc. R.I.A. 64, Sect. B, 117-130 (1965).

[16] FARKAS T., Untersuchungen über die Fettsäuregarnitur einiger für den Stoffkreislauf einheimischer Gewässer wichtiger Crustaceen (deutsche Zusammenfassung), Annal. Biol. Tihany 25, 197-208 (1958).

[17] Farkas T., und Herodek S., Seasonal Changes in the Fat Contents of the Crustacean Plankton in Lake Balaton, Annal. Biol. Tihany 27, 3-7 (1960).

[18] Farkas T., und Herodex S., Seasonal Changes in the Fatty Acid Composition of Fresh Water Crustaceans, Annal. Biol. Tihany 28, 91-94 (1961).

[19] Fehlmann J.W., Gutachten betreffend die Fischereiverhältnisse im Greifensee und Aabach (an die Finanzdirektion des Kantons Zürich) vom 11. August 1915.

[20] GAEchter R., Phosphorhaushalt und planktische Primärproduktion im Vierwaldstättersee (Horwer Bucht), Schweiz. Z. Hydrol. 30, 1-66 (1968).

[21] Guyer O., Beiträge zur Biologie des Greifensees mit besondevev Berücksichtigung der Saisonvaviation von Cevatium hirundinella (E. Schweizerbartsche Verlagsbuchhandlung, Stuttgart 1910).

[22] Herbst H.V., Blattfusskrebse (Kosmos Verlag Franckh, Stuttgart 1962).

[23] Ingle L., Wood T.R., und Banta A.M., A Study of Longevity, Growth, Reproduction and Heart Rate in Daphnia longispina as influenced by limitations in Quantity of Food, J. Exp. Zool. $76,325-352$ (1937).

[24] Jahresbericht der Fischevei- und Jagdverwaltung des Kantons Zürich über das Geschäftsjahr 1968 (erweiterter Bericht) (1969).

[25] Kiefer F., Ruderfusshrebse (Kosmos Verlag Franckh, Stuttgart 1960).

[26] Kiefer F., und Muckxe R., Beobachtungen am Crustaceenplankton des Überlingersees (Bodensee) 1952-1957, I. Das Aufteten der Arten im Jahresverlauf, Beitr. Naturk. Forsch. SWDeutschl. 18, 5-41 (1959). 
[27] Kozminski Z., Morphometrische und öhologische Untersuchungen an Cyclopiden der strenuus Gruppe, Int. Rev. Hydrobiol. 33, 61-240 (1936).

[28] KRause H. R., Beiträge zur Kenntnis des Chitinabbaus in totem Zooplankton, Arch. Hydrobiol. Suppl. 25, 67-82 (1962).

29] KREY J., Chemical Determinations of Net Plankton with Special Reference to Equivalent Albumin Content, J. mar. Res. 17, 312-324 (1958).

[30] Krishnamurthy K., Nitrogen and Phosphorus in Plankton, Hydrobiologica 30/2, 273-280 (1.967).

[31] LohmanN H., Untersuchungen zur Feststellung des vollständigen Gehaltes des Meeves an Plankton, Wissensch. Meeresunters. 10 (1908).

32] MefFert M.-E., Die Wirkung dev Substanz von Scenedesmus obliquus als Eiweiss-Quelle in Fütterungsversuchen und die Beziehung zur Aminosäuren-Zusammensetzung, Forschungsbericht des Landes Nordrhein-Westfalen, Nr.952 (Westdeutscher Verlag, Koln und Oplade

1961).
[33] Moshirt G.A., und Cummins K.W., Calorific Values for Leptodora kindtii

Cladocera) and Selected Food Organisms, Arch. Hykton und Phytoplankton im See Erken, Symb

[34] Nauwerck A., Die Beziehungen
Bot. Upsal, 17, 5-163 (1963).

[35] Pavonx M., Die Bedeutung des Nannoplanktons im Vergleich zum Netzplankton, Schweiz. Z. Hydrol. 25, 219-341 (1963).

[36] Richterich R., Klinische Chemie (Verlag S. Karger, Basel, Schweiz/New York 1965).

[37] Schmid M., Die Bestimmung kleiner Mengen von organischem Stickstoff im Wasser von Binnenseen, Schweiz. Z. Hydrol. 30, 244-266 (1968)

[38] Schroeder R., Die Vertikalwanderungen des Crustacenplanktons der Seen des sïdlichen Schwarzwaldes, Arch. Hydrobiol. Suppl. 25, 1-43 (1959).

[39] SCHROEDER R., Untersuchungen ïber die Planktonverteilung mit Hilfe der Unterwasser-Fernsehanlage und des Echographen, Arch. Hydrobiol. Suppl. 25, 228-241 (1961).

[40] Sebestyen O., Quantitative Plankton Studies on Lake Balaton. IX. A Summary of the Biomass studies, Annal. biol. Tihany 25, 281-292 (1958).

[41] Silberschmidt W., Gutachten betr. Greifensee und Aabach (an die Finanzdirektion des Kantons Zürich) vom 8. Januar 1916.

[42] Smyly W.J.P., Some Aspects of the Biology of Cyclops leuckarti, Verh. Internat. Verein. Limnol. 14, 946-949 (1961).

[43] SPINDLER K.-D., Experimentelle Untersuchungen zur Dormanz bei Cyclops vicinus, Naturwissenschaften 56, 93-94 (1969).

44] Straskraba M., Preliminary Results of a New Method for the Quantitative Sorting of Freshwater Net Plankton into Main Groups, Limnol. Oceanogr. 9, 268-270 (1964).

[45] Strickland J.D.H., Production of Organic Matter in the Primary Stages of the Marine Food Chain, Chemical Oceanography 1 (Riley and Skirrow Academic Press, London and New York

1965), S.477-610.
[46] StrickLand J.D.H., und Parsons, T.R., A Practical Handbook Fisheries Research Board of Canada, Bulletin Zooplanktons im Vierwaldstättersee, Diplomarbeit

[47] STRICKLER R., Die neweve Entwii

[48] Szlauer L., The Resting Stages of Cyclopidae in Stary Dwor Lake, Pol. Arch. Hydrobiol. 11, 385-394 (1963).

[49] Thomas E. A., Biologische Untersuchungen am Greifensee, Ber. Schweiz. Bot. Ges. 54, 141-196 (1944).

[50] Thomas E.A., Stoffhaushalt und Sedimentation im oligotrophen Aegerisee und im eutrophen Pfäffiker- und Greifensee, Mem. Ist. Ital. Idrobiol. Suppl. 8, 357-465 (1955).

51] Tranter D.J., Kerrn J.D., und Heron A.C., Effects of Hauling Speed on Zooplankton Catches, Aust. J. mar. Freshwater 19, 65-75 (1968).

[52] Trevon B., und Schmut J.-M., La Réaction sulfo-phospho-vanillique dans l'étude des Lipides sériques, Soc. pharm. Lyon 8, 173-178 (1964).

[53] Utermoenl H., Zur Vervollkommnung der quantitativen Phytoplanktonmethodik, Mitt. internat. Verein. theor. angew. Limnol. 9, 1-38 (1958). 
[54] Wierzbicka M., On the Resting Stage and Mode of Life of Some Species of Cyclopoida, Pol. Arch. Hydrobiol. 10, 216-229 (1962). [55] Wierzbicka M., und Kedzrerski S., On the Datural Conditions, Polsk. Arch. Hydrobiol. 12, 47-80 (1964). Experimental and Natural Conditions, [56] WinkLer L.W., Die Bestimmung des im 2843-2855 (1888). Sauerstoffs im Wasser, Chem. Ber. 21,

[57] WORTHINGTON E. B., Vertical Movement 25, 394-436 (1931).

[58] ZIMMERMANN U., Oekologische unter besonderer Berücksichtigung von Licht und Temperatur, Schweiz. Z. Hydrol. 31, 1-58 (1969). [59] ZOELLNER N., und KIRScH K., Über die quantitative Bestimmung von Lipoiden (Minsamen Sulfomittels der vielen natirtichen Lipoiden. Med. 135, 545 (1962).

phosphovanillin-Reaktion, Z. gntersuchung der obersten Schlammschichten, zur Messung des

[60] ZUELLiG H., Ein neues Lot zur Untersure Wasserschichten, Schweiz. Z. Hydrol. 15, 275 Sedimentabsatzes bis $283(1953)$.

Anschrift des Autors: Dr. Erik Mittelholzer, Tulpenweg 5, CH-4310 Rheinfelden (Schweiz). 